\title{
WestVirginiaUniversity
}

THE RESEARCH REPOSITORY @ WVU

Graduate Theses, Dissertations, and Problem Reports

2017

\section{Differential Response Policy and Child Maltreatment Re-report}

Amy A. Hunter

Follow this and additional works at: https://researchrepository.wvu.edu/etd

\section{Recommended Citation}

Hunter, Amy A., "Differential Response Policy and Child Maltreatment Re-report" (2017). Graduate Theses, Dissertations, and Problem Reports. 5844.

https://researchrepository.wvu.edu/etd/5844

This Dissertation is protected by copyright and/or related rights. It has been brought to you by the The Research Repository @ WVU with permission from the rights-holder(s). You are free to use this Dissertation in any way that is permitted by the copyright and related rights legislation that applies to your use. For other uses you must obtain permission from the rights-holder(s) directly, unless additional rights are indicated by a Creative Commons license in the record and/ or on the work itself. This Dissertation has been accepted for inclusion in WVU Graduate Theses, Dissertations, and Problem Reports collection by an authorized administrator of The Research Repository @ WVU.

For more information, please contact researchrepository@mail.wvu.edu. 


\title{
Differential Response Policy and Child Maltreatment Re-report
}

\author{
Amy A. Hunter, MPH \\ Dissertation submitted \\ to the School of Public Health \\ at West Virginia University \\ in partial fulfillment of the requirements for the degree of \\ Doctor of Philosophy in \\ Epidemiology
}

\author{
Ian R.H. Rockett, MA, PhD, MPH, FACE, Chair \\ Danielle Davidov, PhD \\ George A. Kelley, DA, FACSM \\ Dustin Long, PhD, MS \\ Jiyoung Tabone, PhD, MSW
}

Department of Epidemiology

Morgantown, West Virginia

2017

Keywords: child maltreatment, policy, differential response, re-report, recurrence, systematic review

Copyright 2017 Amy A. Hunter 


\section{ABSTRACT \\ Differential Response Policy and Child Maltreatment Re-report Amy A. Hunter, MPH}

Child maltreatment is a serious public health issue. The decisions made by Child Protective Services (CPS) in response to reports of maltreatment may influence a child's risk of subsequent maltreatment. Studies have found a direct relationship between adverse childhood events (ACEs), (e.g., experiencing maltreatment, exposure to violence) and negative health outcomes across the lifespan (e.g., disease, developmental delays, suicidality, injury and death). Traditional CPS investigations focus on determining details of abuse events, and use that information to assess child safety and risk of future harm. The introduction of differential response policy provides supportive and preventive services to mitigate the risk of maltreatment without a full investigation. It is unclear how the introduction of this policy alters child risk for consequent maltreatment. This dissertation examines and compares the risk of child maltreatment re-report, a measure of the effectiveness of CPS efforts, in children who received either a traditional investigation or a differential response. Using constructs of Family Systems Theory, we conducted qualitative and quantitative analysis to evaluate these associations. Results suggest that children receiving differential response experience equal or lesser risk of re-report than do children receiving investigation. However, our results also revealed discrepancies in data quality that introduced bias in our results. Improvements in data collection and CPS implementation are needed to accurately describe the relationship between policy and maltreatment re-report. 


\section{Dedication}

This dissertation is dedicated to my daughters, Olivia and Sydney. Your love of life and learning gives me hope for the future. I love you both more than words could ever describe. 


\section{Acknowledgements}

This dissertation would not have been possible without the guidance and expertise of my committee. To my committee chair, Dr. Rockett, you have been an amazing mentor. Thank you for your unwavering encouragement. Working with you has been an honor. Dr. Davidov, thank you for introducing me to this topic and for your guidance and positivity. Dr. Kelley, I have learned so much from you. Thank you for being truly invested in your students! Dr. Long, I am a better statistician because of you. Thank you for challenging me, and trusting me to find the answers. Finally, Dr. Tabone, your contribution was invaluable.

Students of the WVU School of Public Health, I could not have made it without out you. Meagan, Zelalem, Toni, Courtney, Amna, Termeh, Sherry and Halima, friendships such as ours are rare, and I am so grateful that we could share this experience together.

Dr. Keith Zullig, thank you for believing in me and for your steadfast support over the last six years. I have enjoyed our work together. To Dr. Jeffrey Coben, thank you for supporting me through the WVU ICRC, and for your assistance in securing the data for this dissertation.

To the staff at the WU ICRC, words cannot express how much you mean to me. You have created such a wonderful environment for students, and I will miss working with you all.

Much appreciation to the National Data Archive on Child Abuse and Neglect for allowing me to use the NCANDS data. Special thanks to Mr. Andres Arroyo, Mr. Michael Dineen and Dr. Elliott G. Smith for data support. 


\section{TABLE OF CONTENTS}

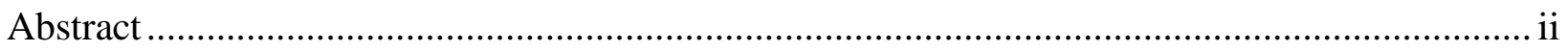

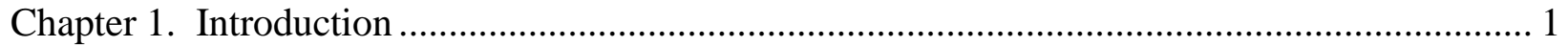

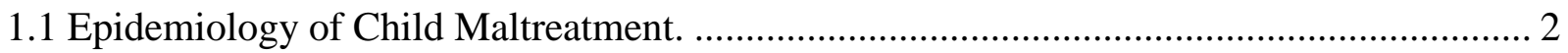

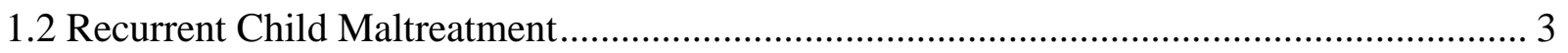

1.3 Brief History of Child Protection in the United States......................................................... 4

1.4 Traditional Child Protective Services Investigation. ......................................................... 4

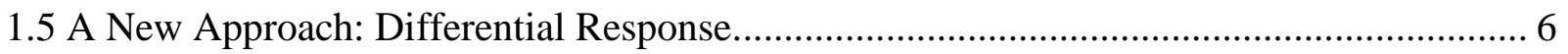

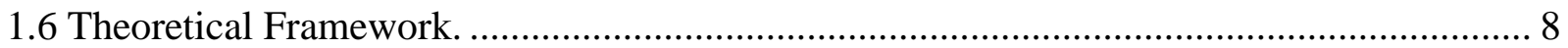

1.7 Directed Acyclic Graphs .............................................................................................. 9

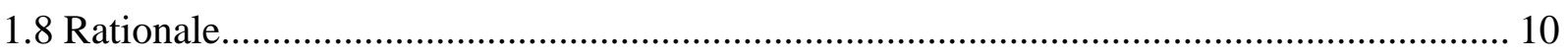

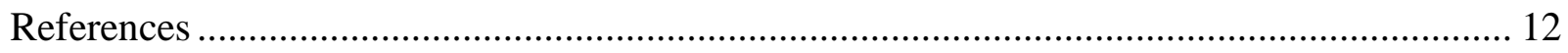

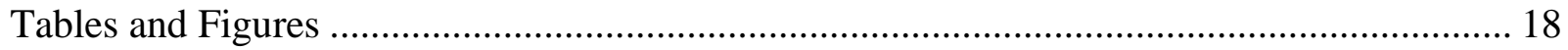

Figure 1 : Stages of the Traditional Child Protection Investigation in the United States.... 19

Figure 2 : Mapping Differential Response Implementation in the United States................. 20

Table 1: Application of Family Systems Theory ................................................................ 21

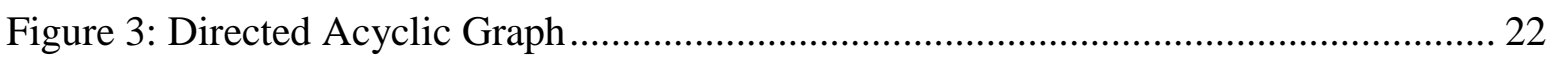

Chapter 2. Differential Response Policy and Child Maltreatment Re-report: A Systematic

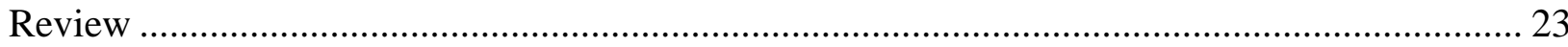

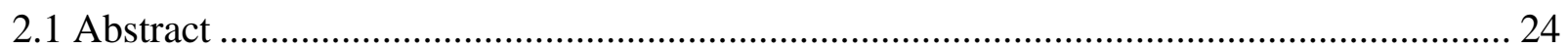

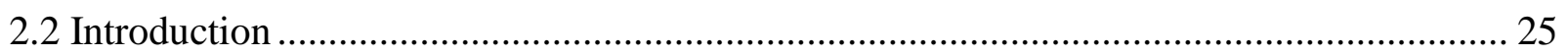

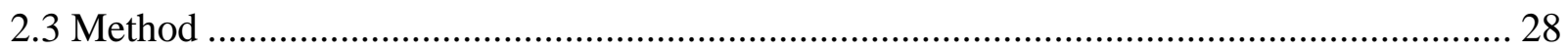

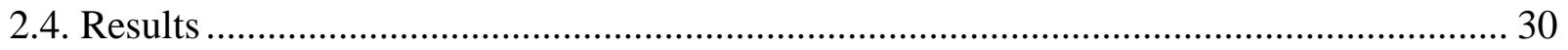

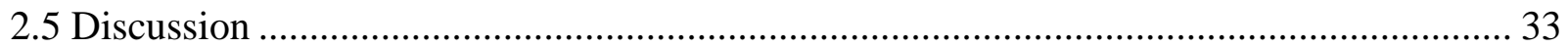

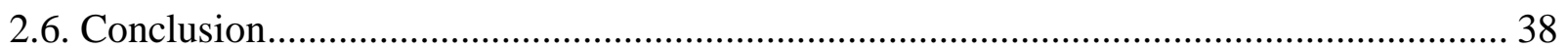

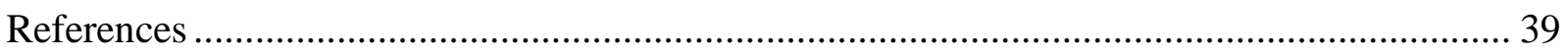

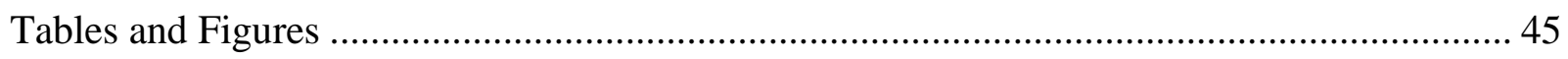

Table 1. Comparison of Differential Response and Investigation........................................ 46

Table 2. Example of search strategy (PROQUEST) ........................................................... 47

Table 3. Abbreviated Downs and Black Checklist for Non-Randomized Studies ............... 48

Table 4. Characteristics of included studies ....................................................................... 49

Figure 1: Flow diagram for the selection of studies. ........................................................ 51 
Table 5. Description of Differential Response by Study

Chapter 3. Long Term Effectiveness of Differential Response in Preventing Child Maltreatment Re-Report.... 53

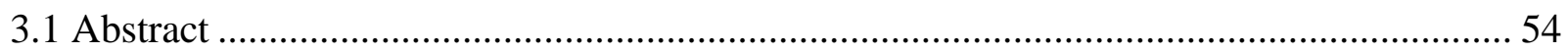

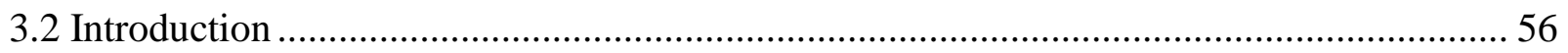

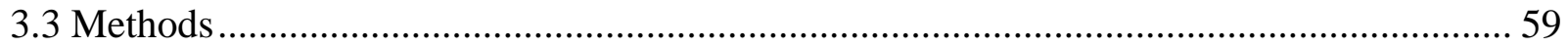

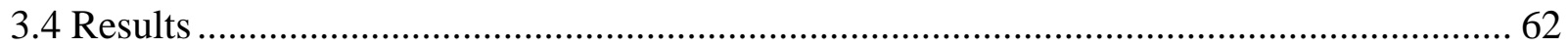

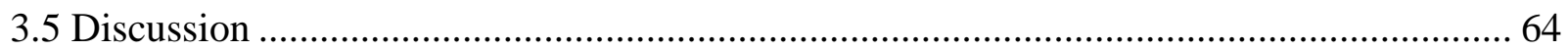

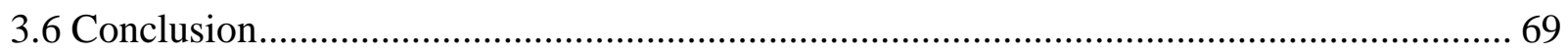

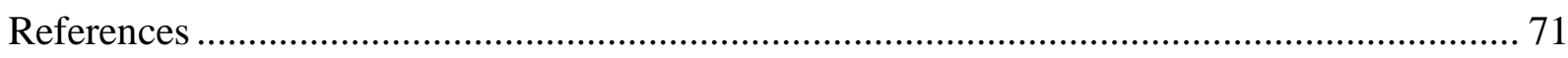

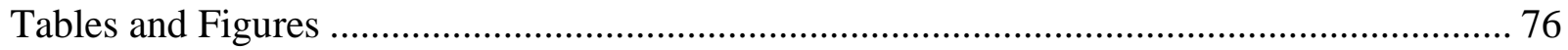

Figure 1. Survival Curves for CPS Response. ........................................................ 77

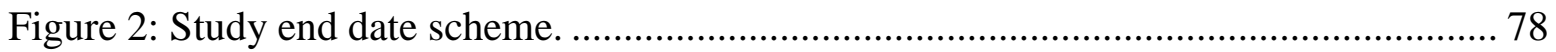

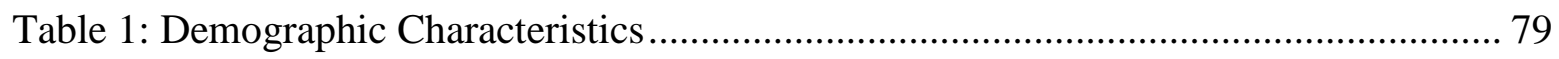

Table 2 : Association of CPS Response with Demographic and Case Characteristics ........ 81

Table 3: Association of Re-report with Demographic and Case Characteristics................. 83

Table 4. Risk of Re-Report of Child Maltreatment by Response Type............................. 85

Table 5. Sensitivity Analysis: Risk of Re-Report of Child Maltreatment by Response Type;

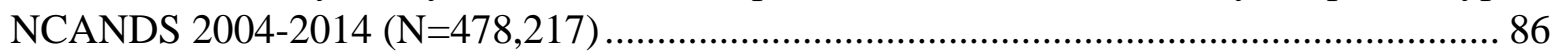

Chapter 4. Comparison of Characteristics of Child Maltreatment Re-Report In Periods Before

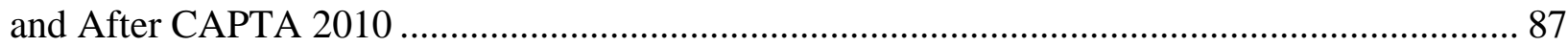

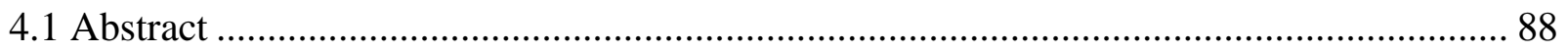

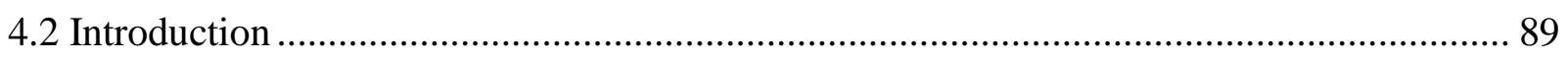

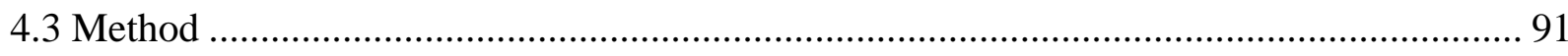

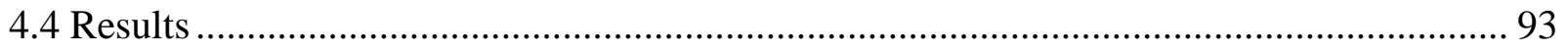

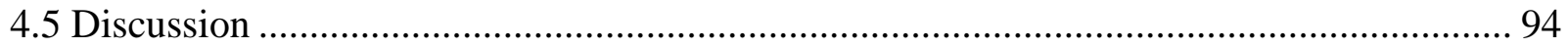

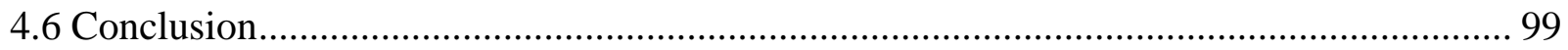

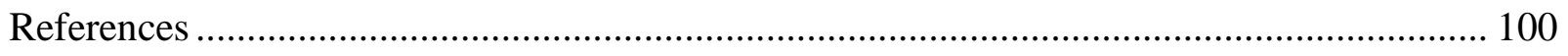

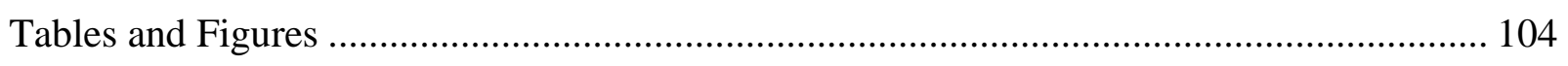

Table 1: Baseline Demographic Characteristics by Year ............................................ 105

Table 2 : Baseline Demographic Characteristics by State ............................................ 107

Table 3 : Association between Re-report and Demographics by Intervention .................. 110

Table 4 : Association between Re-report and Demographics by Policy Period ................ 112 


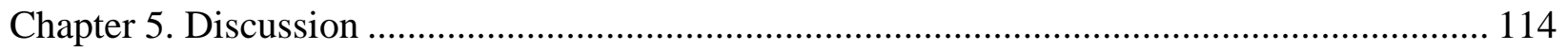

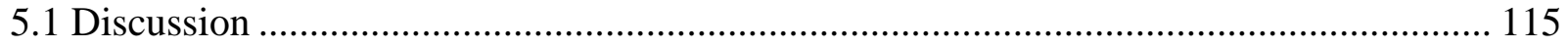

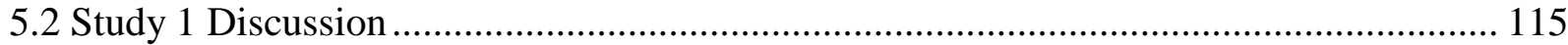

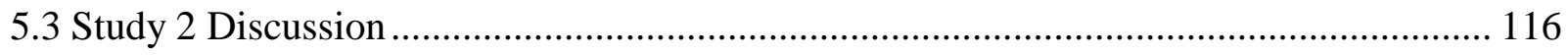

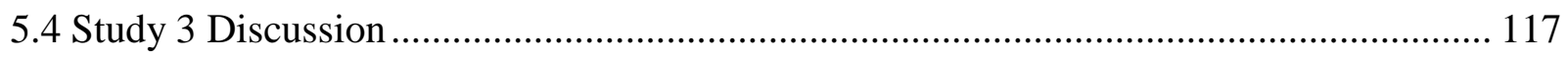

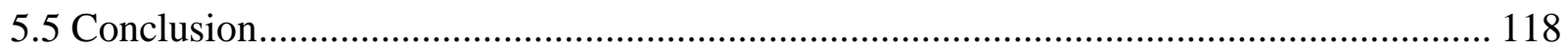


CHAPTER 1. INTRODUCTION 


\subsection{Epidemiology of Child Maltreatment.}

Child maltreatment is defined by the Centers for Disease Control and Prevention (CDC) as 'Any act or series of acts of commission or omission by a parent or other caregiver that results in harm, potential for harm, or threat of harm to a child' ${ }^{1}$ The term child refers to an individual who is under the age of 18 , except in the case of sexual abuse where the precedent for defining a child is left to the state. ${ }^{1,2}$

In 2015, Child Protective Services (CPS) in the United States (US) received four million reports involving 7.2 million suspected victims of maltreatment across 52 states and territories. $^{3}$ Of those reports, 58.2\% received a response and 683,000 unique victims were identified (9.2 per 1,000); 1,585 cases were fatal. ${ }^{3}$ Neglect $(75.3 \%)$ was the most common form of maltreatment in 2015, followed by physical abuse (17.2\%), sexual abuse (8.4\%), and other abuse and neglect (6.9\%) (e.g. medical, dental, educational, threat of abuse, parental alcohol and other substance use, exposure to violence). ${ }^{3}$ Females experienced maltreatment more often than males. However, males died more frequently from injuries attributed to maltreatment. ${ }^{3}$ Children of white race (43.2\%) experienced maltreatment more often than children of black race (21.4\%) or Hispanic ethnicity $(23.6 \%)^{3}$

Maltreated children are at excess risk of experiencing acute and long-term adverse behavioral and health outcomes during adolescence and adulthood. ${ }^{4,5}$ These include cognitive and academic delays, psychological and social maladjustment, injury, hospitalization, disease and death. ${ }^{6-16}$ The estimated lifetime cost per non-fatal case of child maltreatment in the US is $\$ 210,012$, and the estimated cost of a child maltreatment fatality is $\$ 1.27$ million. ${ }^{8}$ 
In $2015,522,476$ unique perpetrators of maltreatment were identified. ${ }^{3}$ Perpetrators were most often female, a biological parent, and between the ages of 18-44 years; less than eight percent were involved in multiple reports. ${ }^{3}$

\subsection{Recurrent Child Maltreatment}

The consequences of child maltreatment become more serious with repeated abuse. ${ }^{17-19}$ Maltreatment recurrence arises when a case of substantiated maltreatment involves a child or family who was involved in an investigation of previous substantiated abuse. ${ }^{20}$ The true incidence of child maltreatment recurrence is unknown, but it has been reported in as many as $60 \%$ of child victims of abuse. ${ }^{21-24}$ Known risk factors for maltreatment recurrence include the initial type of abuse, poverty, young maternal age, maternal stress, parental alcohol and other substance use and abuse, exposure to violence, child disability, child age, family structure and family size..$^{21,22,25-27}$

A re-report of child maltreatment occurs when a child or family, who was previously reported to CPS for suspicion of abuse (with or without substantiation), is the subject of a subsequent investigation regardless of the case outcome. ${ }^{28}$ Studies have shown that the risk of prospective abuse and the outcomes associated with child maltreatment recurrence and re-report are similar regardless of substantiation status. ${ }^{20,25,29,30}$

Understanding child maltreatment re-report and recurrence is of importance because these measures serve as indicators of the effectiveness of child protection efforts. ${ }^{31}$ Title IV, Sections B and E of the Social Security Act Amendment of 2004 require states to report

recurrence as a safety measure outcome for child and family services. ${ }^{32}$ Re-report is often used as a proxy when recurrence cannot be measured directly. ${ }^{33}$ 


\subsection{Brief History of Child Protection in the United States.}

Efforts to protect children against maltreatment in the US began as a private charitable endeavor by the American Society for the Prevention of Cruelty to Animals (ASPCA) founder Henry Bergh with the development of the New York Society for the Prevention and Cruelty of Children in $1865 .{ }^{34}$ In the 50 years following, child protection was a matter for private organizations. As the issue of child protection became more visible, federal agencies such as the Children's Bureau in 1912 were developed with the goal of improving the health of women and children. Child Protection was made a federal priority when stipulations for child protection were included in Title IV of the Social Security Act of 1935 (Grants to States for Aid to Dependent Children). ${ }^{35}$ Subsequently, the Child Abuse Prevention and Treatment Act (CAPTA) of 1974 and its reauthorization of 2010 would task states with outlining protocols for protecting children from mistreatment. ${ }^{36}$

\subsection{Traditional Child Protective Services Investigation.}

When a report of maltreatment is received by CPS, it is traditionally referred to an investigation which follows a seven stage process (Figure 1) ${ }^{37}$ In 2015, the average response time was 3.3 days; response times may differ in cases of severe maltreatment or when CPS agencies are overburdened with their caseload. ${ }^{3}$ At the end of the investigation, a formal determination is made which may or may not include post-investigative services. In some states, with confirmation of abuse, the perpetrator will be placed in a registry of offenders. ${ }^{38}$ This process differs for Native American and tribal families, who are covered under the Indian Child Welfare Act. ${ }^{39}$

Challenges stemming from a child protection investigation begin at the intake and screening stage, because access to CPS is contingent upon entering the child welfare system. It is 
during this stage that reports of child maltreatment are received, and the decision to explore or dismiss a report of suspected abuse is made. Failure to identify an abused child at this stage will prevent intervention, thus increasing risk of abuse to perpetuate. The first concern with the intake and screening process is that reports of suspected maltreatment are often received by an individual improperly trained or unqualified to assess current and future risk of abuse. ${ }^{40}$ Even when reports are received by trained social workers or CPS investigators, research has shown that these individuals are inadequately equipped to evaluate risk of future abuse accurately. ${ }^{41}$ Secondly, maltreatment is most often reported by health, education and law enforcement professionals..$^{3,25,42}$ A report by an individual, who does not live proximal to the location where abuse most often occurs, has limited details about specific abuse events. This paucity of detail may prevent a report of abuse from crossing the threshold to warrant an official response.

Information obtained during investigation is contingent upon family assessment. Yet, CPS response time to reports of maltreatment can range from 24 hours to 14 days depending on the assessed risk during intake. ${ }^{37}$ Unstable family dynamics can change drastically during this time, preventing important details from being disclosed to an investigator. Scant details, or low perceived risk on the part of the individual receiving the report of suspected abuse, may result in determining there is insufficient information to proceed with an investigation, or to premature case closure.

Even when a suspected case of child maltreatment is determined to require investigation, there are still shortcomings in the traditional approach, which might prevent substantiation of a true case of maltreatment. The most common criticism of traditional investigations is that they are adversarial to suspected perpetrators of abuse, usually a parent or caregiver. ${ }^{43}$ Second, the lack of a systematic method to determine response and service needs has prompted researchers to 
question whether families are correctly identified for investigation. With a growing number of reports each year, CPS was tasked with finding more effective methods for managing alleged abuse. $^{44,45}$

\subsection{A New Approach: Differential Response.}

Introduced in 1993, differential response is an innovative child welfare policy that takes an innovative approach to addressing a report of child maltreatment. It is not intended for cases of serious physical abuse, serious neglect or sexual abuse. ${ }^{38,46}$ Under differential response policy, families reported for abuse that is perceived to be of low to moderate severity are provided with preventive and supportive services in lieu of a traditional investigation. ${ }^{47}$ Deemed less adversarial than traditional investigations, families receiving differential response are interviewed as a unit and no formal determination of abuse is made. ${ }^{48}$ In 2006 , Merkel-Holguin identified the following core elements of differential response ${ }^{48}$ :

1. Two or more response paths for reports of maltreatment that are screened in and accepted for response;

2. Path assignment determined by an assessment of the composite details of current and past reports;

3. Ability to change path assignment based on assessment;

4. Establishment of differential response in statute, policy and/or protocols;

5. Voluntary acceptance of services; refusal is without consequence;

6. No formal determination of maltreatment occurrence

7. Alleged perpetrator's name not placed in central registry.

As of 2014, The Kempe Center for the Prevention and Treatment of Child Abuse reported that 20 states and the District of Columbia have adopted differential response at the state level,

(Figure 2). ${ }^{38}$ These include Alabama, Arkansas, Connecticut, Delaware, Hawaii, Kentucky, 
Louisiana, Massachusetts, Maine, Minnesota, Missouri, North Carolina, Ohio, Oklahoma, Pennsylvania, South Carolina, Tennessee, Virginia, Vermont, and Wyoming.

Similar to the traditional investigation, differential response policy has also encountered criticism. CPS investigations serve the purpose of protecting children, who are the suspected victims of abuse, from suffering additional harm. ${ }^{49}$ Differential response may contradict this purpose by changing the objective from identifying abuse to temporarily ameliorating problems that carry serious underlying causes and future consequences. This becomes dangerous when serious issues surrounding abuse are not addressed, allowed to manifest into more serious offences. This neglect may lead to child death.

Families receiving differential response are often investigated as a unit. ${ }^{50}$ This precludes individuals, particularly victims of abuse, from having the opportunity to report their experiences anonymously, and to divulge specific circumstances (location, time, ancillary events, cooccurring abuse) that are critical for future prevention. ${ }^{50}$ In a group setting, victims and witnesses of abuse may also be intimidated by the abuser, if he or she is a member of the family unit. Consequently, these individuals may withhold information about family dynamics, and be less likely to seek help if subsequent abuse occurs after receipt of differential response. In contrast, offenders receiving differential response avoid punishment for their harmful behavior, and may learn new ways to mask abuse under this policy.

Differential response is voluntary for families assigned to this path. ${ }^{48}$ Although many state policies indicate that families who refuse services may be transferred to a traditional response, the frequency with which this occurs has not been consistently reported. In addition to differential response being voluntary, receipt keeps perpetrators of abuse from being listed on a registry of child maltreatment offenders. ${ }^{45,48}$ 
Finally, there is no systematic screening for placing children in an alternative (differential) track versus a traditional investigation. ${ }^{51}$ Thus, track selection (investigation or differential response) is at the discretion of the individual responsible for screening, introducing considerable variability and bias. Although evidence has shown that CPS workers are often illequipped to assess current and future risk of maltreatment, ${ }^{40}$ a differential response model is predicated on the notion that the individual completing the screening is able to assess probability of risk, as well as severity of abuse. Despite these challenges, there is potential for aspects of this policy to reduce child maltreatment recurrence.

The Child Abuse Prevention and Treatment Act (CAPTA) reauthorization of 2010 requires that all states have written policies for implementing and evaluating child maltreatment investigations, including differential response. ${ }^{36}$ Therefore, to maximize the safety of children receiving this policy intervention, differential response should be studied comprehensively to determine its influence on child protection outcomes.

\subsection{Theoretical Framework.}

Much of the theoretical perspective applied to child maltreatment research takes an ecological approach. ${ }^{13,52-54}$ Because child maltreatment occurs within a family unit, it may be appropriate to use a theoretical approach that closely examines maltreatment within a family context. ${ }^{55}$

Family Systems Theory posits that families are comprised of individuals who function on an emotionally interdependent level. ${ }^{56}$ Behaviors within a family occur in predictable patterns that can be understood through systems thinking, which states that the function of a whole (family) can be explained by understanding its parts (individuals) and how those parts interact. ${ }^{57}$ These patterned behaviors may be impacted by the external environment based on a continuum 
of open to closed boundaries established by the family unit. These boundaries are directly related to risk factors for maltreatment, such as race, income, and family dynamics.

This dissertation aims to examine how differential response policy may permeate open and closed boundaries by influencing socioeconomic, demographic and case level characteristics of child maltreatment. Table 1 illustrates the risk factors to be explored using constructs of Family Systems Theory. ${ }^{58}$

A review of literature has shown that Family Systems theory is often used to describe family interactions in counseling and social work. In these situations, individual constructs of the theory are explored, but there has been no examination of how they are affected collectively by differential response with respect to inspiring change in family function and reducing recurrence.

\subsection{Directed Acyclic Graphs}

In many analyses, statistical decisions for assessing confounders are based on rules of thumb, which may or may not be supported by scientific literature. These decisions may bias study results, and subsequently bias their interpretation. ${ }^{59}$ One method for reducing bias involves using extant literature to develop path diagrams which are visual representations of existing literature used to identify confounders, mediators and colliders. Two approaches for creating these diagrams are structural equation modeling (SEM) and directed acyclic graphs (DAGs). The distinction between these approaches is that paths between variables in SEM may be bidirectional, while paths in DAGs are unidirectional. ${ }^{60}$ Another distinction between SEM and DAGs is that SEM is most effective in evaluating continuous outcomes, whereas DAGs are appropriate for continuous and categorical outcomes. For a DAG to be considered causal, all common causes of variables must be identified and graphed. ${ }^{61}$ Based on these criteria, this 
dissertation will assess confounders and potential mediators using directed acyclic graphs (DAGs) developed from existing literature (Figure 3). DAGitty software was used to create the DAG. $^{62}$

\subsection{Rationale}

The current understanding of child maltreatment recurrence is based on studies examining traditional investigations, where a determination is made regarding whether or not maltreatment occurred. ${ }^{21,24,26,63-65}$ Because differential response does not require a final determination, these cases are omitted in the study of child maltreatment recurrence, despite the reality that families receiving differential response have the potential to be re-reported and substantiated in the future. There is growing evidence that children who are reported for maltreatment experience the same long-term consequences associated with abuse, regardless of whether or not their case was substantiated. ${ }^{20,29,63}$

To date, most studies examining differential response policy have focused on: (1) understanding the associations between demographic and county-level characteristics related to the odds of a child or family receiving one particular investigation type over the other, (2) the cost-benefit of differential response in comparison to a traditional investigation, (3) determining whether children who received a differential response are at an increased risk for recurrence and maltreatment-related fatality than children receiving a traditional investigation, (4) family and CPS satisfaction with program and (5) child safety comparisons. ${ }^{33,50,66-68}$

No systematic review has been conducted to assess the efficacy and effectiveness of differential response since its introduction in 1993. However, the literature examining how this policy impacts child maltreatment and recurrence has exposed areas in need of additional 
consideration. ${ }^{69}$ Studies have consistently reported that implementation of differential response is inconsistent across and within states. ${ }^{67}$ In short, the screening process, number and type of response paths, and services offered are highly variable. ${ }^{33,70}$ Further, although differential response is intended for families with a report of suspected maltreatment of low to moderate severity and risk of future harm, research suggests that this intention does not always translate into practice. ${ }^{33}$ For example, one analysis found that in Texas, as high as $54 \%$ of sexual abuse reports and 50\% of physical abuse reports received a differential response. ${ }^{33}$ Finally, the implications of differential response are unclear in the long-term, and with regard to how adoption of this this policy influences the risk of maltreatment and its characteristics. The following three chapters of this dissertation will address the aforementioned gaps in the literature, and the final chapter will summarize the findings and discuss public health implications of this research. 


\section{References}

1. Centers for Disease Control and Prevention. Child Maltreatment Prevention. Violence Prevention 2013; http://www.cdc.gov/violenceprevention/childmaltreatment/. Accessed January 20, 2016.

2. United States. Child Abuse Prevention and Treatment Act as amended by PL 111-320, the CAPTA reauthorization act of 2010. Washington, DC: United States Government Publishing Office; 2010.

3. U.S. Department of Health and Human Services, Administration for Children and Families, Administration on Children, Youth and Families. Child Maltreatment 2015. 2017: http://www.acf.hhs.gov/programs/cb/research-data-technology/statisticsresearch/child-maltreatment.

4. Felitti VJ, Anda RF, Nordenberg D, et al. Relationship of childhood abuse and household dysfunction to many of the leading causes of death in adults: The Adverse Childhood Experiences (ACE) Study. American Journal of Preventive Medicine. 1998;14(4):245258.

5. Gilbert R, Widom CS, Browne K, Fergusson D, Webb E, Janson S. Burden and consequences of child maltreatment in high-income countries. The Lancet. 2009;373(9657):68-81.

6. Chartier M, Walker J, Naimark B. Childhood abuse, adult health, and health care utilization: results from a representative community sample. American Journal of Epidemiology. 2007;165(9):1031-1038.

7. Coohey C, Renner LM, Hua L, Zhang YJ, Whitney SD. Academic achievement despite child maltreatment: A longitudinal study. Child Abuse \& Neglect. 2011;35(9):688-699.

8. Fang X, Brown DS, Florence CS, Mercy JA. The economic burden of child maltreatment in the United States and implications for prevention. Child Abuse \& Neglect. 2012;36(2):156-165.

9. Farst K, Ambadwar PB, King AJ, Bird T, Robbins JM. Trends in hospitalization rates and severity of injuries from abuse in young children, 1997-2009. Pediatrics. 2013;131(6):e1796-e1802.

10. Hoertel N, Franco S, Wall MM, et al. Childhood maltreatment and risk of suicide attempt: a nationally representative study. The Journal of Clinical Psychiatry. 2015;76(7):1,478-923.

11. King A, Farst K, Jaeger M, Onukwube J, Robbins J. Maltreatment-related emergency department visits among children 0 to 3 years old in the United States. Child Maltreatment. 2015;20(3):151-161. 
12. Klevens J, Leeb RT. Child maltreatment fatalities in children under 5: Findings from the National Violence Death Reporting System. Child Abuse \& Neglect. 2010;34(4):262-266.

13. Lanier P, Jonson-Reid M, Stahlschmidt MJ, Drake B, Constantino J. Child maltreatment and pediatric health outcomes: A longitudinal study of low-income children. Journal of Pediatric Psychology. 2009;35(5):511-522.

14. Norman RE, Byambaa M, De R, Butchart A, Scott J, Vos T. The long-term health consequences of child physical abuse, emotional abuse, and neglect: a systematic review and meta-analysis. PLOS Medicine. 2012;9(11).

15. Schwartz KA, Preer G, McKeag H, Newton AW. Child maltreatment: a review of key literature in 2013. Current Opinion in Pediatrics. 2014;26(3):396-404.

16. Slade EP, Wissow LS. The influence of childhood maltreatment on adolescents' academic performance. Economics of Education Review. 2007;26(5):604-614.

17. Kempe CH, Silverman FN, Steele BF, Droegemueller W, Silver HK. The battered-child syndrome. JAMA. 1984;251(24):3288-3294.

18. Keshavarz R, Kawashima R, Low C. Child abuse and neglect presentations to a pediatric emergency department. The Journal of Emergency Medicine. 2002;23(4):341-345.

19. Ortega HW, Vander Velden H, Kreykes NS, Reid S. Childhood death attributable to trauma: is there a difference between accidental and abusive fatal injuries? The Journal of Emergency Medicine. 2013;45(3):332-337.

20. Casanueva C, Tueller S, Dolan M, Testa M, Smith K, Day O. Examining predictors of rereports and recurrence of child maltreatment using two national data sources. Children and Youth Services Review. 2015;48:1-13.

21. Dakil SR, Sakai C, Lin H, Flores G. Recidivism in the child protection system: Identifying children at greatest risk of reabuse among those remaining in the home. Archives of Pediatrics \& Adolescent Medicine. 2011;165(11):1006-1012.

22. Hélie S, Laurier C, Pineau-Villeneuve C, Royer M-N. A developmental approach to the risk of a first recurrence in child protective services. Child Abuse \& Neglect. 2013;37(12):1132-1141.

23. Levy HB, Markovic J, Chaudhry U, Ahart S, Torres H. Reabuse rates in a sample of children followed for 5 years after discharge from a child abuse inpatient assessment program. Child Abuse \& Neglect. 1995;19(11):1363-1377.

24. Solomon D, Åsberg K. Effectiveness of child protective services interventions as indicated by rates of recidivism. Children and Youth Services Review. 2012;34(12):23112318. 
25. Bae H, Solomon PL, Gelles RJ. Multiple child maltreatment recurrence relative to single recurrence and no recurrence. Children and Youth Services Review. 2009;31(6):617-624.

26. Connell CM, Bergeron N, Katz KH, Saunders L, Tebes JK. Re-referral to child protective services: The influence of child, family, and case characteristics on risk status. Child Abuse \& Neglect. 2007;31(5):573-588.

27. Lee J, Lee R, Park M. Fathers' alcohol use and spousal abuse and mothers' child abuse in multicultural families in South Korea: the mediating role of acculturation and parenting stress. Children and Youth Services Review. 2016;63:28-35.

28. Fluke J, Shusterman GR, Hollinshead D, Yuan Y. Rereporting and Recurrence of Child Maltreatment: Findings from NCANDS. Washington, DC: U.S. Department of Health and Human Services; 2005.

29. Fluke JD, Shusterman GR, Hollinshead DM, Yuan Y-YT. Longitudinal analysis of repeated child abuse reporting and victimization: Multistate analysis of associated factors. Child Maltreatment. 2008;13(1):76-88.

30. Kohl PL, Jonson-Reid M, Drake B. Time to leave substantiation behind findings from a national probability study. Child Maltreatment. 2009;14(1):17-26.

31. DePanfilis D, Zuravin SJ. Epidemiology of child maltreatment recurrences. Social Service Review. 1999;73(2):218-239.

32. United States. Social Security Act, Title IV-Grants to States for Aid and Services to Needy Families with Children and For Child-Welfare Services. Washington, DC: U.S. Government Printing Office; 2004.

33. Shusterman GR, McDonald WR. Alternative Responses to Child Maltreatment: Findings from NCANDS. Washington, DC: US Department of Health and Human Services; 2005.

34. Myers JE. Short History of Child Protection in America, A. Fam. LQ. 2008;42:449.

35. United States. Social Security Act of 1935. Washington, DC: U.S. Government Printing Office; 1935.

36. US Department of Health and Human Services. Administration for Children and Families, Administraton on Children, Youth and Families, Children's Bureau. Child Abuse Prevention and Treatment Act as amended by PL 111-320, the CAPTA reauthorization act of 2010.2010.

37. Myers JE. The APSAC Handbook on Child Maltreatment. 3rd ed. Los Angeles, CA: Sage; 2011.

38. Child Welfare Information Gateway. Differentianl Response to Reports of Child Abuse and Neglect. Washington, DC: U.S. Department of Health and Human Services, Children's Bureau; 2014. 
39. Baker DR. Indian Child Welfare Act. Child. Legal Rts. J. 1994;15:28.

40. Dorsey S, Mustillo SA, Farmer EM, Elbogen E. Caseworker assessments of risk for recurrent maltreatment: Association with case-specific risk factors and re-reports. Child Abuse \& Neglect. 2008;32(3):377-391.

41. Douglas EM, Mohn BM, Gushwa MK. The Presence of Maltreatment Fatality-Related Content in Pre-service Child Welfare Training Curricula: A Brief Report of 20 States. Child and Adolescent Social Work Journal. 2015;32(3):213-218.

42. Fuller T, Nieto M. Child welfare services and risk of child maltreatment rereports: Do services ameliorate initial risk? Children and youth services review. 2014;47:46-54.

43. Kaplan C, Merkel-Holguin L. Another look at the national study on differential response in child welfare. Protecting Children. 2008;23(1\&2):5-21.

44. Casanueva C, Tueller S, Dolan M, Testa M, Smith K, Day O. Examining predictors of rereports and recurrence of child maltreatment using two national data sources. Children and Youth Services Review. 2015;48(2):1-13.

45. SAS [computer program]. Version 9.4. Cary, NC ,2016.

46. Child Welfare Information Gateway. Differential Response to Reports of Child Abuse and Neglect. Washington, DC: U.S. Department of Health and Human Services; 2008.

47. Child Welfare Information Gateway. Differential Response to Reports of Child Abuse and Neglect. Washington, DC: U.S. Department of Health and Human Services, Children's Bureau; 2014.

48. Merkel-Holguín LA, Kaplan C, Kwak A, Association AH. National study on differential response in child welfare. Washington, DC: American Humane Association and Child Welfare League of America; 2006.

49. DePanfilis D, Zuravin SJ. Rates, patterns, and frequency of child maltreatment recurrences among families known to CPS. Child Maltreatment. 1998;3(1):27-42.

50. Loman LA, Siegel GL. Alternative response in Minnesota: Findings of the program evaluation. Protecting Children. 2005;20(2\&3):78-92.

51. Hunter A, Lewis, Kelsey, Kelley, George, Tabone, Jiyoung, Davidov, Danielle, Long, Dustin, Rockett, Ian,. Differential response policy and child maltreatment recurrence: a systematic review with meta- analysis, if appropriate. Prospero: CRD42015025388; 2015.

52. Krishnan V, Morrison KB. An ecological model of child maltreatment in a Canadian province. Child Abuse \& Neglect. 1995;19(1):101-113. 
53. Little L, Kaufman Kantor G. Using ecological theory to understand intimate partner violence and child maltreatment. Journal of Community Health Nursing. 2002;19(3):133145 .

54. Algood CL, Hong JS, Gourdine RM, Williams AB. Maltreatment of children with developmental disabilities: An ecological systems analysis. Children and Youth Services Review. 2011;33(7):1142-1148.

55. Stith SM, Liu T, Davies LC, et al. Risk factors in child maltreatment: A meta-analytic review of the literature. Aggression and Violent Behavior. 2009;14(1):13-29.

56. Papero DV. Bowen family systems theory. Boston, MA: Allyn and Bacon; 1990.

57. Gavazzi SM. Family systems theory. Encyclopedia of Adolescence. New York, NY: Springer; 2011:963-967.

58. Kerr ME. One family's story: A primer on Bowen theory. 1st ed. Washington, DC: Bowen Center for the Study of the Family, Georgetown Family Center; 2002.

59. Hernán MA, Hernández-Díaz S, Werler MM, Mitchell AA. Causal knowledge as a prerequisite for confounding evaluation: an application to birth defects epidemiology. American Journal of Epidemiology. 2002;155(2):176-184.

60. Tu Y-K, Greenwood DC. Modern methods for epidemiology. Dordrecht: Springer; 2012.

61. Sauer B, VanderWeele TJ. Supplement 2. Use of Directed Acyclic Graphs.

62. Textor J, Hardt J, Knuppe S. DAGitty: A Graphical Tool for Analyzing Causal Diagrams. Epidemiology 2011;5(22):745.

63. Bae H-o, Solomon PL, Gelles RJ. Multiple child maltreatment recurrence relative to single recurrence and no recurrence. Children and Youth Services Review. 2009;31(6):617-624.

64. Dolan M, Casanueva C, Smith K, Day O, Dowd K. Child abuse and neglect re-reports: Combining and comparing data from two national sources. Children and Youth Services Review. 2014;47:323-333.

65. Drake B, Jonson-Reid M, Way I, Chung S. Substantiation and recidivism. Child Maltreatment. 2003;8(4):248-260.

66. Conley A, Berrick JD. Community-based child abuse prevention: Outcomes associated with a differential response program in California. Child Maltreatment. 2010;15(4):282292.

67. Hughes RC, Rycus JS, Saunders-Adams SM, Hughes LK, Hughes KN. Issues in differential response. Research on Social Work Practice. 2013;23(5):493-520. 
68. Marshall SK, Charles G, Kendrick K, Pakalniskiene V. Comparing differential responses within child protective services: A longitudinal examination. Child Welfare. 2010;89(3):57.

69. Waldfogel J. The future of child protection revisited. Child welfare research: Advances for practice and policy. 2008:235-241.

70. Ortiz MJ, Shusterman GR, Fluke JD. Outcomes for children with allegations of neglect who receive alternative response and traditional investigations: Findings from NCANDS. Protecting Children. 2008;23(1\&2):57-70. 
Tables and Figures 
Figure 1 : Stages of the Traditional Child Protection Investigation in the United States.

$\left.\sum \begin{array}{c}\text { Intake \& } \\ \text { Screening }\end{array}\right\rangle \begin{gathered}\text { Assessment } \\ \& \\ \text { Investigation }\end{gathered}\left|>\begin{array}{c}\text { Family } \\ \text { Assessment }\end{array}\right\rangle$


Figure 2 : Mapping Differential Response Implementation in the United States: 2014. Kempe Center for the Prevention and Treatment of Child Abuse.

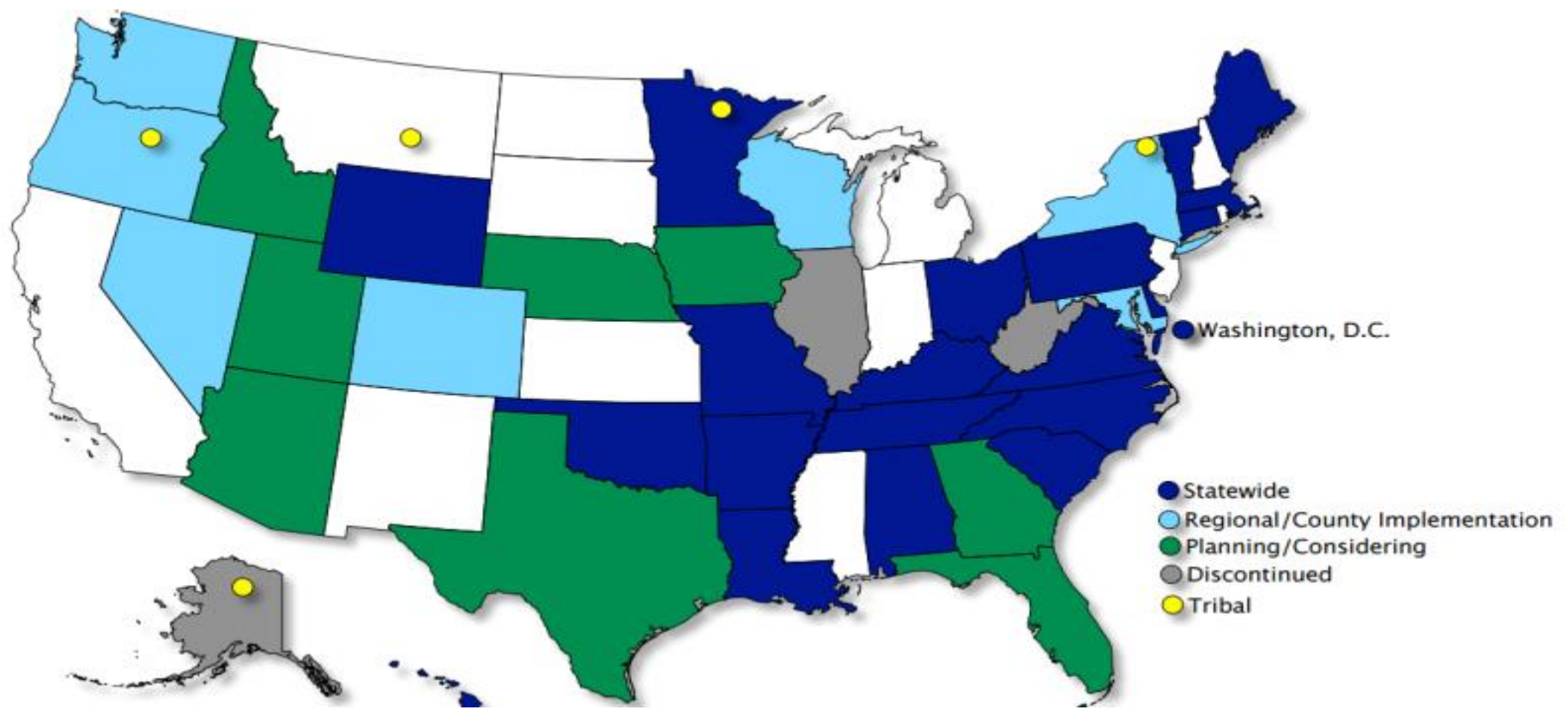


Table 1: Application of Family Systems Theory

\begin{tabular}{|c|c|c|}
\hline CONSTRUCT & DEFINTION & RISK FACTORS \\
\hline Triangles & $\begin{array}{l}\text { Three-person relationship } \\
\text { systems }\end{array}$ & $\begin{array}{l}\text { Family Size, family } \\
\text { composition, domestic } \\
\text { violence }\end{array}$ \\
\hline $\begin{array}{l}\text { Transmission of problems to } \\
\text { child }\end{array}$ & $\begin{array}{l}\text { Caregiver stress/problems } \\
\text { are taken out on the child }\end{array}$ & $\begin{array}{l}\text { Caregiver substance use, } \\
\text { poverty, parental disability, } \\
\text { military family }\end{array}$ \\
\hline Nuclear family & & $\begin{array}{l}\text { Family composition/marital } \\
\text { status }\end{array}$ \\
\hline - Marital Conflict & $\begin{array}{l}\text { Tension in marital } \\
\text { relationship }\end{array}$ & Domestic Violence \\
\hline $\begin{array}{l}\text { - Dysfunction in one } \\
\text { spouse }\end{array}$ & $\begin{array}{l}\text { Behavioral expectations } \\
\text { between spouses }\end{array}$ & $\begin{array}{l}\text { Disability, alcohol and other } \\
\text { substance use of parent }\end{array}$ \\
\hline - Child impairment & $\begin{array}{l}\text { Child } \\
\text { disability/dysfunction }\end{array}$ & $\begin{array}{l}\text { Disability, alcohol and other } \\
\text { substance use of child }\end{array}$ \\
\hline Differentiation of self & $\begin{array}{l}\text { Willingness or ability to } \\
\text { conform to family ideals }\end{array}$ & Behavior problem \\
\hline Emotional cutoff & $\begin{array}{l}\text { Managing stressful } \\
\text { relationships through } \\
\text { reducing or terminating } \\
\text { emotional contact }\end{array}$ & Type of abuse \\
\hline
\end{tabular}




\section{Figure 3: Directed Acyclic Graph}

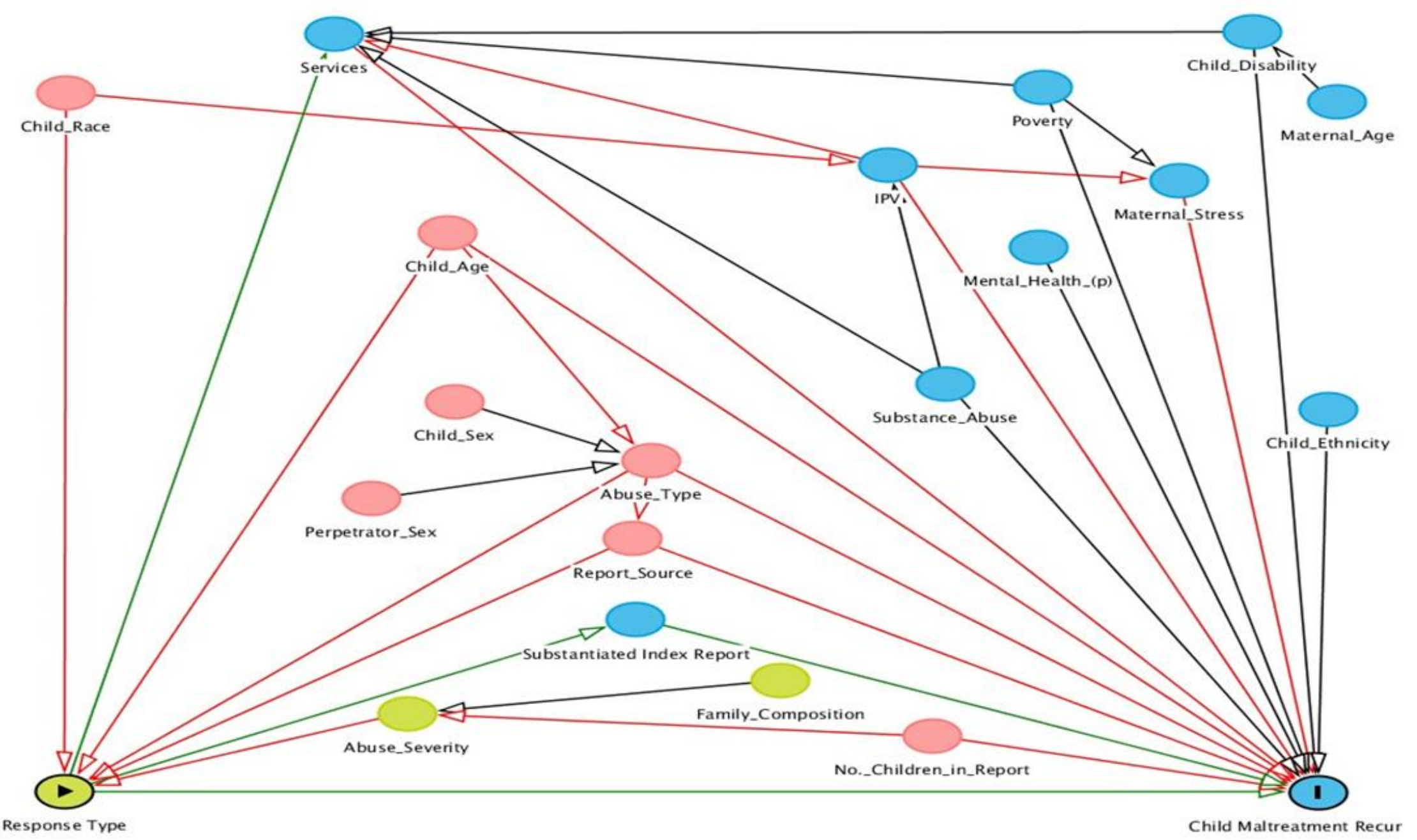


CHAPTER 2. DIFFERENTIAL RESPONSE POLICY AND CHILD MALTREATMENT RE-REPORT: A SYSTEMATIC REVIEW 


\subsection{Abstract}

Background: Differential response (DR) is an alternative approach to investigating reports of low to moderate child maltreatment. DR differs from traditional child protective service investigations by providing preventive and supportive services (e.g., referral for housing and financial assistance, counseling, child care). While prior research has identified discrepancies in how DR is operationalized within and between states, it is unclear if this policy is effective in reducing the incidence of maltreatment re-report. This systematic review addresses the policy gap.

Method: The protocol for this systematic review is registered with PROSPERO (\#CRD42015025388). Included studies that addressed DR in children and adolescents ages 0-18 years were identified through searching seven electronic databases. The primary exposure of interest was a state-level DR policy and the primary outcome was first-time child maltreatment recurrence or re-report. Socio-economic and case-level characteristics were qualitatively evaluated. Studies were selected and coded independently by two researchers. The Downs and Black checklist for non-randomized studies was used to assess the quality of reporting and bias for included studies.

Results: A total of 1,009 studies were screened; 10 met the inclusion criteria. Included studies compared 596,609 children between the ages of 0-18 years from 1992-2010. Discrepancies between written policy and practice were documented, and the review suggested a need for improvements in the surveillance and reporting of DR.

Conclusion: Additional research is needed to examine how changes in child welfare policy impact the recurrence of child maltreatment. 


\subsection{Introduction}

The decision to investigate or dismiss a report of child maltreatment is critical because, in true cases of abuse, this choice determines whether or not a child remains in a violent environment ${ }^{1}$. The consequences of child maltreatment become more serious with repeated abuse, and exposure to violence during childhood has been associated with disease, as well as injury morbidity and mortality ${ }^{2-8}$. In 2015, child protective services (CPS) in the United States (US) received over four million reports of suspected child maltreatment involving more than seven million children

${ }^{9}$. Fewer than half of these reports were investigated, and only 683,000 investigated cases were substantiated $^{9}$.

The effectiveness of CPS efforts to protect children from future harm is often measured using recurrence, defined as a case of substantiated maltreatment involving a child or family with a previously substantiated case ${ }^{10,11}$. Re-reports of maltreatment are used as a proxy for recurrence when substantiation cannot be measured ${ }^{12}$. Studies have shown that the risk of prospective abuse and the outcomes associated with child maltreatment recurrence and re-report are similar regardless of substantiation ${ }^{10,13,14}$. Known risk factors for recurrent maltreatment include the initial type of abuse, poverty, maternal stress, young maternal age, parental alcohol and other substance misuse and abuse, exposure to violence, child disability, child age, family structure and family size ${ }^{13,15-18}$.

The traditional response to child protection involves an investigation, where the details of reported abuse events are verified to assess child safety and risk of future harm ${ }^{19}$. At the end of the investigation, a formal determination is made that may or may not include post investigative services. This approach to child protection has been criticized as adversarial to parents and caregivers, thus impeding their cooperation with CPS ${ }^{20}$. Moreover, when investigated reports of 
maltreatment lack enough evidence for substantiation, they are dismissed despite the reality that families may need social service intervention ${ }^{21}$.

In an effort to improve CPS response to reports of suspected maltreatment, 20 states and the District of Columbia have adopted differential response at the state level ${ }^{22}$. Under this policy, families with reports of child maltreatment, perceived to be of low to moderate severity, are evaluated and provided with preventive and supportive services to overcome deficiencies directly related to maltreatment and its recidivism ${ }^{23,24}$. The core elements of differential response, as defined by Merkel-Holguin and colleagues ${ }^{25}$, and utilized consistently in the literature $^{23,24,26,27}$, are described in Table 1, and compared with the investigative approach. Studies examining differential response have exposed areas of promise and concern. Results suggested that child safety is equivalent or reduced in those receiving differential response when compared to an investigation ${ }^{28-33}$. However, these same studies reported that implementation is inconsistent across and within states, and that the screening process, number and type of response, and services offered are highly variable ${ }^{23,34,35}$. In addition, although differential response is intended for cases of low to moderate maltreatment, evidence has shown that this response is also being delivered to cases of high maltreatment severity (e.g., physical and sexual abuse) ${ }^{12}$.

Despite the challenges described, the Child Abuse Protection and Treatment Act (CAPTA) reauthorization of 2010 requires all states to have provisions for differential response implementation and evaluation ${ }^{36}$. This mandate is important because CAPTA provides the funding and agenda for child protection agencies in the US ${ }^{37}$. Given that 20 states and the District of Columbia have currently operationalized differential response, and 15 more states are 
in the planning and pilot stages ${ }^{22}$, elucidation of the impact of this policy on child maltreatment re-report and recurrence is of great importance.

Much of the theoretical perspective applied to child maltreatment research adopts an ecological approach ${ }^{38-41}$. However, because child maltreatment occurs in a family unit, most often perpetrated by biological parents ${ }^{9}$, it may be best understood through family level evaluation. Using this idea, family systems theory postulates that behaviors within a family can be understood through systems thinking ${ }^{42}$. Applied to the context of child maltreatment, the function of the family can be explained by understanding its members and their interaction ${ }^{42-44}$. Family systems theory proposes that families comprise individuals who interact in predictable patterns, which may be influenced by the external environment through a continuum of open and closed boundaries. We explored this idea in the present study by qualitatively examining the influence of CPS response on preventing recurrent maltreatment.

At the time of this study, we were unable to identify any existing systematic reviews that examined the relationship between child maltreatment response (investigation or differential response) and recurrence and/or re-report of abuse. One narrative literature review did provide a brief summary of six studies examining this relationship, as well as implications of differential response for policy and practice ${ }^{34}$. Its conclusions suggested that child safety is not compromised in those receiving differential response. However, the review was non-systematic, and optimally, it has been suggested that literature on the topic of interest should be reviewed every two years for currency ${ }^{45}$.

Two systematic reviews were identified that examined the outcomes of child maltreatment rereport and recurrence ${ }^{8,46}$. The first review examined the characteristics of recurrent child maltreatment using substantiated cases of abuse ${ }^{46}$. The second was an update ${ }^{8}$. However, 
neither review examined recurrence or re-report according to type of CPS response. To address this gap in the literature, the purpose of this systematic review was to analyze the relationship between differential response policy and the recurrence of child maltreatment.

\subsection{Method}

2.3.1. Registration. The protocol for this systematic review is registered with PROSPERO (\#CRD42015025388) ${ }^{47}$.

2.3.2. Study eligibility. Studies were selected using the PICOS approach for inclusion and exclusion ${ }^{48,49}$. The a priori inclusion criteria were as follows: (1) observational (cohort, casecontrol, cross-sectional), and field studies, (2) data available on maltreatment recurrence and/or re-report for those receiving either differential response or an investigation following a first report of abuse. Studies were excluded if they manifested one or more of the following characteristics: included (1) children and adolescents who had been removed from their homes (e.g., foster care, group homes), (2) cases of chronic child maltreatment (children or adolescents with more than two reports of child maltreatment), (3) had an inappropriate study design, (4) were studies published in a non-English language source, (5) did not report the type of maltreatment, (6) did not report the number of prior maltreatment events, (7) included families with cases involving more than one child, (8) exposure or outcome was obtained via self-report, and (9) were conference presentations (abstracts, posters, oral presentations). To avoid potential publication bias, grey literature (e.g. master's theses, doctoral dissertations) was not excluded from this systematic review.

2.3.3. Data sources. The following databases were searched up to October of 2015: (1) Scopus, (2) Web of Science, (3) PubMed, (4) ProQuest, (5) PsycINFO, (6) ERIC, and (7) Academic Search Complete. An updated search, conducted in February of 2017, yielded no additional 
pertinent studies. The search strategy for one of the databases (PROQUEST) is exemplified in Table 2. Reference lists from selected articles were cross-referenced to identify additional studies meeting the eligibility criteria. An effort-to-yield measure of search precision, number needed to read (NNR), was calculated by taking the inverse of the precision of the searches. Precision was calculated by dividing the number of included studies by the number of screened studies, after removal of duplicates. Number needed to read quantifies the number of articles that would need to be read before finding one that meets the established inclusion criteria. Dependent upon the subject and inclusion criteria, this number provides insights about the time and resources needed for replication, or to conduct a similar study.

\subsubsection{Study selection and data abstraction. Studies were selected and coded independently by}

two researchers $(\mathrm{AH}, \mathrm{KL})$, who subsequently met to compare code sheets and resolve discrepancies through consensus. Coding sheets were developed using Microsoft Excel, and agreement between coding was measured using Cohen's kappa statistic ( $\kappa)$. Prior to resolving discrepancies, overall agreement between coders was 0.86 . A third author was consulted for resolution when consensus could not be attained (GK).

\subsubsection{Risk of bias assessment. A priori, we intended to use the Strengthening the Reporting of}

Observational Studies in Epidemiology (STROBE) instrument to assess the quality of the included observational studies. However, this instrument is not designed to assess bias in experimental studies ${ }^{50}$. After identifying six studies with quasi-experimental study designs that met our inclusion criteria, we elected to use an abbreviated, seven-item Downs and Black checklist for non-randomized studies post hoc ${ }^{51}$, (Table 3). This decision allowed for consistent evaluation of quality across all included studies using a validated instrument. Each item is scored 
as 0 (no) or 1 (yes), with one indicating lowest risk of bias. The sum of all items can range from 0-7, with higher scores representing a lower risk of bias.

2.3.6. Synthesis of data. Differential response implementation, and definitions of child maltreatment and its reporting standards vary by state ${ }^{23}$. Therefore, we were unable to combine endpoints quantitatively, i.e., through meta-analysis, including calculation of a standardized effect size. Qualitative data synthesis at the individual and case-levels was used to analyze included studies. We aimed to evaluate socioeconomic (income, family composition, geographic region), behavioral (substance use, domestic violence), demographic (age, sex, ethnicity, race, disability) and case-level (type of abuse, time since first report, report source, fatality, perpetrator-victim relationship) characteristics of recurrent maltreatment in victims and perpetrators of child maltreatment.

\subsection{Results}

In this study, we examined the relationship between CPS response and child maltreatment rereport, using the principles of Family Systems Theory. Overall, we found families receiving differential response experienced equal or lesser subsequent reports of maltreatment. However, the methodology in the included studies prevented a thorough assessment of known confounders. 2.4.1 Study Characteristics. Study characteristics are described in Table 4. Of the 1,009 studies screened, a total of 10 representing 596,609 unique children met our inclusion criteria ${ }^{12,21,28-}$ $33,52,53$. Search precision was 0.001 and the NNR was 97 . Eight studies were conducted in the United States (US), representing nine states (California, Kentucky, Missouri, Minnesota, North Carolina, New Jersey, Oklahoma, Washington and Wyoming). The two remaining studies were conducted in British Columbia, Canada ${ }^{33}$, and Australia ${ }^{52}$. All US studies that examined differential response at the state level were conducted during the period 1992-2010, prior to the 
CAPTA 2010 reauthorization. Seven additional studies were identified with unclear study eligibility ${ }^{17,54-59}$. Attempts to contact two authors for clarification were unsuccessful, and additional information provided by the remaining five authors confirmed their studies did not meet our inclusion criteria. A flow diagram of the study selection process is shown in Figure 1. A list of studies excluded, including the reasons, is provided in Supplementary File A.

Nine studies were published in peer-reviewed journals ${ }^{12,21,29-33,52,53}$, and one study was a doctoral dissertation ${ }^{28}$. Among the US studies, two used data from the National Child Abuse and Neglect Data System (NCANDS) ${ }^{12,53}$, five used a statewide database ${ }^{28-32}$, and the data source of the other was not disclosed ${ }^{21}$. The two foreign studies utilized data from the Government Ministry Database in Canada ${ }^{33}$, and the Western Australian Department of Community Development ${ }^{52}$. Four studies employed an observational study design ${ }^{12,33,52,53}$, whereas the other six were quasi-experimental ${ }^{21,28-32}$. The number of families assigned to differential response ranged from $19.0 \%$ to $71.0 \%$. Eight studies reported use of two response paths ${ }^{12,21,28,29,31-33,53}$, and the two others reported three or more responses ${ }^{30,52}$. Comparison groups included both families who received investigation, and families who were not subject to intervention because their cases were screened out following an initial assessment.

Differential response was delivered by bachelor level para-professionals, master's level social workers, and public health nurses. One state in the US used a screening tool to determine response ${ }^{30,33}$, Washington ${ }^{11}$, as did the Canadian province of British Columbia ${ }^{33}$. Seven studies followed participant outcomes for 18 months or less ${ }^{12,28-31,33,53}$. Differential response was delivered as both a preventive and supportive service. Services offered to families varied by state, and included home visitation, financial and employment assistance, temporary assistance 
for needy families (TANF), food stamps, childcare assistance, housing and rental payments, and counseling or therapy services.

One study was limited to cases of neglect, ${ }^{53}$, whereas the remaining studies examined multiple forms of maltreatment. Family size/composition was reported in two studies ${ }^{21,30}$, and report source was reported in four ${ }^{12,33,53}$. Seven studies reported child race and ethnicity ${ }^{12,21,28-}$ $30,32,53$, five reported child sex ${ }^{12,28-30,53}$, and four reported child age ${ }^{12,29,30,53}$. One study reported the relationship of perpetrator to child ${ }^{30}$, and none reported the perpetrator characteristics of age, sex, race, or ethnicity.

\subsubsection{Study outcomes}

Re-report ranged from $17 \%$ to $53 \%$. Seven studies compared differential response to traditional investigations of child maltreatment ${ }^{12,21,29,31-33,53}$. Of these studies, one found risk of re-report decreased in those who received differential response ${ }^{53}$, and the remaining six found no significant difference in risk of re-report. One study found risk of re-report comparable between families who received differential response and those with no CPS intervention. Finally, two studies compared differential response to a multiple response comparison group ${ }^{30,52}$. Harries et al. found a reduction in re-report in those receiving differential response, and English et al. concluded there was no difference in re-report according to CPS response. A description of differential response by study is provided in Table 5 .

One study, which examined the role of the interventionist on the outcome, found that risk of re-report increased by $50 \%$ when differential response was delivered by a public health nurse as compared to a master's level social worker ${ }^{33}$. Three studies evaluated the risk of foster care placement by response, and found risk of entry was equivalent between both responses ${ }^{30,32,53}$. The study by Marshall et al. was not included in our evaluation of foster care placement because 
they did not distinguish the risk of re-report between children who received a care plan and those placed into foster care ${ }^{33}$. Finally, one study evaluated the difference in cost between differential response and investigation, with delivery of differential response being cheapest ${ }^{32}$.

\subsection{Discussion}

This systematic review evaluated the relationship between CPS response, and child and family level characteristics of child maltreatment recurrence using Family Systems Theory as our theoretical framework.

\subsubsection{Implications for research and reporting}

The results of this systematic review have several implications for future research. First, we found that the evaluation period for all studies, which met our inclusion criteria, occurred prior to the CAPTA reauthorization of 2010. Briefly, Title 1 Section 106, Grants to States for Child Abuse or Neglect Prevention and Treatment Programs, was amended to include provisions for differential response implementation and reporting ${ }^{36}$. Since CAPTA directs programming and funding for child protection in the US, further investigation is necessary for determining if this requirement influences CPS assignment and, subsequently, the incidence of re-report.

Second, this review only identified research that examined the relationship between CPS response and re-report in nine US states, although differential response is employed statewide in 20 US states and the District of Columbia. Further, we identified studies from British Columbia, Canada $^{33}$ and Australia ${ }^{52}$, reporting utilization of differential response policy. Both regions share many common socioeconomic, economic, political and cultural characteristics with the US. Future studies should focus on investigating how use of differential response in various geographic and cultural environments affects the outcome of re-report. For example, we only 
identified three southern US states within the included studies, ${ }^{12,53}$ with most others concentrated in the midwestern US.

Third, the majority of studies included in this systematic review utilized short follow-up periods, typically 6-18 months, thus precluding long-term evaluation of differential response policy. The reason for short follow-up times was unclear, considering that the national and state data used in these studies were available for multiple years. Studies examining maltreatment rereport over longer periods have shown that the greatest recidivism occurred within two years of an index report ${ }^{60}$, and it is unknown whether CPS response influences time to a consequent maltreatment event.

Fourth, we observed a considerable lag time between study period and publication. With differential response usage becoming more prevalent in the last ten years, we suggest that studies examining this policy focus on the most recent data to evaluate the impact of child welfare on recurrence.

Fifth, nine studies in this systematic review combined multiple forms of maltreatment in their assessment ${ }^{12,21,28-33,52}$. However, the etiology of various forms of maltreatment is different ${ }^{61}$, and they may be differentially influenced by policy. This possibility is important when examining service-based programs, such as differential response, which are suggested to be most effective in rectifying family-level challenges related to neglect ${ }^{62}$. Forms of maltreatment, such as physical or sexual abuse, may require a more involved response in addressing psychological and behavioral difficulties not amenable to remediation through needs-based service programs. Future studies, which examine CPS response, should concentrate on understanding its relationship with individual forms of abuse. 
Sixth, little information was reported on perpetrators of abuse. To combat recurrent maltreatment, it is imperative to understand their characteristics.

Seventh, we identified only one study that reported outcomes related to use of services post investigation ${ }^{32}$. This is of particular concern because differential response is a service-based program. Future examinations of this policy should describe which services are being utilized, when, and if there are modifiable barriers.

Eighth, we only identified one state in the US that used a screening tool for CPS response assignment ${ }^{30}$. Lack of a standardized screening instrument leaves response assignment to the discretion of the recipient of the initial report of maltreatment, and biases demographic and behavioral characteristics of reports. There is evidence that individuals receiving these reports are inadequately equipped to assess maltreatment severity and risk, and families are likely misclassified to a response ${ }^{63}$. Consequently, those requiring services may be denied, and those needing serious intervention may not receive it. We recommend that a standardized instrument be developed and validated to assess risk and severity of abuse.

Ninth, results from this qualitative synthesis show a similar risk of entering foster care between both response paths. This suggests the risk of future harm in those receiving differential response is equivalent to those being investigated, that path assignments based on risk assessment are flawed, or both. Each possibility warrants further investigation. Finally, we found only one study that evaluated the change in response after assessment or investigation ${ }^{32}$.

\subsubsection{Implications for practice}

This study has several implications for practice. First, one of the characteristics of differential response is that CPS response assignment may be changed in light of information learned during 
assessment and service. We identified only one study that examined the incidence of reassignment, and reassignment occurred in less than three percent of reports ${ }^{32}$. Practitioners need to be cognizant of family dynamics during assessment, and be willing to probe further to determine if a change in response assignment is warranted.

Second, we identified one study that found significant differences in re-report based on the interventionist. This finding suggests a need for universal training across disciplines for those delivering differential response.

Third, because differential response is a service-based program, it is important to ensure that prescribed services align with family need, rather than service availability. Provided services should be sustainable for families.

Fourth, prior studies, which compared the cost to implement differential response and traditional CPS investigations, found that the cost of differential response was less than or comparable to that of a CPS investigation ${ }^{27,64,65}$. We identified one study in our systematic review that compared cost, and the results supported the previous conclusions ${ }^{32}$. Although results suggest that differential response is more cost effective than an investigation, the longterm implications for child health remain unclear.

\subsubsection{Implications for policy}

Differential response is being delivered as both a preventive and a supportive program. This range of services makes synthesizing of results difficult, as definitions and implementation vary. For example, some states deliver differential response to reports of maltreatment that are screened out of CPS, others deliver services to cases of low to moderate severity, while still others assign all cases of neglect to this response. Lack of a consistent definition of child maltreatment also creates barriers to services for families in need, and results in inconsistencies 
in funding allocations for states requesting grants under CAPTA. Elements of differential response, as outlined by Merkel-Holguin ${ }^{25}$, should be updated to reflect current practices.

\subsubsection{Strengths and Limitations.}

To the best of our knowledge, this is the first study to systematically review the relationship between differential response and child maltreatment re-report. Included studies covered a number of US states, and also identified international use of this policy. Examining studies representing nearly 600,000 children, we were able to qualitatively analyze individual and caselevel characteristics impacting the relationship between CPS response and re-report. Finding that only ten studies met our inclusion criteria provided support for the need for additional research elucidating the relationship between child welfare policy and recurrent maltreatment. This is especially important for public health, where the most effective prevention efforts are proactive and evidence based.

This study has several limitations. As with all systematic reviews, our synthesis was limited by the rigor and reporting of the included studies. Many socioeconomic, demographic and behavioral factors were also missing from these studies, limiting our ability to evaluate their influence on the relationship between our exposure and outcome measures. Furthermore, the number of studies identified in our search was limited by selected search terms. Differential response programs vary considerably, and it is possible that programs implemented at the state level were not identified for this analysis due to unknown nomenclature and program designs.

Finally, the included studies were few for various reasons. Some authors declined to explicitly specify whether services were offered under differential response policy or a competing intervention ${ }^{17,59}$, and one group of authors did not discern between first time and repeat maltreatment cases in their study populations ${ }^{54}$. We also identified several studies that evaluated 
maltreatment outcomes as either substantiated or unsubstantiated, without consideration for those who received a differential response ${ }^{55,64,66,67}$. Future studies should examine these exposures independently in order to better understand the heterogeneity in risk factors, as well as in short and long-term outcomes.

\subsection{Conclusion}

There is need for more research distinguishing risk of child maltreatment re-report according to CPS response. Universal guidelines for assigning maltreatment response may help reduce assignment bias. In addition, research is needed to analyze the long-term impact of differential response on the re-report of abuse.

Since this systematic review focused only on statewide differential response implementation, an examination of states with countywide implementation should also be conducted to evaluate the influence of implementation type on re-report. 


\section{References}

1. Kempe CH, Silverman FN, Steele BF, Droegemueller W, Silver HK. The battered-child syndrome. JAMA. 1984;251(24):3288-3294.

2. Felitti VJ, Anda RF, Nordenberg D, et al. Relationship of childhood abuse and household dysfunction to many of the leading causes of death in adults: The Adverse Childhood Experiences (ACE) Study. American Journal of Preventive Medicine. 1998;14(4):245258.

3. Norman RE, Byambaa M, De R, Butchart A, Scott J, Vos T. The long-term health consequences of child physical abuse, emotional abuse, and neglect: a systematic review and meta-analysis. PLOS Medicine. 2012;9(11).

4. Farst K, Ambadwar PB, King AJ, Bird T, Robbins JM. Trends in hospitalization rates and severity of injuries from abuse in young children, 1997-2009. Pediatrics. 2013;131(6):e1796-e1802.

5. Ortega HW, Vander Velden H, Kreykes NS, Reid S. Childhood death attributable to trauma: is there a difference between accidental and abusive fatal injuries? The Journal of Emergency Medicine. 2013;45(3):332-337.

6. Hoertel N, Franco S, Wall MM, et al. Childhood maltreatment and risk of suicide attempt: a nationally representative study. The Journal of Clinical Psychiatry. 2015;76(7):1,478-923.

7. King A, Farst K, Jaeger M, Onukwube J, Robbins J. Maltreatment-related emergency department visits among children 0 to 3 years old in the United States. Child Maltreatment. 2015;20(3):151-161.

8. White OG, Hindley N, Jones DP. Risk factors for child maltreatment recurrence: an updated systematic review. Medicine, Science and the Law. 2015;55(4):259-277.

9. U.S. Department of Health and Human Services, Administration for Children and Families, Administration on Children, Youth and Families. Child Maltreatment 2015. 2017: http://www.acf.hhs.gov/programs/cb/research-data-technology/statisticsresearch/child-maltreatment.

10. Casanueva C, Tueller S, Dolan M, Testa M, Smith K, Day O. Examining predictors of rereports and recurrence of child maltreatment using two national data sources. Children and Youth Services Review. 2015;48:1-13.

11. English DJ, Marshall DB, Brummel S, Orme M. Characteristics of repeated referrals to child protective services in Washington State. Child Maltreatment. 1999;4(4):297-307.

12. Shusterman GR, McDonald WR. Alternative Responses to Child Maltreatment: Findings from NCANDS. Washington, DC: US Department of Health and Human Services; 2005. 
13. Bae H, Solomon PL, Gelles RJ. Multiple child maltreatment recurrence relative to single recurrence and no recurrence. Children and Youth Services Review. 2009;31(6):617-624.

14. Fluke J, Shusterman GR, Hollinshead DM, Yuan Y-YT. Longitudinal analysis of repeated child abuse reporting and victimization: Multistate analysis of associated factors. Child Maltreatment. 2008;13(1):76-88.

15. Connell CM, Bergeron N, Katz KH, Saunders L, Tebes JK. Re-referral to child protective services: The influence of child, family, and case characteristics on risk status. Child Abuse \& Neglect. 2007;31(5):573-588.

16. Dakil SR, Sakai C, Lin H, Flores G. Recidivism in the child protection system: Identifying children at greatest risk of reabuse among those remaining in the home. Archives of Pediatrics \& Adolescent Medicine. 2011;165(11):1006-1012.

17. Hélie S, Laurier C, Pineau-Villeneuve C, Royer M-N. A developmental approach to the risk of a first recurrence in child protective services. Child Abuse \& Neglect. 2013;37(12):1132-1141.

18. Koniak-Griffin D, Turner-Pluta C. Health risks and psychosocial outcomes of early childbearing: a review of the literature. The Journal of Perinatal \& Neonatal Nursing. 2001;15(2):1-17.

19. Myers JE. The APSAC Handbook on Child Maltreatment. 3rd ed. Los Angeles, CA: Sage; 2011.

20. Kaplan C, Merkel-Holguin L. Another look at the national study on differential response in child welfare. Protecting Children. 2008;23(1\&2):5-21.

21. Loman LA, Siegel GL. Effects of anti-poverty services under the differential response approach to child welfare. Children and Youth Services Review. 2012;34(9):1659-1666.

22. The Kempe Center for the Prevention and Treatment of Child Abuse and Neglect. Differential Response Impementation. 2014: http://www.ucdenver.edu/academics/colleges/medicalschool/departments/pediatrics/subs/ can/QIC-DR/Documents/DR\%20Map\%20as\%20of\%20Sept\%202\%202014.pdf.

23. Child Welfare Information Gateway. Differential Response to Reports of Child Abuse and Neglect. Washington, DC: U.S. Department of Health and Human Services, Children's Bureau; 2014.

24. Fluke J, Harlaar, N., Heisler, K., Darnell, A., Brown, B., Merkel-Holguin, L. ASPE Research Brief: Differential Response and the Safety of Children Reported to Child Protective Services: A Tale of Six States. Denver, CO: U.S. Department of Health and Human Services; 2016. 
25. Merkel-Holguín LA, Kaplan C, Kwak A, Association AH. National study on differential response in child welfare. Washington, DC: American Humane Association and Child Welfare League of America; 2006.

26. National Quality Improvement Center on Differential Response in Child Protective Services. Final Report : QIC-DR cross-site evaluation. Denver, CO2014.

27. Winokur M, Colorado State University, \& National Quality Improvement Center on Differential Response in Child Protective Services. Program Evaluation of the Colorado Consortium on Differential Response. 2014.

28. Conley A, Berrick JD. Implementation of differential response in ethnically diverse neighborhoods. Protecting Children. 2008;23(1\&2):30-38.

29. Conley A, Berrick JD. Community-based child abuse prevention: Outcomes associated with a differential response program in California. Child Maltreatment. 2010;15(4):282292.

30. English DJ, Wingard T, Marshall D, Orme M, Orme A. Alternative responses to child protective services: Emerging issues and concerns. Child Abuse \& Neglect. 2000;24(3):375-388.

31. Lawrence CN, Rosanbalm KD, Dodge KA. Multiple response system: Evaluation of policy change in North Carolina's child welfare system. Children and youth services review. 2011;33(11):2355-2365.

32. Loman LA, Siegel GL. Alternative response in Minnesota: Findings of the program evaluation. Protecting Children. 2005;20(2\&3):78-92.

33. Marshall SK, Charles G, Kendrick K, Pakalniskiene V. Comparing differential responses within child protective services: A longitudinal examination. Child Welfare. 2010;89(3):57.

34. Kyte A, Trocme N, Chamberland C. Evaluating where we're at with differential response. Child Abuse \& Neglect. 2013;37(2):125-132.

35. Hughes RC, Rycus JS, Saunders-Adams SM, Hughes LK, Hughes KN. Issues in differential response. Research on Social Work Practice. 2013;23(5):493-520.

36. United States. Child Abuse Prevention and Treatment Act as amended by PL 111-320, the CAPTA reauthorization act of 2010. Washington, DC: United States Government Publishing Office; 2010.

37. Child Wefare Information Gateway. About CAPTA: A Legislative History. Washington, DC: U.S. Department of Health and Human Services, Children's Bureau; 2011. 
38. Algood CL, Hong JS, Gourdine RM, Williams AB. Maltreatment of children with developmental disabilities: An ecological systems analysis. Children and Youth Services Review. 2011;33(7):1142-1148.

39. Krishnan V, Morrison KB. An ecological model of child maltreatment in a Canadian province. Child Abuse \& Neglect. 1995;19(1):101-113.

40. Lanier P, Jonson-Reid M, Stahlschmidt MJ, Drake B, Constantino J. Child maltreatment and pediatric health outcomes: A longitudinal study of low-income children. Journal of Pediatric Psychology. 2009;35(5):511-522.

41. Little L, Kaufman Kantor G. Using ecological theory to understand intimate partner violence and child maltreatment. Journal of Community Health Nursing. 2002;19(3):133145.

42. Gavazzi SM. Family systems theory. Encyclopedia of Adolescence. New York, NY: Springer; 2011:963-967.

43. Kerr ME. One family's story: A primer on Bowen theory. 1st ed. Washington, DC: Bowen Center for the Study of the Family, Georgetown Family Center; 2002.

44. Papero DV. Bowen family systems theory. Boston, MA: Allyn and Bacon; 1990.

45. French SD, McDonald S, McKenzie JE, Green SE. Investing in updating: how do conclusions change when Cochrane systematic reviews are updated? BMC Medical Research Methodology. 2005;5(1).

46. Hindley N, Ramchandani PG, Jones DP. Risk factors for recurrence of maltreatment: a systematic review. Archives of Disease in Childhood. 2006;91(9):744-752.

47. Hunter A, Lewis K, Kelley G, et al. Differential response policy and child maltreatment recurrence: a systematic review with meta- analysis, if appropriate.

2015(CRD42015025388).

http://www.crd.york.ac.uk/PROSPERO/display_record.asp?ID=CRD42015025388.

48. Littell JH, Corcoran J, Pillai VK. Systematic reviews and meta-analysis. New York, NY: Oxford University Press; 2008.

49. Higgins JP, Green S. Cochrane handbook for systematic reviews of interventions. Vol 4: John Wiley \& Sons; 2011.

50. Vandenbroucke JP, Von Elm, E., Altman, D. G., Gøtzsche, P. C., Mulrow, C.D., Pocock, S. .J, Poole, C., Schlesselman, J.J., Egger, M., STROBE Initiative. Strengthening the Reporting of Observational Studies in Epidemiology (STROBE): explanation and elaboration. PLOS Medicine. 2007;4(10). 
51. Downs SH, Black N. The feasibility of creating a checklist for the assessment of the methodological quality both of randomised and non-randomised studies of health care interventions. Journal of Epidemiology and Community Health. 1998;52(6):377-384.

52. Harries M, Cant RL, Bilson A, Thorpe D. Responding to information about children in adversity: Ten years of a differential response model in Western Australia. Child Abuse \& Neglect. 2015;39:61-72.

53. Ortiz MJ, Shusterman GR, Fluke JD. Outcomes for children with allegations of neglect who receive alternative response and traditional investigations: Findings from NCANDS. Protecting Children. 2008;23(1\&2):57-70.

54. Alaggia R, Gadalla TM, Shlonsky A, Jenney A, Daciuk J. Does differential response make a difference: examining domestic violence cases in child protection services. Child \& Family Social Work. 2015;20(1):83-95.

55. Campbell KA, Thomas AM, Cook LJ, Keenan HT. Longitudinal experiences of children remaining at home after a first-time investigation for suspected maltreatment. The Journal of Pediatrics. 2012;161(2):340-347.

56. Drake B, Jonson-Reid M, Sapokaite L. Rereporting of child maltreatment: Does participation in other public sector services moderate the likelihood of a second maltreatment report? Child Abuse \& Neglect. 2006;30(11):1201-1226.

57. Jones AS. Implementation of differential response: A racial equity analysis. Child Abuse \& Neglect. 2015;39(3):73-85.

58. Lipien L, Forthofer MS. An event history analysis of recurrent child maltreatment reports in Florida. Child Abuse \& Neglect. 2004;28(9):947-966.

59. Sinanan AN. The impact of child, family, and child protective services factors on reports of child sexual abuse recurrence. Journal of Child Sexual Abuse. 2011;20(6):657-676.

60. Dolan M, Casanueva C, Smith K, Day O, Dowd K. Child abuse and neglect re-reports: Combining and comparing data from two national sources. Children and Youth Services Review. 2014;47:323-333.

61. Gilbert R, Widom CS, Browne K, Fergusson D, Webb E, Janson S. Burden and consequences of child maltreatment in high-income countries. The Lancet. 2009;373(9657):68-81.

62. DePanfilis D. Child neglect: A guide for prevention, assessment, and intervention. US Department of Health and Human Services, Adminsitration for Children and Families, Administration on Children, Youth and Families, Children's Bureau, Office on Child Abuse and Neglect; 2006. 
63. Dorsey S, Mustillo SA, Farmer EM, Elbogen E. Caseworker assessments of risk for recurrent maltreatment: Association with case-specific risk factors and re-reports. Child Abuse \& Neglect. 2008;32(3):377-391.

64. Fuller T, Nieto M. Child welfare services and risk of child maltreatment rereports: Do services ameliorate initial risk? Children and youth services review. 2014;47:46-54.

65. Murphy J, Newton-Curtis L, Kimmich M. Ohio SOAR project: Final report. Tualatin, OR: Human Services Research Insititute. 2013.

66. Drake B, Jonson-Reid M, Way I, Chung S. Substantiation and recidivism. Child Maltreatment. 2003;8(4):248-260.

67. Jonson-Reid M, Drake B, Chung S, Way I. Cross-type recidivism among child maltreatment victims and perpetrators. Child Abuse \& Neglect. 2003;27(8):899-917. 
Tables and Figures 


\begin{tabular}{|c|c|}
\hline $\begin{array}{c}\text { Differential Response } \\
\text { (Merkel-Holguín et al., 2006) }\end{array}$ & $\begin{array}{l}\text { Investigative Response } \\
\text { (Myers, 2011) }\end{array}$ \\
\hline $\begin{array}{l}\text { Two or more responses offered for reports of } \\
\text { maltreatment that are screened in and } \\
\text { accepted for CPS response }\end{array}$ & $\begin{array}{l}\text { Single response to reports of child } \\
\text { maltreatment screened in and accepted for } \\
\text { CPS response }\end{array}$ \\
\hline $\begin{array}{l}\text { Response determined by assessment of } \\
\text { immediate risk, and prior engagement with } \\
\text { CPS; low or moderate reports assigned to } \\
\text { non-investigative response }\end{array}$ & $\begin{array}{l}\text { May be used for low to severe reports of } \\
\text { maltreatment and cases involving legal and } \\
\text { judicial systems }\end{array}$ \\
\hline $\begin{array}{l}\text { Response may be changed based on } \\
\text { information received during assessment or } \\
\text { investigation }\end{array}$ & -- \\
\hline $\begin{array}{l}\text { Multiple responses are established and } \\
\text { codified in statue, policy, and/or protocols }\end{array}$ & --- \\
\hline $\begin{array}{l}\text { Services are voluntary; families may refuse } \\
\text { participation after assessment without } \\
\text { consequence }\end{array}$ & Participation is mandatory \\
\hline $\begin{array}{l}\text { No official determination of maltreatment is } \\
\text { documented }\end{array}$ & Investigation outcome is documented \\
\hline $\begin{array}{l}\text { Perpetrators of abuse are not placed on a } \\
\text { registry of offenders }\end{array}$ & $\begin{array}{l}\text { Perpetrators of abuse are identified and placec } \\
\text { on a central registry of offenders }\end{array}$ \\
\hline
\end{tabular}




\section{Table 2. Example of search strategy (PROQUEST)}

\begin{tabular}{|c|c|}
\hline Database & PROQUEST \\
\hline Search Date & $10 / 20 / 2015$ \\
\hline Search Terms & $\begin{array}{c}\text { ((differential OR alternative OR dual track OR policy OR family } \\
\text { assessment response) AND (maltreat* OR abuse* OR mistreat* } \\
\text { OR neglect)) AND (recurrence OR recidivism OR re-report) } \\
\text { AND (child protective services OR cps OR welfare) AND } \\
\text { (child* OR adolescent*or youth) }\end{array}$ \\
\hline Total Retrieved & 760 \\
\hline
\end{tabular}




\begin{tabular}{|l|l|}
\hline \multicolumn{2}{|l|}{ Table 3. Abbreviated Downs and Black Checklist for Non-Randomized Studies } \\
\hline Is the hypothesis/aim/objective of the study clearly described? & Yes/No \\
\hline $\begin{array}{l}\text { Are the main outcomes to be measured clearly described in the Introduction } \\
\text { or Methods section? }\end{array}$ & Yes/No \\
\hline $\begin{array}{l}\text { Are the characteristics of the patients (study participants) included in the } \\
\text { study clearly described? }\end{array}$ & Yes/No \\
\hline Are the interventions of interest clearly described? & Yes/No \\
\hline $\begin{array}{l}\text { Are the distributions of principal confounders in each group of subjects to be } \\
\text { compared clearly described? }\end{array}$ & Yes/No \\
\hline \begin{tabular}{l} 
Are the main findings of the study clearly described? \\
\hline $\begin{array}{l}\text { Were the patients in different intervention groups (trials and cohort studies) or } \\
\text { were the cases and controls (case-control studies) recruited from the same } \\
\text { population? }\end{array}$
\end{tabular} & Yes/No \\
\hline
\end{tabular}


Table 4. Characteristics of included studies

\begin{tabular}{|c|c|c|c|c|c|c|c|}
\hline Author [ref] & $\begin{array}{l}\text { Publication } \\
\text { Year }\end{array}$ & Country & $\begin{array}{c}\text { Included } \\
\text { States/Territories }\end{array}$ & $\begin{array}{l}\text { Follow-Up } \\
\text { Period }\end{array}$ & Participants (N) & $\begin{array}{l}\text { Type(s) of } \\
\text { Abuse }\end{array}$ & Comparison \\
\hline $\begin{array}{l}\text { (Conley \& } \\
\text { Berrick, 2008) }\end{array}$ & 2008 & United States & California & $\begin{array}{l}9 \text { months, may be } \\
\text { extended to } 12 \\
\text { months }\end{array}$ & 618 & Multiple & $\begin{array}{c}\text { No } \\
\text { intervention }\end{array}$ \\
\hline $\begin{array}{l}\text { (Conley \& } \\
\text { Berrick, 2010) }\end{array}$ & 2010 & United States & California & 1 year & 645 & Multiple & Investigation \\
\hline $\begin{array}{l}\text { (English et al., } \\
\text { 2000) }\end{array}$ & 2000 & United States & Washington & $\begin{array}{l}18 \text { months post } \\
\text { service delivery }\end{array}$ & 1,263 & Multiple & Multiple \\
\hline $\begin{array}{l}\text { (Harries et al., } \\
\text { 2015) }\end{array}$ & 2015 & Australia & Western Australia & 5 years & 55,785 & Multiple & Multiple \\
\hline $\begin{array}{l}\text { (Lawrence et } \\
\text { al., 2011) }\end{array}$ & 2011 & United States & North Carolina & 1 year & 122,367 & Multiple & Investigation \\
\hline $\begin{array}{l}\text { (Loman \& } \\
\text { Siegel, 2005) }\end{array}$ & 2005 & United States & Minnesota & 3 years & 4,165 & Multiple & Investigation \\
\hline $\begin{array}{l}\text { (Loman \& } \\
\text { Siegel, 2012) }\end{array}$ & 2012 & United States & Undisclosed & $8-9$ years & 3,765 & Multiple & Investigation \\
\hline $\begin{array}{l}\text { (Marshall et } \\
\text { al., 2010) }\end{array}$ & 2010 & Canada & British Columbia & 18 months & 587 & Multiple & Investigation \\
\hline $\begin{array}{l}\text { (Ortiz et al., } \\
\text { 2008) }\end{array}$ & 2008 & United States & $\begin{array}{c}\text { Kentucky, } \\
\text { Minnesota, } \\
\text { Oklahoma, } \\
\text { Washington and } \\
\text { Wyoming }\end{array}$ & 1 year & 93,576 & Neglect & Investigation \\
\hline
\end{tabular}




\begin{tabular}{|c|c|c|c|c|c|c|c|}
\hline $\begin{array}{l}\text { (Shusterman } \\
\text { \& McDonald, } \\
\text { 2005) }\end{array}$ & 2008 & United States & $\begin{array}{c}\text { Kentucky, } \\
\text { Minnesota, } \\
\text { Missouri, New } \\
\text { Jersey, Oklahoma, } \\
\text { Wyoming }\end{array}$ & 1 year & 313,838 & Multiple & Investigation \\
\hline
\end{tabular}


Figure 1: Flow diagram for the selection of studies.

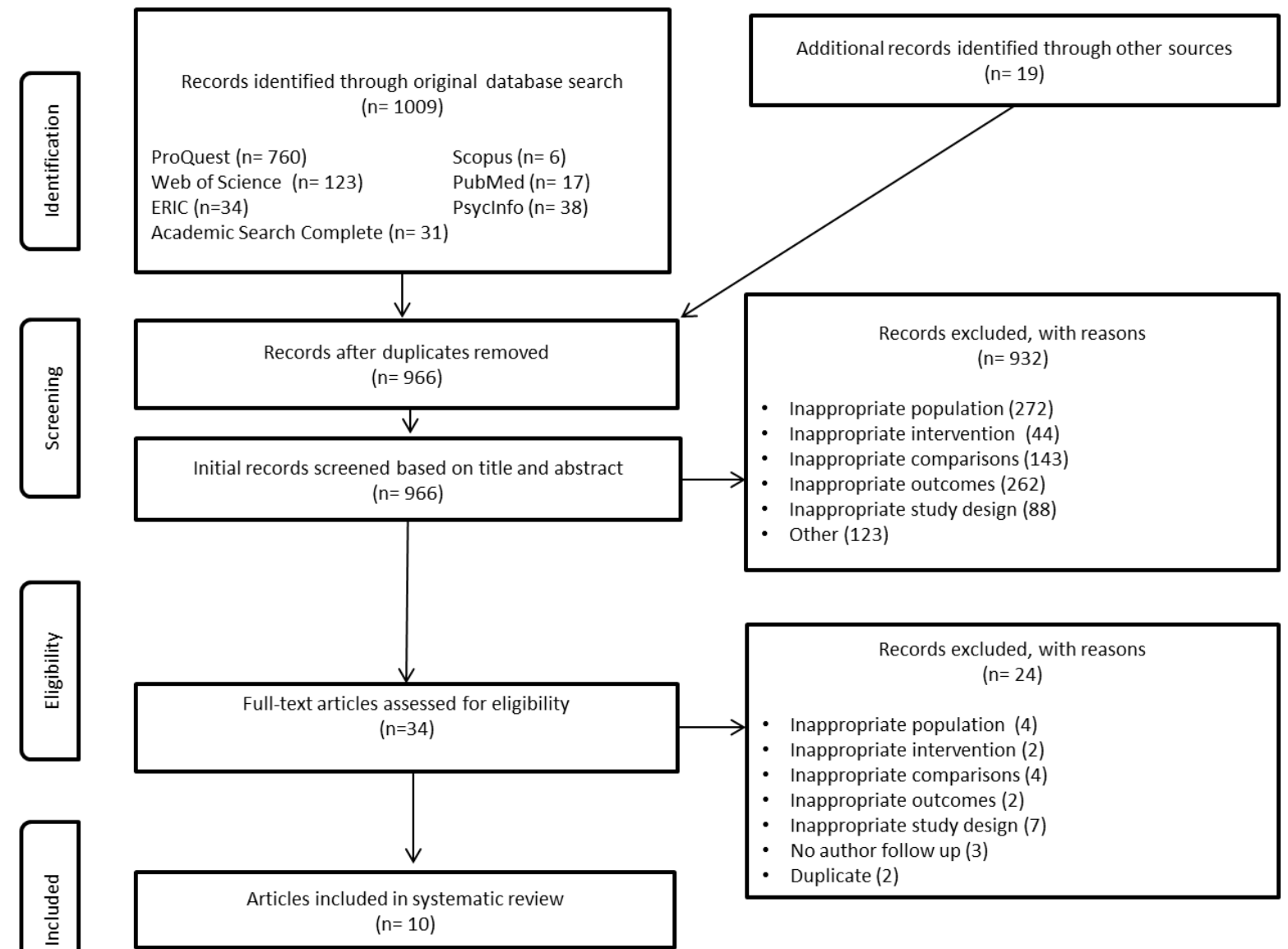




\begin{tabular}{|c|c|}
\hline Author [ref] & Differential Response \\
\hline (Conley \& Berrick, 2008) & $\begin{array}{l}\text { Families screened out of CPS are assessed and receive } \\
\text { voluntary, home visitation focused on improving familial } \\
\text { relationship and social support on a weekly basis by para- } \\
\text { professionals. Limited financial support provided (e.g. gift } \\
\text { cards). }\end{array}$ \\
\hline (Conley \& Berrick, 2010) & $\begin{array}{l}\text { Families screened out of CPS are assessed and receive } \\
\text { voluntary, home visitation focused on improving familial } \\
\text { relationship and social support on a weekly basis by para- } \\
\text { professionals. Limited financial support provided (e.g. gift } \\
\text { cards). }\end{array}$ \\
\hline (English et al., 2000) & $\begin{array}{l}\text { Families screened out of CPS are assessed and receive home } \\
\text { visitation services by master's level social workers and } \\
\text { public health nurses; financial assistance as needed. }\end{array}$ \\
\hline (Harries et al., 2015) & $\begin{array}{l}\text { Supportive services (undefined) provided to families by } \\
\text { social workers, following assessment. }\end{array}$ \\
\hline (Lawrence et al., 2011) & $\begin{array}{l}\text { Family assessment by social workers, followed by service } \\
\text { provision as needed. }\end{array}$ \\
\hline (Loman \& Siegel, 2005) & Family assessment and service provision. \\
\hline (Loman \& Siegel, 2012) & $\begin{array}{l}\text { Anti-poverty services (e.g. housing, food, utilities, clothing, } \\
\text { financial assistance) and home visitation delivered by county } \\
\text { intake workers. }\end{array}$ \\
\hline (Marshall et al., 2010) & $\begin{array}{l}\text { Family assessment, followed by referral to community } \\
\text { agencies as needed. Sexual abuse may not be assigned to } \\
\text { differential response. }\end{array}$ \\
\hline (Ortiz et al., 2008) & Defined by NCANDS. \\
\hline $\begin{array}{l}\text { (Shusterman \& McDonald, } \\
\text { 2005) }\end{array}$ & Defined by NCANDS. \\
\hline
\end{tabular}


CHAPTER 3. LONG TERM EFFECTIVENESS OF DIFFERENTIAL RESPONSE IN PREVENTING CHILD MALTREATMENT RE-REPORT 


\subsection{Abstract}

Objective: Differential response policy allows families reported for child maltreatment to receive supportive services in place of an investigation. Studies show similar results in the prevalence of maltreatment re-report for differential response and investigation at 2 years. However, the longterm effectiveness of this policy is unknown. This study compares the risk of child maltreatment re-report in those receiving differential response and those receiving an investigation following first report of maltreatment.

Method: This analysis used data on 897,088 children $<18$ years of age from the National Child Abuse and Neglect Data System (NCANDS) Child File for 2004-2014. Included states (Louisiana, Minnesota, Missouri, and Wyoming) utilized a state-level differential response policy throughout the study period. Cox proportional hazards analysis was used to calculate adjusted and unadjusted hazard ratios (HRs). A Directed Acyclic Graph (DAG) was developed as the theoretical statistical model.

Results: After 11 years, risk of re-report was $14 \%$ greater in differential response cases than those receiving an investigation (HR: 1.14, 95\% CI 1.12, 1.15). This relationship persisted after controlling for demographic characteristics. Report source and baseline type of abuse attenuated results. Forty-six percent of our sample was derived from Missouri, which classified $92 \%$ of baseline maltreatment as 'other'. In sensitivity analysis, we excluded reports from Missouri and found that the risk of re-report was decreased in those receiving differential response in unadjusted and fully adjusted models (HR: 0.92, 95\%CI: 0.91, 0.93).

Conclusion: Results showed increased risk of re-report in those receiving differential response. However, sensitivity analysis suggests that these results are confounded by the poor quality and 
lack of fidelity in the baseline maltreatment variable. Universal screening instruments should be developed to minimize challenges in determining abuse type and, subsequently, CPS response. 


\subsection{Introduction}

Reports of suspected child maltreatment have traditionally received an investigation to identify child victims and perpetrators, as well as prevent future harm. ${ }^{1,2}$ Differential response is a relatively new child welfare policy that takes an innovative approach to addressing reports of child maltreatment by replacing the traditional investigative response with supportive and preventive services. ${ }^{3}$ The number of responses and services offered, which include home visitation, referral for food and housing, and counseling, vary depending upon individual state policies and resources. ${ }^{4,5}$ In 2015, 3.4 million children in the United States received either an investigation or a differential response to a report of child maltreatment. ${ }^{6}$ As of 2014,20 states and the District of Columbia use this policy at the state level, seven at the county or regional level, and eight are in the planning stages, according to The National Quality Center on Differential Response in Child Protective Services (QIC-DR). ${ }^{7}$ As utilization of differential response increases, understanding the long term implications of its use is critical.

A defining characteristic of differential response in many states is the assessment of families receiving this response as a unit. ${ }^{8}$ This precludes individuals, particularly victims of abuse, from having the opportunity to report their experiences confidentially, and to divulge specific circumstances (location, time, ancillary events, co-occurring abuse) that are critical for future abuse prevention. In a group setting, victims, witnesses and perpetrators may withhold information about family dynamics and co-occurring abuse that have the potential to inform decision making during CPS response. Moreover, perpetrators of maltreatment who receive differential response avoid placement on child abuse offender registries. ${ }^{3,9}$ This lack of consequence may hinder perpetrators from correcting abusive behavior, and allows for future interaction with children, including the child victim. 
Differential response is intended for cases of low to moderate reports of maltreatment, ${ }^{3}$ However, a review of the literature revealed that reports of sexual abuse and serious physical abuse have received this response. ${ }^{10}$ Because there is no universal screening tool to determine an appropriate response, ${ }^{9,11}$ differential response is most frequently delivered to cases of neglect (lack of supervision, medical, educational) and cases involving caregiver drug and alcohol abuse. ${ }^{12}$ Two states (Louisiana, Washington) were identified that use screening instruments. ${ }^{3,13}$ In most instances, response selection (investigation or differential response), made immediately during intake, is left to the discretion of the individual responsible for screening. This introduces considerable variability, bias and misclassification. ${ }^{5}$ Despite evidence that child protection workers are ill-equipped to assess current and future risk of maltreatment, ${ }^{9,14,15}$ differential response is predicated on the notion that the individual receiving the initial report of abuse is able to accurately assess the probability of future maltreatment risk, as well as severity of abuse.

By design, differential response is voluntary, and families may refuse services without consequence. ${ }^{3}$ Yet, the purpose of an investigation by child protective services (CPS) is to protect children, who are the suspected victims of abuse, from suffering additional harm. Differential response may contradict this purpose by changing the objective from identifying and preventing abuse to temporarily ameliorating problems that carry serious future ramifications. If unresolved issues surrounding abuse are not formally addressed, they may escalate into more serious offences, and potentially the death of a child. ${ }^{16}$ Contact with CPS following a maltreatment report may be the only opportunity for intervention. ${ }^{17}$ Ortega and colleagues found that victims of child maltreatment fatalities were likely to come into contact with a professional with the ability to intervene within two months of death. ${ }^{18}$ 
The effectiveness of child maltreatment prevention efforts is measured by the rates of recurrence, defined as a case of substantiated maltreatment involving a child or family with a previously confirmed case. ${ }^{19}$ Because differential response does not require an investigation or substantiation, re-report is often used as a proxy measure. Studies comparing the risk of maltreatment re-report by response have reported similar risks between those receiving a differential response and investigation. ${ }^{10,13,20-25}$ With the exception of a recent research brief by Fluke and colleagues,${ }^{26}$ those studies lacked adequate control groups and, were conducted over short periods of time, thus precluding longer term evaluation of this policy. Other studies have combined differential response and investigation exposure when reporting the risk of re-report, hence preventing comparative analysis. ${ }^{27}$ Nonetheless, the Child Abuse Prevention and Treatment Act (CAPTA) reauthorization of 2010 requires states to include provisions for implementing and evaluating differential response despite a lack of evidence regarding the policy's effectiveness in reducing subsequent maltreatment. ${ }^{28}$ In order to effectively combat maltreatment recurrence in the US, an imperative is to understand how this policy may help or hinder current practices.

This study compares the risk of child maltreatment re-report in those receiving either an investigation or differential response using 11 years of data from the National Child Abuse and Neglect Data System (NCANDS). Results will have the potential to augment existing evidence on policy effectiveness in preventing subsequent maltreatment events. 


\subsection{Methods}

\section{Data Source and Population}

The National Child Abuse and Neglect Data System (NCANDS) was established to surveille the magnitude and nature of child maltreatment in the US in accordance with title 1 section 106 of CAPTA. ${ }^{28}$ The NCANDS Child File includes annual reports of maltreatment screened and accepted for either an investigation or differential response. Each record in the Child File contains data at the child, perpetrator and case level. Prior to compiling the Child File, reports submitted voluntarily by states were checked for accuracy and completeness. Each report, child and perpetrator was given a unique identifier, permitting longitudinal tracking. Since 2004, NCANDS data have been collected according to the Federal Fiscal Year, October 1-September $30 .{ }^{29}$

This analysis included records from children 0-17 years living in the four states (Louisiana, Minnesota, Missouri, and Wyoming) with statewide differential response policies that have submitted reports of investigation and differential response to NCANDS each year during the period 2004-2014 (N=1,664,153). Records were excluded if more than one re-report of maltreatment was associated with a unique child ID, the child's $18^{\text {th }}$ birthday occurred between the case report and case closure date, information in the record indicated that a child had encounters with CPS prior to start of the study, or if the record was missing either the report disposition type (e.g. differential response or investigation) or the outcome decision (e.g. substantiated, unsubstantiated). The final study populations included 897,088 records. 


\section{Variables}

The exposure of interest was the type of response received during the index report of child maltreatment, either differential response or investigation. This variable was derived from the NCANDS variable of report disposition. Records with an index response of alternative responsenot a victim were categorized as differential response. Records with an index response of substantiated, indicated, alternative response- victim, unsubstantiated, closed-no finding, and intentionally false were categorized as having received an investigation.

The primary outcome of interest was child maltreatment re-report; unique child ID was used to count this outcome longitudinally. The NCANDS prior victim variable was used to exclude any unique child IDs that may have appeared in the NCANDS data before the study start date of October 1, 2004.

Each race (American Indian or Alaska Native, Asian, Black or African American, Hawaiian or Other Pacific Islander, White or other) and ethnicity (Hispanic, non-Hispanic) was documented as separate variables in NCANDS. These variables were combined to create a single race and race/ethnicity variable. Sex was recorded as the gender of the child as identified at the time of report. The NCANDS variable of child age was used to determine the age of the child at the index report of maltreatment. Age categories $(<5,5-11,12-17)$ were created to assess differences in the incidence of our outcome according to census recommendations for children under 18 years. ${ }^{30}$ Date of birth was used to determine the child's $18^{\text {th }}$ birthday for censoring.

Maltreatment was categorized into three primary groups: physical abuse, sexual abuse, and neglect (deprivation of necessities and medical needs). A fourth group of 'other abuse' was 
created to capture any additional form of abuse documented in NCANDS, including emotional and psychological maltreatment.

\section{Statistical Analysis}

NCANDS datasets 2004-2014 from Louisiana, Minnesota, Missouri and Wyoming were combined and checked for errors in coding and level and degree of missingness. Descriptive statistics for case-level, socioeconomic and demographic and behavioral characteristics of maltreatment were expressed using univariate analyses. Statistical differences between descriptive statistics were analyzed using either t-tests or chi-square tests, as appropriate, and the level of statistical significance was set at alpha $\leq 0.05$.

A Directed Acyclic Graph (DAG) was developed as the statistical model for this analysis (Chapter 1, Figure 3). Directed Acyclic Graphing is a method for reducing bias in statistical analysis by creating a visual representation of the relationships between an exposure and outcome from existing literature. This diagram is then used to identify mediators, confounders and colliders. ${ }^{31-35}$ Bivariate analyses were used evaluate statistical relationships identified and excluded from the DAG. Child sex, child age, child race, perpetrator sex, abuse type, and report source were identified as potential confounding variables.

The Cox proportional hazards model was used to calculate and compare the unadjusted and adjusted hazard ratios of child maltreatment re-report in those who received either a differential response or a traditional investigation during the index report of child maltreatment. Survival curves did not overlap as a function of time, signifying that the assumption of proportional odds was not violated (Figure 1). 
The disposition date from the first child maltreatment report, for each unique child ID, was used as the index date. Selection of the study end date for each unique child ID is described in Figure 2. The duration of time contributed by each child to the model was calculated in months by subtracting end date from index date. Covariates in the model were selected based on the DAG as previously described. All analyses were conducted using SAS software, version 9.4, Cary, N.C. ${ }^{36}$

\subsection{Results}

Demographic characteristics of the study population are presented in Table 1. This analysis included 879,088 children 0-17 years, living in Louisiana (29.1\%), Minnesota (20.4\%), Missouri (46.7\%) and Wyoming (3.8\%) during the period 2004-2014 from the National Child Abuse and Neglect Data System (NCANDS). Fifty-seven percent of the study population were nonHispanic white, and sex was evenly distributed. The median age of the study population was 6.00 years, with reports of maltreatment received being most common for children ages 5-11 years $(38.4 \%)$.

Neglect (34.2\%) was the second most common form of maltreatment. The maltreatment category of 'other abuse' was recorded in nearly half of the reports (47.7\%). Those with 'other abuse' were nearly four times as likely to be assigned to differential response than any other abuse type (OR: 3.78, 95\%CI: 3.75, 3.82), and more likely to experience re-report (OR: 1.21, 95\%CI: 1.19, 1.22). These associations remained after controlling for demographic and case characteristics, and further by state (Table 2). Sexual abuse was reported in four percent of total reports; investigation was assigned in $93 \%$ of these cases. 
Forty-five percent of cases were assigned to differential response. Louisiana utilized the policy the least (15\%), while Wyoming assigned three quarters of reports to this response. Minnesota and Missouri utilized differential response more often than investigation; 60\% and 55\%, respectively. Reports receiving differential response were more likely to involve children ages 5-17 years, males, and Hispanic-whites. The latter two groups were also more likely to experience re-report. Hispanic-whites were twice as likely as non-Hispanic-whites to receive a differential response in fully adjusted models; blacks were less likely than non-Hispanic whites to receive a differential response, regardless of black ethnicity.

Maltreatment reported by education professionals was more likely to receive a differential response than reports by social services, whereas reports by law enforcement and medical professionals were more likely to receive an investigation. When abuse type was added to the model, the association with law enforcement changed direction. Families with reports of maltreatment by social services were more likely to experience re-report than reports from any other reporting group (e.g. law enforcement, medical/health professional, parent or other relative), in unadjusted and adjusted models.

Re-report of maltreatment occurred in $38 \%$ of the study population during the 11-year observation period (Table 3). Males, Hispanic-whites, reports by law enforcement and educational professionals, and abuse in the residual or 'other' category were more likely to experience re-report. Results from a survival analysis, presented in Table 4, show that the risk of re-report was $14 \%$ greater in those who received a differential response (OR: 1.14, 95\% CI:1.12, 1.15). Results remained unchanged after controlling for demographic characteristics (child age, race/ethnicity and sex). Controlling for baseline report source and abuse type eliminated the association between abuse type and response. 
Trends in national data have consistently identified neglect as the most common form of maltreatment, followed by physical and then sexual abuse. ${ }^{37}$ However, our data included a disproportionate number of reports with the abuse type listed as 'other'. Analysis by state revealed that Missouri assigned $92 \%$ of baseline abuse as 'other', which biased our population. Further investigation showed that $100 \%$ of differential response cases and $82 \%$ of investigations in Missouri were classified in this manner. In sensitivity analysis, presented in Table 5, we excluded Missouri and found that risk of re-report decreased in those receiving differential response, in both unadjusted and fully adjusted models (0.92, 95\% CI: 0.91-0.93).

\subsection{Discussion}

We used longitudinal analysis to differentiate the risk of child maltreatment re-report according to CPS response over an 11-year observation period. Few studies have calculated the risk of rereport by CPS response, and those identified reported that the risk of re-report in those receiving differential response was less than or equal to those who were previously investigated. ${ }^{10,13,21-}$ ${ }^{23,38,39}$ However, these studies were unable to assess long term risk because follow up periods usually only ranged from six months to one-year. One study we identified did employ a follow up period of 18 -months. ${ }^{13}$

A recent research brief by Fluke and colleagues found that rate of re-report was lower in those receiving differential response. ${ }^{26}$ This report used county level aggregate data to evaluate differential response in states with a statewide policy from 2004-2013 using data from NCANDS. This report differed from ours in two key areas. First, the policy brief did not differentiate between written policy and policy use. For example, three of the six states included in the analysis did not provide data to NCANDS for a portion of the study period. Secondly, not 
all states with a statewide policy reporting to NCANDS for both differential response and investigation were included in the analysis.

We found that the risk of maltreatment re-report increased in those who received a differential response. This finding remained after controlling for demographic characteristics (age, sex, race/ethnicity), suggesting they are not confounders. We did not observe any difference in the odds of re-report based on child sex.

Our data contained a disproportionate number of cases with abuse classified as 'other', most of which were derived from Missouri. It is unlikely that the distribution of maltreatment in Missouri departs so sharply from the remaining United States, and explanations for the observed dissimilarity should be carefully explored, since they markedly impact our understanding of the relationship between CPS assignment and re-report. This is especially important because Missouri has been recognized as the flagship state in terms of understanding differential response.

The proportion of cases referred to differential response vary by state. A recent systematic review by the authors of this paper found that most states with statewide differential response policy assigned this response in $<40 \%$ of reports. ${ }^{11}$ The assignment of differential response to $45 \%$ of our cases was higher than reported in other studies. ${ }^{10,21,24,39}$ This variation is likely a result of two distinctions in our data. First, the majority of records were derived from Missouri (47\%), which has utilized differential response at the state level since 1994. More cases may have been assigned to differential response in this state because the program protocols and training of personnel have long been established. However, Wyoming, which represented only $3 \%$ of our sample, sent three-quarters of its reports to differential response. The policy has been utilized at varying levels in this state over time, and was officially passed at the state level in 
2005. Secondly, almost half of maltreatment cases were recorded with an abuse type of 'other'. Our results showed that differential response assignment was more likely when type of maltreatment at baseline deviated from the three primary groups of neglect, physical and sexual abuse. Differential response is likely assigned to these reports because this form of abuse is poorly understood, and considered less serious or non-life threatening. In these cases, the services provided may be inappropriate, and therefore unsustainable for future abuse prevention. Psychological and emotional maltreatment have been studied far less than the previously mentioned types of abuse. Most studies have focused on assessing the relationship between neglect, physical and sexual abuse, and health outcomes without addressing cases where abuse type may be unclear or challenging to classify.

Differential response is not intended for serious (physical, sexual) abuse. Our results showing 93\% of sexual abuse cases assigned to investigation is consistent with the policy intention and distribution of response assignments reported in the existent literature. A study by Shusterman and colleagues was the only investigation we identified that showed a significant number of sexual and physical abuse cases receiving differential response. ${ }^{10}$

It has been suggested that the frequency and severity of maltreatment decreases with child age. ${ }^{37}$ However, our study found that the greatest frequency of maltreatment occurred among children ages 5-12 years. In two previous studies, Theodore and colleagues found differences in the types of maltreatment according to child sex and age. ${ }^{40,41}$ Abuse was variable although the distribution of sex was relatively equal in the states included in this analysis. For example, Missouri documented the form of maltreatment in $92 \%$ of cases during our observation period as 'other', whereas the remaining states documented most cases as neglect. The deviation in our results from national trends is again likely attributed to the high proportion of unknown maltreatment 
forms in our data. Despite this deviation, we found that children under age five years were still more likely to receive an investigative response.

In 2015, a racial equity analysis by Jones found that children of Hispanic ethnicity were more likely than other race/ethnic groups to receive differential response. ${ }^{42}$ Our results only identified this relationship in Hispanic-whites; plausibly an artifact of the small proportion of Hispanicblacks in our study population $(0.3 \%)$.

Reporting requirements for maltreatment vary greatly by state, and in many studies the type of reporter has been associated with response type. ${ }^{43,44}$ Specifically, reports by law enforcement and medical/health professionals generally receive an investigation, and are less likely to experience re-report. We observed these same results in our unadjusted model. However, after adjusting for race/ethnicity, sex and baseline abuse-type, our results suggested that differential response was most likely assigned when maltreatment was reported by these two groups. Baseline maltreatment appears to be driving this relationship, and should be explored as a potential mediator.

The objective of differential response is to provide families with a CPS response that is tailored towards their specific needs through service provision. This approach is a source of concern given the evidence that services are positively associated with maltreatment re-report and recurrence. ${ }^{45,46}$ We suggest this finding is partially due to these individuals being easily identified because they are actively engaged with social services for other vulnerabilities related to poverty (e.g. insufficient housing, job placement services). ${ }^{47}$ Our results, which support these prior findings, have monetary implications, since the cost to deliver an investigation versus a differential response is higher. 
Fang and colleagues have estimated the cost of each nonfatal case of child maltreatment to be $\$ 210,012 .^{48}$ This estimate was based on a median child age of six years at baseline report, and included productivity loss, child welfare and legal costs, and healthcare costs during both childhood and adulthood. However, because of limitations in the available data at the time of analysis, this estimate excludes important factors shown to alter costs, such as differences in response, and type and severity of abuse. The exclusion of psychological maltreatment from the cost estimate is of particular relevance to our study because this class of abuse is included in the 'other' category that dominated our cases. In addition to financial costs, overwhelming evidence exists that demonstrates both acute and long term negative health and social outcomes resulting from exposure to adverse childhood events. ${ }^{49,50}$ These adverse outcomes include the development of diminished academic performance, social maladjustment, chronic and infectious disease development, and suicidality. ${ }^{51-55}$

\section{Strengths and Limitations}

This study has several strengths. For example, our analysis used a large, nationally representative dataset to prospectively evaluate the relationship between CPS response and risk of child maltreatment re-report. NCANDS includes records of all reports of maltreatment in the US that received either an investigation or differential response. Previous research, using NCANDS data, has been widely disseminated, facilitating comparison. ${ }^{10,38}$ In addition, we also included states with statewide differential response policies, limiting some of the variation that emerges from analyses including states with county or regional implementation. These variations are related to the number of response paths, programs offered, and level of training required for those delivering the intervention. Previous studies have not discriminated between policy level implementation. 
Our study has potential limitations. First, several child, perpetrator, case-level and behavioral characteristics within the NCANDS, such as exposure to child disability, intimate partner violence (IPV), family poverty, caregiver drug and alcohol abuse, and use of public assistance services, contained a large number of missing values (>75\%). Many of these characteristics have been identified as risk factors for child maltreatment re-report. The large number of missing values for these variables prevented imputation. However, we treated these missing variables analytically. Secondly, although NCANDS allows for multiple forms of maltreatment to be documented, we were unable take into account co-occurring forms of maltreatment due to gaps in reporting.

Thirdly, methods used to classify reports of maltreatment, involving more than one child, may have biased our results. Such cases within NCANDS reports, were assigned the same response outcome. This classification method precluded us from precisely defining our exposure of interest. However, unique cases represent the majority of NCANDS records.

\subsection{Conclusion}

The results from this study suggest that the family-centered practice approach of differential response may be ineffective in reducing the long term risk for subsequent maltreatment reports. However, sensitivity analysis showed that the type of abuse recorded at baseline impacts our understanding of this relationship. Lack of a standardized maltreatment classification tool may have resulted in a large number of unspecified abuse cases in our data. Universal screening instruments should be developed to minimize the current deficiencies in maltreatment classifications. 
Our finding that reporter and abuse type weaken relationships between response and re-report should also be examined, in order to determine potential mediating or moderating effects of these exposures. 


\section{References}

1. Myers JE. The APSAC Handbook on Child Maltreatment. 3rd ed. Los Angeles, CA: Sage; 2011.

2. Myers JE. A Short History of Child Protection in America. Family Law Quarterly. 2008;42(3):449-463.

3. Merkel-Holguín LA, Kaplan C, Kwak A, Association AH. National study on differential response in child welfare. Washington, DC: American Humane Association and Child Welfare League of America; 2006.

4. Child Welfare Information Gateway. Differential Response to Reports of Child Abuse and Neglect. Washington, DC: U.S. Department of Health and Human Services; 2008.

5. Child Welfare Information Gateway. Differential Response to Reports of Child Abuse and Neglect. Washington, DC: U.S. Department of Health and Human Services; 2014.

6. U.S. Department of Health and Human Services, Administration for Children and Families, Administration on Children, Youth and Families. Child Maltreatment 2015. 2017: http://www.acf.hhs.gov/programs/cb/research-data-technology/statisticsresearch/child-maltreatment.

7. The Kempe Center for the Prevention and Treatment of Child Abuse and Neglect. Differential Response Impementation. 2014; http://www.ucdenver.edu/academics/colleges/medicalschool/departments/pediatrics/subs/ can/QIC-DR/Documents/DR\%20Map\%20as\%20of\%20Sept\%202\%202014.pdf. Accessed September 20, 2015.

8. Loman LA, Siegel GL. Alternative response in Minnesota: Findings of the program evaluation. Protecting Children. 2005;20(1\&2):78-92.

9. Hughes RC, Rycus JS, Saunders-Adams SM, Hughes LK, Hughes KN. Issues in differential response. Research on Social Work Practice. 2013;23(5):493-520.

10. Shusterman GR, McDonald WR. Alternative Responses to Child Maltreatment: Findings from NCANDS. Washington, DC: US Department of Health and Human Services; 2005.

11. Hunter A, Lewis, Kelsey, Kelley, George, Tabone, Jiyoung, Davidov, Danielle, Long, Dustin, Rockett, Ian,. Differential response policy and child maltreatment recurrence: a systematic review with meta- analysis, if appropriate. 2015(CRD42015025388). http://www.crd.york.ac.uk/PROSPERO/display_record.asp?ID=CRD42015025388.

12. Thomas K, Moore K, Fluke J. Family Engagement: Defining, Measuring, and Modeling the Complexities. Washington, DC: National Conference on Child Abuse and Neglect; 2016. 
13. English DJ, Wingard T, Marshall D, Orme M, Orme A. Alternative responses to child protective services: Emerging issues and concerns. Child Abuse \& Neglect.

2000;24(3):375-388.

14. Douglas EM, Mohn BM, Gushwa MK. The Presence of Maltreatment Fatality-Related Content in Pre-service Child Welfare Training Curricula: A Brief Report of 20 States. Child and Adolescent Social Work Journal. 2015;32(3):213-218.

15. Dorsey S, Mustillo SA, Farmer EM, Elbogen E. Caseworker assessments of risk for recurrent maltreatment: Association with case-specific risk factors and re-reports. Child Abuse \& Neglect. 2008;32(3):377-391.

16. Ross AH, Juarez CA. A brief history of fatal child maltreatment and neglect. Forensic Science, Medicine, and Pathology. 2014;10(3):413-422.

17. Schwartz KA, Preer G, McKeag H, Newton AW. Child maltreatment: a review of key literature in 2013. Current Opinion in Pediatrics. 2014;26(3):396-404.

18. Ortega HW, Vander Velden H, Kreykes NS, Reid S. Childhood death attributable to trauma: is there a difference between accidental and abusive fatal injuries? The Journal of Emergency Medicine. 2013;45(3):332-337.

19. Fluke J, Shusterman GR, Hollinshead D, Yuan Y. Rereporting and Recurrence of Child Maltreatment: Findings from NCANDS. Washington, DC: U.S. Department of Health and Human Services; 2005.

20. Conley A, Berrick JD. Implementation of differential response in ethnically diverse neighborhoods. Protecting Children. 2008;23(1\&2):30-38.

21. Conley A, Berrick JD. Community-based child abuse prevention: Outcomes associated with a differential response program in California. Child Maltreatment. 2010;15(4):282292.

22. Lawrence CN, Rosanbalm KD, Dodge KA. Multiple response system: Evaluation of policy change in North Carolina's child welfare system. Children and youth services review. 2011;33(11):2355-2365.

23. Loman LA, Siegel GL. Effects of anti-poverty services under the differential response approach to child welfare. Children and Youth Services Review. 2012;34(9):1659-1666.

24. Marshall SK, Charles G, Kendrick K, Pakalniskiene V. Comparing differential responses within child protective services: A longitudinal examination. Child Welfare. 2010;89(3):57.

25. Fluke J, Harlaar, N., Heisler, K., Darnell, A., Brown, B., Merkel-Holguin, L. ASPE Research Brief: Differential Response and the Safety of Children Reported to Child Protective Services: A Tale of Six States. Denver, CO: U.S. Department of Health and Human Services; 2016. 
26. Fluke J, Harlaar N, Heisler K, Darnell A, Brown B, Merkel-Holguin L. ASPE Research Brief: Differential Response and the Safety of Children Reported to Child Protective Services: A Tale of Six States. Denver, CO: U.S. Department of Health and Human Services; 2016.

27. Campbell KA, Thomas AM, Cook LJ, Keenan HT. Longitudinal experiences of children remaining at home after a first-time investigation for suspected maltreatment. The Journal of Pediatrics. 2012;161(2):340-347.

28. United States. Child Abuse Prevention and Treatment Act as amended by PL 111-320, the CAPTA reauthorization act of 2010. Washington, DC: United States Government Publishing Office; 2010.

29. Administration for Children, Youth and Families. Child Maltreatment 2004. Washington, DC: U.S. Department of Health and Human Services, Children's Bureau; 2004.

30. Klein RJ, Schoenborn CA. Age adjustment using the 2000 projected U.S. population. Hyatsville, MD: Department of Health and Human Services, Centers for Disease Control and Prevention, National Center for Health Statistics 2001.

31. Hernán MA, Hernández-Díaz S, Werler MM, Mitchell AA. Causal knowledge as a prerequisite for confounding evaluation: an application to birth defects epidemiology. American Journal of Epidemiology. 2002;155(2):176-184.

32. Shrier I, Platt RW. Reducing bias through directed acyclic graphs. BMC Medical Research Methodology. 2008;8(1):70.

33. Textor J, Hardt J, Knuppe S. DAGitty: A Graphical Tool for Analyzing Causal Diagrams. Epidemiology 2011;5(22):745.

34. Tu Y-K, Greenwood DC. Modern methods for epidemiology. Dordrecht: Springer; 2012.

35. VanderWeele TJ, Shpitser I. A new criterion for confounder selection. Biometrics. 2011;67(4):1406-1413.

36. SAS [computer program]. Version 9.4. Cary, NC ,: SAS Institute Inc.; 2016.

37. Child Maltreatment 2014. Services USDoHaH, trans. Administration for Children and Families, Administration on Children, Youth and Families, Children's Bureau 2016.

38. Ortiz MJ, Shusterman GR, Fluke JD. Outcomes for children with allegations of neglect who receive alternative response and traditional investigations: Findings from NCANDS. Protecting Children. 2008;23(1\&2):57-70.

39. Ortiz MJ, Shusterman GR, Fluke JD. Outcomes for children with allegations of neglect who receive alternative response and traditional investigations: Findings from NCANDS. Exploring Differential. 2008. 
40. Theodore A, Runyan D, Chang JJ. Measuring the risk of physical neglect in a populationbased sample. Child Maltreatment. 2007;12(1):96-105.

41. Theodore AD, Chang JJ, Runyan DK, Hunter WM, Bangdiwala SI, Agans R. Epidemiologic features of the physical and sexual maltreatment of children in the Carolinas. Pediatrics. 2005;115(3):e331-e337.

42. Jones AS. Implementation of differential response: A racial equity analysis. Child Abuse \& Neglect. 2015;39(3):73-85.

43. Child Welfare Information Gateway. Mandatory reports of child abuse and neglect. Washington, DC: U.S. Department of Health and Human Services, Children's Bureau; 2016.

44. Palusci VJ, Vandervort FE, Lewis JM. Does changing mandated reporting laws improve child maltreatment reporting in large US counties? Children and Youth Services Review. 2016;66:170-179.

45. Fuller T, Nieto M. Child welfare services and risk of child maltreatment rereports: Do services ameliorate initial risk? Children and youth services review. 2014;47:46-54.

46. Casanueva C, Tueller S, Dolan M, Testa M, Smith K, Day O. Examining predictors of rereports and recurrence of child maltreatment using two national data sources. Children and Youth Services Review. 2015;48:1-13.

47. Jonson-Reid M, Drake B, Kohl PL. Is the overrepresentation of the poor in child welfare caseloads due to bias or need? Children and Youth Services Review. 2009;31(3):422-427.

48. Fang X, Brown DS, Florence CS, Mercy JA. The economic burden of child maltreatment in the United States and implications for prevention. Child Abuse \& Neglect. 2012;36(2):156-165.

49. Felitti VJ, Anda RF, Nordenberg D, et al. Relationship of childhood abuse and household dysfunction to many of the leading causes of death in adults: The Adverse Childhood Experiences (ACE) Study. American Journal of Preventive Medicine. 1998;14(4):245258.

50. Chartier M, Walker J, Naimark B. Childhood abuse, adult health, and health care utilization: results from a representative community sample. American Journal of Epidemiology. 2007;165(9):1031-1038.

51. Coohey C, Renner LM, Hua L, Zhang YJ, Whitney SD. Academic achievement despite child maltreatment: A longitudinal study. Child Abuse \& Neglect. 2011;35(9):688-699.

52. Slade EP, Wissow LS. The influence of childhood maltreatment on adolescents' academic performance. Economics of Education Review. 2007;26(5):604-614. 
53. Hoertel N, Franco S, Wall MM, et al. Childhood maltreatment and risk of suicide attempt: a nationally representative study. The Journal of Clinical Psychiatry. 2015;76(7):1,478-923.

54. Lanier P, Jonson-Reid M, Stahlschmidt MJ, Drake B, Constantino J. Child maltreatment and pediatric health outcomes: A longitudinal study of low-income children. Journal of Pediatric Psychology. 2009;35(5):511-522.

55. Norman RE, Byambaa M, De R, Butchart A, Scott J, Vos T. The long-term health consequences of child physical abuse, emotional abuse, and neglect: a systematic review and meta-analysis. PLOS Medicine. 2012;9(11). 
Tables and Figures 
Figure 1. Survival Curves for CPS Response.

Survivor Function Estimate

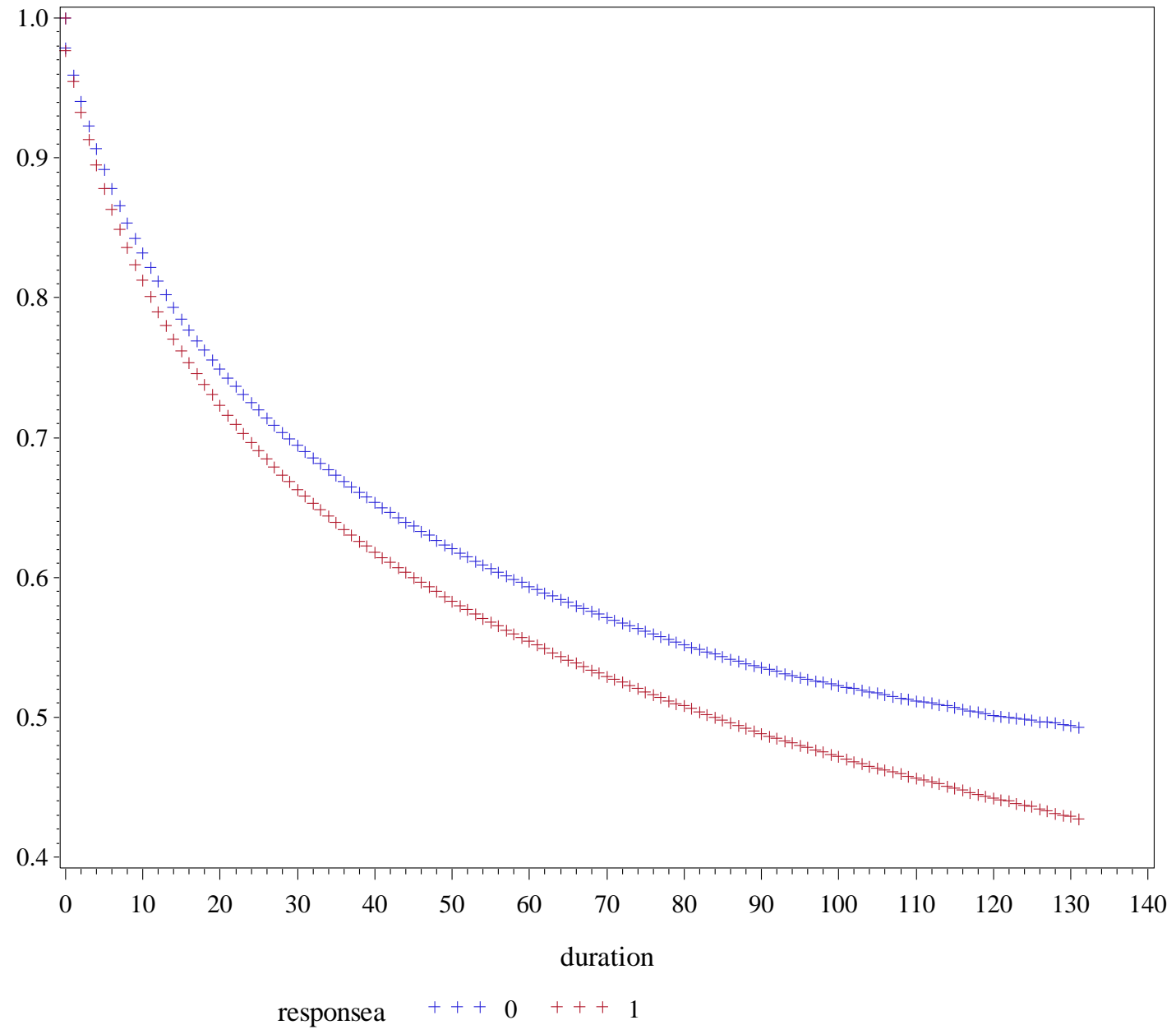


Figure 2: Study end date scheme.

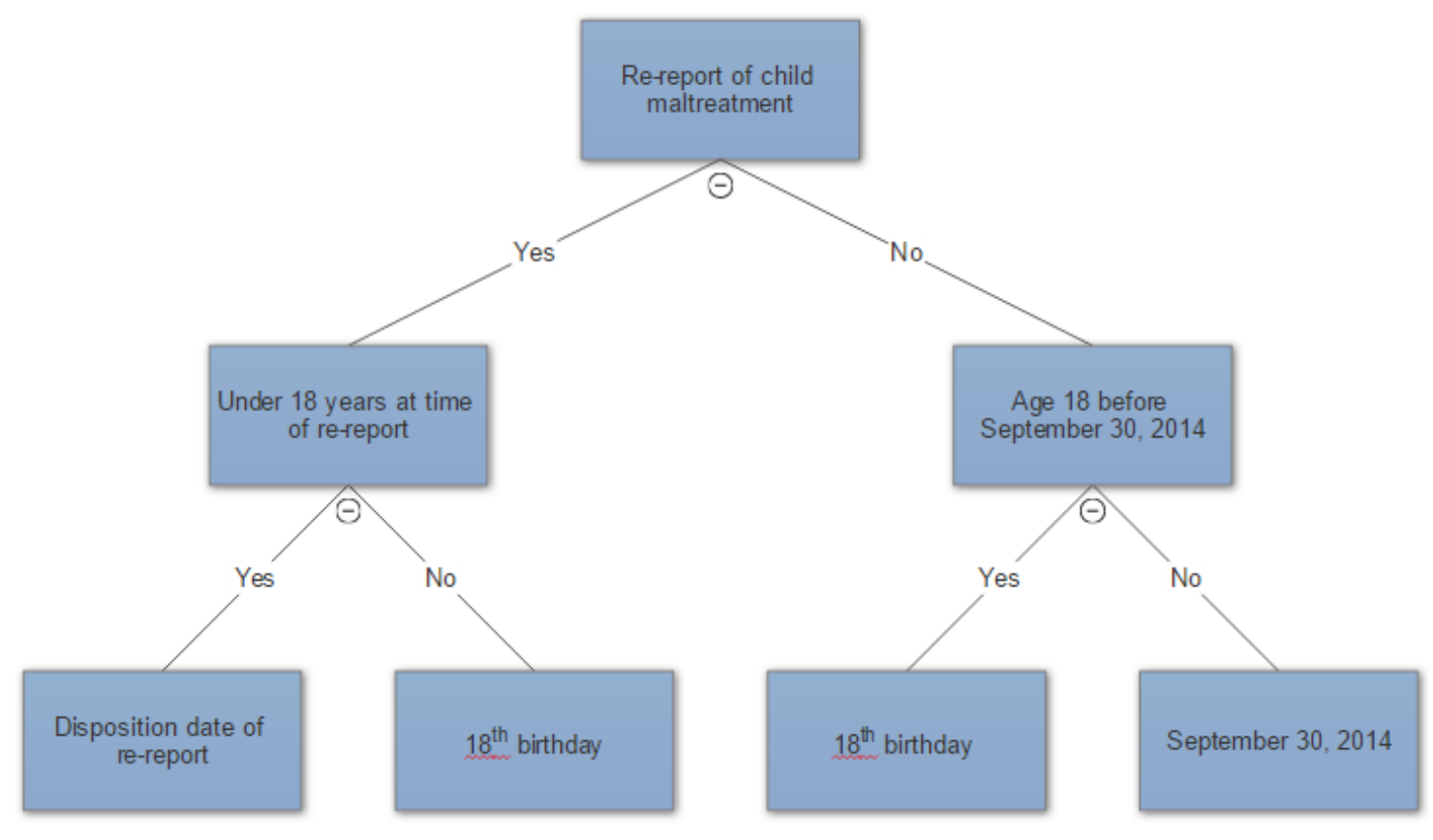


Table 1: Demographic Characteristics

\begin{tabular}{|c|c|c|c|c|}
\hline \multicolumn{5}{|c|}{$\begin{array}{l}\text { Demographic Characteristics of NCANDS Child File (N=897,088), 2004-2014 (LA, MN, MO, WY), } \\
\text { Children 0-17 years }\end{array}$} \\
\hline & Total & $\begin{array}{l}\text { Differential } \\
\text { Response }\end{array}$ & Investigation & \\
\hline & $\mathbf{N}(\%)$ & $\mathrm{N}(\%)$ & $\mathbf{N}(\%)$ & \\
\hline & 879,088 & $404,485(45.1)$ & $492,603(54.9)$ & \\
\hline \multicolumn{5}{|l|}{ Characteristic } \\
\hline \multicolumn{5}{|l|}{ Sex } \\
\hline Male & $446,937(49.82)$ & $207,585(51.32)$ & $239,352(48.6)$ & \\
\hline Female & $447,445(49.9)$ & $196,720(48.63)$ & $250,725(50.9)$ & \\
\hline Missing & $2,706(0.3)$ & $180(0.04)$ & $2,526(0.5)$ & $\mathrm{p}<0.0001$ \\
\hline \multicolumn{5}{|l|}{ Age Group } \\
\hline$<5$ years & $311,024(34.6)$ & $126,363(31.2)$ & $184,661(37.5)$ & \\
\hline 5-11 years & $344,991(38.4)$ & $165,197(40.8)$ & $179,794(35.5)$ & \\
\hline 12-17 years & $241,073(27.0)$ & $112,925(27.9)$ & $128,148(26.0)$ & $\mathrm{p}<0.0001$ \\
\hline \multicolumn{5}{|l|}{ Race/Ethnicity } \\
\hline Non-Hispanic White & $510,280(56.9)$ & $252,898(62.5)$ & $257,382(52.2)$ & \\
\hline Non-Hispanic Black & $226,712(25.3)$ & $79,636(19.7)$ & $147,076(29.9)$ & \\
\hline White-Hispanic & $33,411(3.7)$ & $18,699(4.6)$ & $14,712(3.0)$ & \\
\hline Black-Hispanic & $2,342(0.3)$ & $924(0.2)$ & $1,418(0.3)$ & \\
\hline Other & $55,074(6.1)$ & $16,394(4.1)$ & $38,680(7.8)$ & \\
\hline Missing & $69,269(7.7)$ & $35,934(8.9)$ & $33,335(6.8)$ & $\mathrm{p}<0.0001$ \\
\hline \multicolumn{5}{|c|}{ Type of Abuse at Baseline } \\
\hline Physical & $124,802(13.9)$ & $38,306(9.5)$ & $86,496(17.6)$ & \\
\hline Neglect & $306,866(34.2)$ & $94,691(23.4)$ & $212,175(43.1)$ & \\
\hline Sexual & $36,859(4.1)$ & $2,579(0.64)$ & $34,280(7.0)$ & \\
\hline Other & $428,190(47.7)$ & $268,909(66.5)$ & $159,281(32.3)$ & \\
\hline Missing & 371 & 0 & 371 & $\mathrm{p}<0.0001$ \\
\hline \multicolumn{5}{|l|}{ State } \\
\hline Louisiana & $261,017(29.1)$ & $37,966(9.4)$ & $223,051(45.3)$ & \\
\hline Minnesota & $182,986(20.4)$ & $110,577(27.3)$ & $72,409(14.7)$ & \\
\hline Missouri & $418,871(46.7)$ & $230,267(56.9)$ & $188,604(38.3)$ & \\
\hline Wyoming & $265,214 \quad(3.2)$ & $256,675(6.4)$ & $8,539(1.7)$ & $\mathrm{p}<0.0001$ \\
\hline \multicolumn{5}{|c|}{ Reporter Source at Baseline } \\
\hline Social Services & $91,966(10.3)$ & $38,007(9.4)$ & $53,959(11.0)$ & \\
\hline
\end{tabular}




\begin{tabular}{|l|r|r|r|r|}
\hline Medical/Health Professional & $111,548(12.4)$ & $39,932(9.9)$ & $71,616(14.5)$ & \\
\hline Law/Legal Enforcement & $156,958(17.5)$ & $63,653(15.7)$ & $93,305(18.9)$ & \\
\hline Educational & $146,396(16.3)$ & $76,161(18.8)$ & $70,235(14.3)$ & \\
\hline Parent/other relative & $127,975(14.3)$ & $52,389(13.0)$ & $75,586(15.3)$ & \\
\hline Other & $107,787(12.0)$ & $44,657(11.0)$ & $63,131(12.8)$ & \\
\hline Missing & $154,458(17.2)$ & $89,687(22.2)$ & $64,771(13.2)$ & $\mathrm{p}<0.0001$ \\
\hline & & & & \\
\hline Re-report of Maltreatment & & & & \\
\hline Yes & $338,353(37.7)$ & $157,498(38.9)$ & $180,855(36.7)$ & \\
\hline No & $558,735(62.3)$ & $246,987(61.1)$ & $311,748(63.3)$ & $\mathrm{p}<0.0001$ \\
\hline
\end{tabular}


Table 2 : Association of CPS Response with Demographic and Case Characteristics

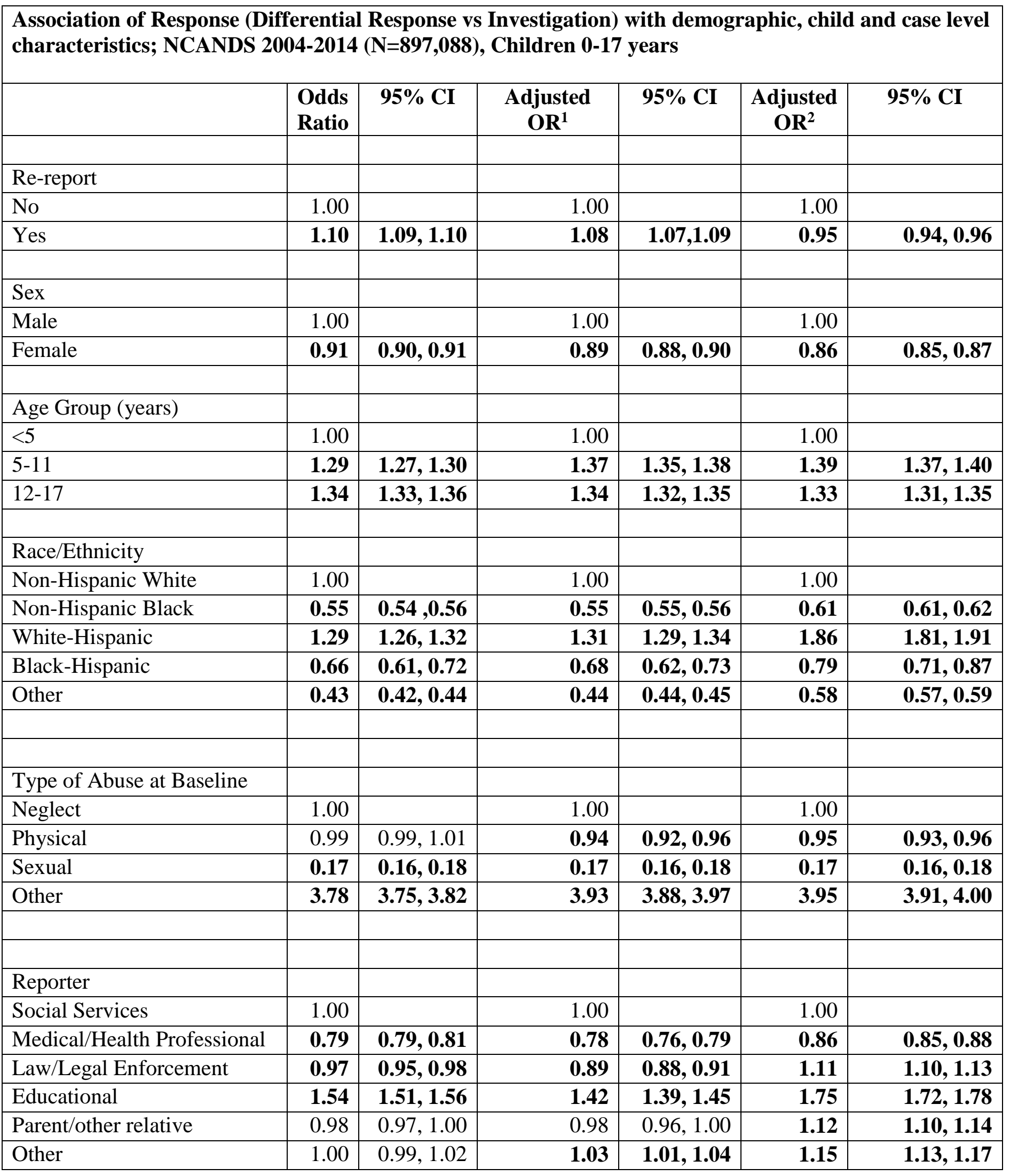




\begin{tabular}{|l|l|l|l|l|l|}
\hline & & & & & \\
\hline & & & & \\
\hline model $^{1}$ adjusts for age, sex, race/ethnicity & & & & \\
\hline model $^{2}$ adjusts for variables in model & & & \\
\hline \multicolumn{2}{|l|}{ plus abuse type and report source } & & \\
\hline & $* *$ analysis includes data from LA, MN, MO, \\
WY & & \\
\hline
\end{tabular}


Table 3: Association of Re-report with Demographic and Case Characteristics

\begin{tabular}{|c|c|c|c|c|c|c|}
\hline \multicolumn{7}{|c|}{$\begin{array}{l}\text { Association of Re-report with demographic, child and case level characteristics; NCANDS 2004-2014 } \\
(\mathrm{N}=897,088) \text {, Children 0-17 years (LA, MN, MO, WY) }\end{array}$} \\
\hline & \begin{tabular}{|l|} 
Odds \\
Ratio
\end{tabular} & $95 \% \mathrm{CI}$ & $\begin{array}{c}\text { Adjusted } \\
\text { OR }^{1}\end{array}$ & $95 \% \mathrm{CI}$ & $\begin{array}{c}\text { Adjusted } \\
\text { OR }^{2}\end{array}$ & $95 \% \mathrm{CI}$ \\
\hline \multicolumn{7}{|l|}{ Characteristic } \\
\hline & & & & & & \\
\hline \multicolumn{7}{|l|}{ Sex } \\
\hline Male & 1.00 & & 1.00 & & & \\
\hline Female & 1.01 & $1.00,1.01$ & 1.00 & $0.99,1.01$ & 1.00 & $1.00,1.01$ \\
\hline \multicolumn{7}{|l|}{ Age Group (years) } \\
\hline$<5$ & 1.00 & & 1.00 & & 1.00 & \\
\hline $5-11$ & 1.37 & $1.36,1.38$ & 1.35 & $1.34,1.37$ & 1.36 & $1.34,1.37$ \\
\hline $12-17$ & 1.11 & $1.10,1.13$ & 1.11 & $1.01,1.13$ & 1.15 & $1.13,1.16$ \\
\hline \multicolumn{7}{|l|}{ Race/Ethnicity } \\
\hline Non-Hispanic White & 1.00 & & 1.00 & & 1.00 & \\
\hline Non-Hispanic Black & 0.84 & $0.83,0.84$ & 0.84 & $0.83,0.85$ & 0.88 & $0.87,0.89$ \\
\hline White-Hispanic & $\mathbf{0 . 7 0}$ & $0.68,0.71$ & 0.70 & $0.68,0.72$ & 0.74 & $0.72,0.76$ \\
\hline Black-Hispanic & 0.91 & $0.84,0.99$ & 0.92 & $0.84,1.00$ & 0.93 & $0.85,1.02$ \\
\hline Other & $\mathbf{0 . 5 1}$ & $0.50,0.52$ & 0.52 & $0.51,0.53$ & 0.60 & $0.58,0.61$ \\
\hline \multicolumn{7}{|l|}{ Type of Abuse at Baseline } \\
\hline Neglect & 1.00 & & 1.00 & & 1.00 & \\
\hline Physical & 0.82 & $0.81,0.83$ & 0.81 & $0.80,0.83$ & 0.81 & $0.79,0.82$ \\
\hline Sexual & 0.64 & $0.62,0.65$ & 0.62 & $0.60,0.64$ & 0.61 & $0.59,0.63$ \\
\hline Other & 1.21 & $1.19,1.22$ & 1.19 & $1.17,1.20$ & 1.07 & $1.05,1.08$ \\
\hline \multicolumn{7}{|l|}{ Reporter } \\
\hline Social Services & 1.00 & & 1.00 & & 1.00 & \\
\hline Medical/Health Professional & 0.89 & $0.87,0.90$ & 0.90 & $0.89,0.92$ & 0.92 & $0.90,0.93$ \\
\hline Law/Legal Enforcement & $\mathbf{0 . 8 9}$ & $0.87,0.90$ & 0.89 & $0.88,0.90$ & 0.92 & $0.90,0.93$ \\
\hline Educational & 0.91 & $0.89,0.92$ & $\mathbf{0 . 8 8}$ & $0.87,0.90$ & 0.90 & $0.88,0.91$ \\
\hline Parent/other relative & 1.01 & $0.99,1.02$ & 1.00 & $0.98,1.02$ & 1.02 & $1.00,1.03$ \\
\hline Other & 1.04 & $1.02,1.06$ & 1.05 & $1.03,0.07$ & 1.06 & $1.04,1.08$ \\
\hline & & & & & & \\
\hline & & & & & & \\
\hline & & & & & & \\
\hline $\begin{array}{l}\text { model }{ }^{1} \text { adjusts for age, sex, } \\
\text { race/ethnicity }\end{array}$ & & & & & & \\
\hline
\end{tabular}


model $^{2}$ adjusts for variables in model $^{1}$ plus abuse type and report source 


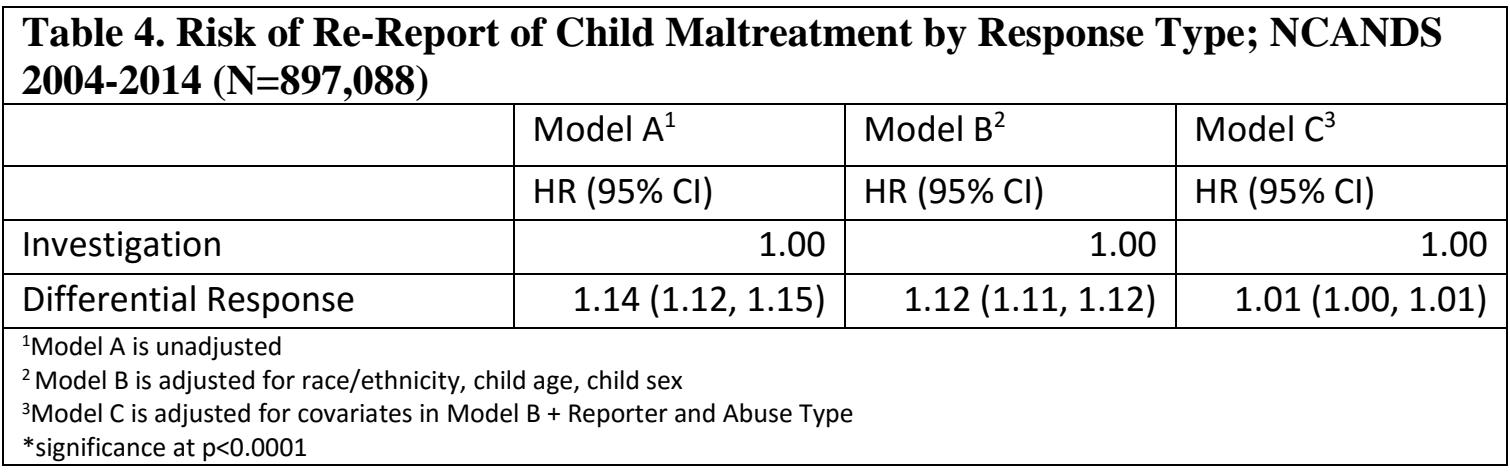




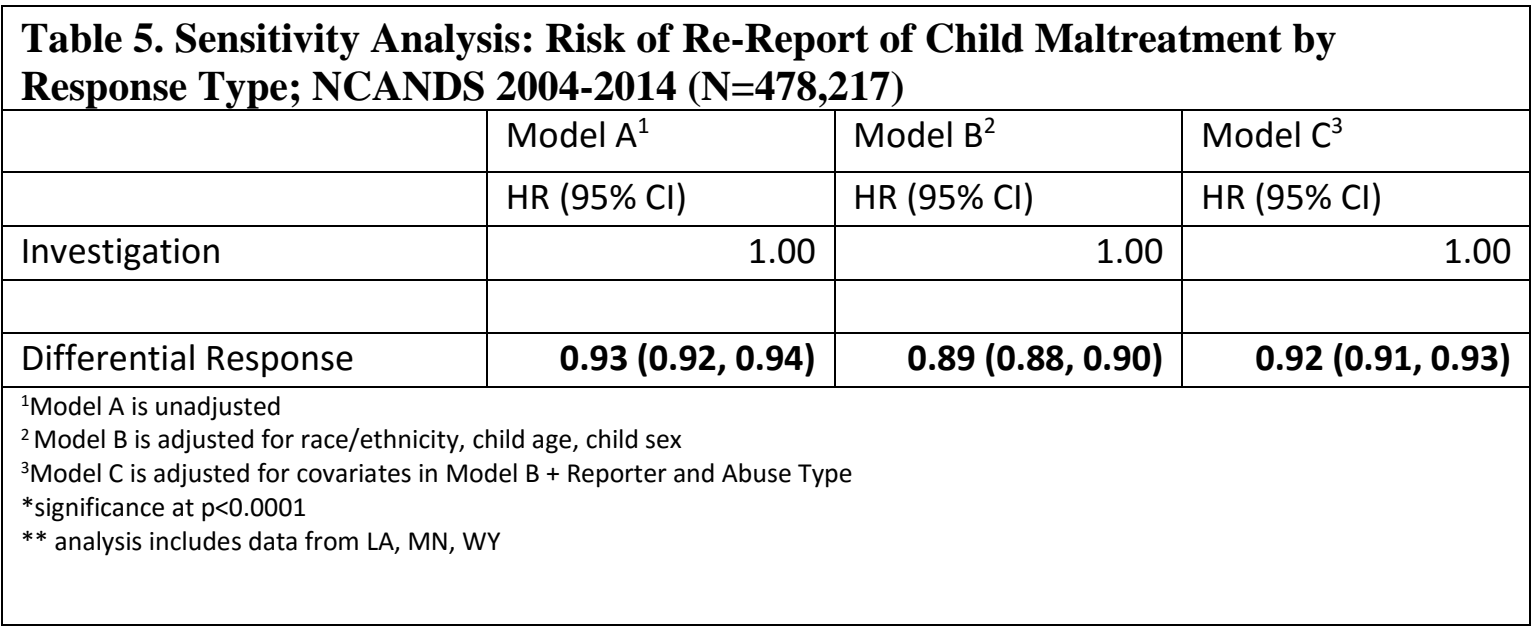


CHAPTER 4. COMPARISON OF CHARACTERISTICS OF CHILD MALTREATMENT RE-REPORT IN PERIODS BEFORE AND AFTER CAPTA 2010 


\subsection{Abstract}

Background: The Child Abuse Prevention and Treatment Act (CAPTA) funds child protection efforts in the United States. In 2010, CAPTA was amended to require states requesting federal funds to have written protocols for implementing and evaluating differential response, a serviced-based prevention policy. This study evaluates the change in risk and characteristics of child maltreatment re-report before and after CAPTA 2010.

Method: This analysis used data on 159,593 children 0-17 years, living in Colorado, Kansas, Massachusetts, and New Hampshire from the National Child Abuse and Neglect Data System (NCANDS). Intervention and control states were selected based on policy implementation and reporting quality. We used a modified Poisson regression to calculate the risk of child maltreatment re-report in the four-year periods immediately before and after CAPTA 2010. Incident Rate Ratios (IRRs) were adjusted for child age, race/ethnicity, and abuse type and report source.

Results: We found that the risk of maltreatment re-report was similar in the pre and post CAPTA periods respectively, IRR: 1.13, 95\% CI: 1.01, 1.17 and IRR: $1.17,95 \%$ CI: $1.13,1.22$. Risk of re-report decreased in children 12-17 years, and increased significantly in Blacks of all ethnicities.

Conclusion: The introduction of differential response policy did not result in a major change in the risk of child maltreatment re-report. However, changes in policy may have magnified existing racial biases in child protection. Competing child welfare policies may have also influenced our results. 


\subsection{Introduction}

Victims of child maltreatment are most often young children living with an abusive biological parent. ${ }^{1}$ In 2015 , only $23 \%$ of child victims were removed from their homes following a report of maltreatment, ${ }^{1}$ indicating that most continue to live with their abusers. Therefore, it is critical to understand the role of Child Protective Services (CPS) response in the prevention of future harm.

Beginning in 1993, state response to reports of maltreatment evolved from a seven-stage investigation, to include differential response. This policy change allows select families, with reports of mild to moderate maltreatment, to receive services in place of an investigation. It is unknown if this policy provision has improved child welfare outcomes.

In the United States (US), CPS programs are funded and directed by the Child Abuse Protection and Treatment Act (CAPTA). ${ }^{2}$ When CAPTA was reauthorized in 2010 (P.L. 113-320), implementation and evaluation of differential response were added as required data items, meaning states must have these written provisions in place to request federal funds. ${ }^{3} \mathrm{~A}$ review of the literature did not reveal any existing studies that quantitatively analyzed changes in maltreatment recurrence after implementation of differential response policy. ${ }^{4-11}$

National reports characterizing the distribution of risk factors and outcomes for child maltreatment do not distinguish between children who received a differential response and those who received an investigation. ${ }^{1}$ Yet this distinction is important because differential response changes how CPS addresses reports of child maltreatment. Specifically, the introduction of this policy provides service-based intervention in place of investigation for cases of perceived low or moderate maltreatment. ${ }^{12,13}$ A recent systematic review identified studies in which differential response was assigned to reports of serious physical and sexual abuse. ${ }^{14,15}$ Nevertheless, this policy change in service provision has the potential to alter the distribution of risk factors with 
known associations with initial and recurrent reports of abuse. Decreases in morbidity and mortality have been observed after the adoption of injury related policies (e.g., ignition interlock, graduated drivers license, protective orders for victims of intimate partner violence, prescription drug monitoring programs $)^{16}$, and it is probable that this decrease would be observed in the area of child maltreatment.

In $2015,75 \%$ of child maltreatment reports in the United States (US) involved neglect, ${ }^{1}$ defined as acts of omission resulting in harm or the potential harm of a child. ${ }^{17}$ Prior studies examining the relationship between abuse type and CPS response have found that families reported for neglect were assigned to differential response more often than to an investigation. ${ }^{15,18}$ This is likely because many services offered through differential response focus on addressing needs associated with risk factors for abuse and neglect, such as poverty (e.g., temporary assistance for needy families (TANF), housing assistance, childcare assistance, counseling), and aiding families who lack a social support network (e.g., parenting skills, conflict resolution). However, the service-based approach of differential response is questionable, as recent studies have shown that families receiving service-based intervention experience re-report more often than families who do not. ${ }^{19-21}$

An insufficient response to reports of abuse may mask or shift the observed symptoms of maltreatment, averting child protection efforts. This may be particularly true when the service response offered is not sustainable, such as temporary financial or childcare assistance. Services requiring sobriety as a qualifier may also create challenges for families experiencing parental alcohol or other substance abuse. Loss of these services may increase parental stressors, result in chronic and more severe abuse, or result in child removal from the home. The latter two 
possibilities, considered adverse childhood experiences or ACEs, increases the risk of negative social and health outcomes for the child. ${ }^{22-29}$

Identifying changes in the rate and characteristics of child maltreatment, before and after CAPTA 2010, may yield insights as to how differential response influences re-report of maltreatment, and whether this policy inadvertently creates additional barriers to child protection. Using data from The National Child Abuse and Neglect Data System (NCANDS), this study will compare the demographic and case characteristics of maltreatment re-report in the two states that began utilizing differential response following the CAPTA 2010 reauthorization; namely, Massachusetts and Colorado.

\subsection{Method}

Data Source and Population: The NCANDS Child File contains annual reports of child maltreatment screened and accepted for child maltreatment from 52 US states and territories. Data include reports of maltreatment collected at the child (e.g., age, sex, race/ethnicity), perpetrator (e.g., age, sex, race/ethnicity), and case level (e.g., maltreatment type, report source). This study will utilize data from children aged 0-17 years during the four-year period immediately prior to and following the CAPTA 2010 reauthorization, who were living in Colorado, Kansas, Massachusetts and New Hampshire.

Colorado and Massachusetts were selected as intervention states because both adopted differential response after the CAPTA 2010 reauthorization, and began reporting cases of differential response to NCANDS in 2011. Kansas and New Hampshire were selected as control states because neither has a differential response policy, and no records of differential response have ever been reported to NCANDS from these states. Moreover, no state or countywide interventions were identified in these states that mirrored a differential response. Intervention 
and control states were matched according to proximal geographic location and similar demographic composition.

Variables: The exposure of interest was CAPTA 2010 period (pre-post), an indicator of policy implementation. The fidelity of this variable was verified through evaluation of state child welfare policies, as well as checking the frequencies of CPS response by year using the NCANDS variable of CPS response (e.g. substantiated, indicated, alternative response- victim, unsubstantiated, closed-no finding, and intentionally false). The outcome of interest was child maltreatment re-report. The NCANDS variable of unique child ID was used to count incident reports of maltreatment longitudinally.

Child race and ethnicity were combined to create a single race/ethnicity variable (nonHispanic black, non-Hispanic white, white-Hispanic, black-Hispanic, other). Sex was recorded as the gender of the child at the time of report. The age categories of $<5,5-11,12-17$ years were derived from child age at first report, and were selected based on the age classification recommendations for children under 18 years by the US Census. ${ }^{30}$ Abuse type was categorized based on the primary form of abuse documented in NCANDS (physical, neglect, sexual, other), and reporter source included social services, medical/health professional, legal/law enforcement, educational, parent/other relative, and other.

Statistical Analysis: Descriptive statistics for case-level, socioeconomic and demographic characteristics of maltreatment were expressed by univariable analyses for continuous variables, and frequencies for categorical variables. Statistical differences between descriptive statistics were based on t-tests or chi-square tests, as appropriate. The level for statistical significance was set at alpha $\leq 0.05$. All analysis were conducted using SAS software, version 9.4, Cary, N.C. ${ }^{31}$ 
The GENMOD procedure in SAS was used to calculate and compare the risk of maltreatment re-report before and after CAPTA 2010. Following identification of the cohorts of maltreatment reports in 2007 and 2011, we used a modified Poisson regression to estimate and compare the risk of maltreatment re-report of maltreatment before and after policy adoption. This method was selected over a log-binomial model in order to allow for the calculation of robust standard errors, and thus narrower confidence intervals. ${ }^{32}$

\subsection{Results}

This analysis included 159,593 children aged 0-17 years living in Colorado (31\%), Kansas (22\%), Massachusetts (40\%) and New Hampshire (7\%) in 2007 and 2011, according to NCANDS. Baseline characteristics are described in Table 1. The median age of the total population was eight years, with baseline reports of maltreatment occurring most often in children between the ages of 5-11 years (37\%). Forty-two percent of the study population was non-Hispanic white, and sex was distributed equally. Neglect (54\%) was the most common form of maltreatment, followed by physical (21\%) and other/undefined (16\%) abuse. Law enforcement $(21 \%)$ and those working in educational settings (17\%) most commonly reported the maltreatment.

Baseline demographic characteristics for children, reported for maltreatment, were comparable in the periods before and after the CAPTA 2010 reauthorization, except age (Table 2). The median age of children reported for maltreatment in 2007 and 2011 was nine and seven years, respectively. Baseline demographic characteristics between intervention and control states varied by race/ethnicity and abuse type. Control states had a disproportionately higher number of non-Hispanic white children in both periods, and Kansas was the only state that identified neglect as the most prevalent form of maltreatment. 
Re-report occurred in $24 \%$ of the total population. After the adoption of CAPTA 2010, the risk of child maltreatment re-report in both intervention and control states increased significantly by $13 \%$ and $17 \%$, respectively (Table 3). Reports involving child neglect were associated with a higher risk of re-report compared to other forms of maltreatment. In both exposure groups, older child age was significantly associated with a decreased risk of re-report; no significant association was identified between child sex and re-report. In the intervention states, black race was associated with an increased risk of re-report. Report source was not associated with rereport in control states, while reports received by law, health and educational professionals were associated with a decreased risk of re-report in the intervention states.

Differential response was assigned to $18 \%$ of child maltreatment cases following CAPTA 2010. Massachusetts utilized the policy the most (41\%) and Colorado the least (7\%). The rate of child maltreatment re-report decreased by $36 \%$ among children aged 12-17 years in interventions states following CAPTA 2010 (Table 4). Post policy, re-reports involving sexual abuse decreased while those involving other/undefined maltreatment significantly increased.

\subsection{Discussion}

This study used longitudinal data to compare the risk and distribution of characteristics associated with child maltreatment re-report in the four-year periods immediately prior to and following CAPTA 2010 reauthorization. Prior studies examining child maltreatment re-report combined outcomes for both responses, inhibiting the understanding of how this policy influences maltreatment re-report. ${ }^{21,33-35}$ Our study included this distinction, and results will provide insights regarding positive and negative policy implications.

We found that the risk of child maltreatment re-report increased following CAPTA 2010 in both intervention and control states. Similarity in magnitude and direction of this association 
for both intervention and control states suggests that the observed increase in risk may not be attributed to differential response. A review of child welfare reform in the US revealed three additional policies enacted during the pre and post CAPTA 2010 periods, which may have competing influences in our results. ${ }^{36}$ First, the Child and Families Improvement Act of 2006 amended part B of the Social Security Act by charging states to minimize the number of children removed from families with caregivers affected by methamphetamine and other substance abuse. ${ }^{37}$ Massachusetts and Colorado failed to report the percentage of children with alcohol and other substance abusing caregivers in 2007 and 2011, precluding our ability to quantify the number of children affected by this policy. Our ability to detect differences in the rate of rereport between the pre and post policy periods may have been limited, if services similar to differential response were delivered to a large proportion of the pre-CAPTA 2010 populations living in these states.

Second, the Patient Protection and Affordable Care Act of 2010 amended title IV of the Social Security Act to provide grants for early childhood home visitation programs. ${ }^{38}$ Home visitation programs have been one of the most effective initiatives in preventing family violence, as demonstrated by results from the Nurse-Family Partnership. ${ }^{39}$ At the 15 -year follow up, lowincome families receiving services by nurses experienced a $50 \%$ reduction in state-verified reports of maltreatment.

Third, the Child and Family Improvement and Innovation Act modified the Child and Families Improvement Act of 2006 by ending permanency efforts for children with a methamphetamine abusing caregiver. ${ }^{40}$ Additionally, this legislation required states to develop protocols for identifying and protecting child victims according to the level of child risk. If effective, implementing a systematic method to assess risk would reduce the caseworker bias in 
determining how authorities screen and respond to reports. As a result, one would expect to see changes in the relationship between abuse type and re-report. Instead, our results revealed the opposite effect, suggesting that this legislation did not interact with CAPTA 2010.

In our study, differential response was assigned to nearly one-fifth of child maltreatment cases in the post-policy period. Examination of CPS response by states revealed that although Massachusetts and Colorado began reporting cases of differential response to NCANDS in 2011, Massachusetts used this response five times more frequently than did Colorado. This difference in assignment is likely due to variations in the definitions of child maltreatment by state, and differential response implementation. For example, in 2011, reports in Massachusetts, which involved disciplinary physical abuse, single acts of neglect resulting in minor injury, educational and medical neglect or neglect that did not cause imminent harm, were referred to differential response. ${ }^{41}$ In the same year, Colorado did not investigate reports of maltreatment when the perpetrator was a parent or caretaker. This is noteworthy because in 2011 a biological parent living with the child victim perpetrated $81.2 \%$ of child maltreatment cases in the US. ${ }^{41}$ The decision of Colorado, which comprised nearly one-third of our study population, to omit these data likely explains why we did not observe the significant associations involving re-report and report source that were identified in other studies.

Our analysis did not find a significant association between child sex and re-report in either period; a finding inconsistent with those from previous studies reporting a correlation between child sex and abuse type. ${ }^{19,20,42}$ Although child sex was evenly distributed across study periods and individual states, consistent with national trends, abuse type was not. Kansas, a control state in our analysis that comprised one fifth of the total study population, was the only state to report physical abuse as the most prevalent form of maltreatment. This deviation in abuse 
type likely diluted the effect of sex on re-report, and warrants subsequent exploration as a potential mediator.

Previous studies have identified an inverse relationship between child age and child maltreatment reports. ${ }^{43}$ In fully adjusted models, we saw a $36 \%$ decrease in the risk of re-report in children aged 12-17 years following adoption of CAPTA 2010. No significant associations were identified among other age groups for our intervention states, suggesting this policy may be most effective for older children with some autonomy over service utilization and program participation. Additionally, CAPTA 2010 included directives to encourage the adoption of older children. ${ }^{3}$ If effective, this provision would help explain, to some degree, the decrease in risk of re-report for this age group.

In post-policy intervention states, we found that Black race, regardless of ethnicity, was associated with an increased risk of re-report in the adjusted models. Racial biases exist in the child protective system, ${ }^{43,44}$ and the introduction of differential response may magnify this bias. Using data from NCANDS, McCallum and colleagues found that Black families, reported for maltreatment, were more likely to be assigned to an investigation than differential response, despite the fact that Blacks experienced more deficits, such as in housing security and, employment, which may be facilitated by services. ${ }^{43}$ The authors did not describe re-report or recurrence. However, a 2010 study by Conley and Berrick, which identified a similar relationship between race and CPS response, found no association between race and re-report. ${ }^{10}$

We further found that those with race defined as "other" experienced diminution in the risk of re-report in both periods. This result was consistent with the survival analysis presented in chapter 3, and might be explained by cultural variations in parenting, as well as in acceptable disciplinary practices. 
Finally, we observed a decrease in sexual abuse in the post-policy intervention group. This result was unexpected, considering that differential response is designed to target less serious offenses, such as neglect. However, it is possible that the reallocation of services in the post-policy period allowed CPS to more adequately address reports of sexual abuse, resulting in a decrease in incidence of re-reports for this group.

\section{Strengths and Limitations}

This study has several strengths. We used a large, nationally representative dataset to evaluate the relationship between policy implementation and child maltreatment re-report. NCANDS has been widely used to describe the burden of child maltreatment in the US, ${ }^{15,19,45,46}$ making our results readily comparable to previous work. The longitudinal nature of the data allowed us to evaluate and compare child maltreatment re-report in two four-year periods. Despite our binary outcome, we were able to use a modified Poisson regression to calculate the risk of re-report using robust estimation methods.

This study also has potential limitations. First, a priori, our outcome of interest was a first time re-report of child maltreatment. We intended to use the NCAND child prior victim variable to remove any child IDs flagged as having been involved in a previous child protection case. However, while examining baseline characteristics, we found that New Hampshire did not utilize this variable. For consistency, we did not utilize that variable across states, and therefore could not discern children between first time and recurrent reports within NCANDS. Second, the distribution of child maltreatment in Kansas deviated from national trends. Because maltreatment type is associated with other factors, such as age, sex, and race, the deviation may have influenced our results. Finally, we were unable to evaluate a number of behavioral characteristics due to missingness and data quality concerns. 


\subsection{Conclusion}

The results of this study showed similarities in the rate of child maltreatment re-report in the pre and post CAPTA 2010 periods. However, provisions in overlapping child welfare legislation may have interacted with, and perhaps diluted, the observed policy effect. Future analysis of this relationship should focus on time series as a method to isolate the periods corresponding to specific legislation. We also found that the introduction of this policy may magnify existing racial biases in child protection, and recommend the development of uniform screening and response assignment tools to minimize this effect. 


\section{References}

1. U.S. Department of Health and Human Services, Administration for Children and Families, Administration on Children, Youth and Families. Child Maltreatment 2015. 2017: http://www.acf.hhs.gov/programs/cb/research-data-technology/statisticsresearch/child-maltreatment.

2. Child Wefare Information Gateway. About CAPTA: A Legislative History. Washington, DC: U.S. Department of Health and Human Services, Children's Bureau; 2011.

3. United States. Child Abuse Prevention and Treatment Act as amended by PL 111-320, the CAPTA reauthorization act of 2010. Washington, DC: United States Government Publishing Office; 2010.

4. Marshall SK, Charles G, Kendrick K, Pakalniskiene V. Comparing differential responses within child protective services: A longitudinal examination. Child Welfare. 2010;89(3):57.

5. Loman LA, Siegel GL. Effects of anti-poverty services under the differential response approach to child welfare. Children and Youth Services Review. 2012;34(9):1659-1666.

6. Loman LA, Siegel GL. Alternative response in Minnesota: Findings of the program evaluation. Protecting Children. 2005;20(2\&3):78-92.

7. Lawrence CN, Rosanbalm KD, Dodge KA. Multiple response system: Evaluation of policy change in North Carolina's child welfare system. Children and youth services review. 2011;33(11):2355-2365.

8. Harries M, Cant RL, Bilson A, Thorpe D. Responding to information about children in adversity: Ten years of a differential response model in Western Australia. Child Abuse \& Neglect. 2015;39:61-72.

9. English DJ, Wingard T, Marshall D, Orme M, Orme A. Alternative responses to child protective services: Emerging issues and concerns. Child Abuse \& Neglect. 2000;24(3):375-388.

10. Conley A, Berrick JD. Community-based child abuse prevention: Outcomes associated with a differential response program in California. Child Maltreatment. 2010;15(4):282292.

11. Conley A, Berrick JD. Implementation of differential response in ethnically diverse neighborhoods. Protecting Children. 2008;23(1\&2):30-38.

12. Merkel-Holguín LA, Kaplan C, Kwak A, Association AH. National study on differential response in child welfare. Washington, DC: American Humane Association and Child Welfare League of America; 2006. 
13. Myers JE. The APSAC Handbook on Child Maltreatment. 3rd ed. Los Angeles, CA: Sage; 2011.

14. Hunter A, Lewis, Kelsey, Kelley, George, Tabone, Jiyoung, Davidov, Danielle, Long, Dustin, Rockett, Ian,. Differential response policy and child maltreatment recurrence: a systematic review with meta- analysis, if appropriate. Prospero: CRD42015025388; 2015.

15. Shusterman GR, McDonald WR. Alternative Responses to Child Maltreatment: Findings from NCANDS. Washington, DC: US Department of Health and Human Services; 2005.

16. Levi J, Segal L, Kohn D. The Facts Hurt: A state-by-state injury prevention policy report. Washington, DC: Trust for America's Health. 2015.

17. Centers for Disease Control and Prevention. Child Maltreatment Prevention. Violence Prevention 2013; http://www.cdc.gov/violenceprevention/childmaltreatment/. Accessed January 20, 2016.

18. Hughes RC, Rycus JS, Saunders-Adams SM, Hughes LK, Hughes KN. Issues in differential response. Research on Social Work Practice. 2013;23(5):493-520.

19. Casanueva C, Tueller S, Dolan M, Testa M, Smith K, Day O. Examining predictors of rereports and recurrence of child maltreatment using two national data sources. Children and Youth Services Review. 2015;48:1-13.

20. Fluke JD, Shusterman GR, Hollinshead DM, Yuan Y-YT. Longitudinal analysis of repeated child abuse reporting and victimization: Multistate analysis of associated factors. Child Maltreatment. 2008;13(1):76-88.

21. Fuller T, Nieto M. Child welfare services and risk of child maltreatment rereports: Do services ameliorate initial risk? Children and youth services review. 2014;47:46-54.

22. Chartier M, Walker J, Naimark B. Childhood abuse, adult health, and health care utilization: results from a representative community sample. American Journal of Epidemiology. 2007;165(9):1031-1038.

23. Felitti VJ, Anda RF, Nordenberg D, et al. Relationship of childhood abuse and household dysfunction to many of the leading causes of death in adults: The Adverse Childhood Experiences (ACE) Study. American Journal of Preventive Medicine. 1998;14(4):245258.

24. Hoertel N, Franco S, Wall MM, et al. Childhood maltreatment and risk of suicide attempt: a nationally representative study. The Journal of Clinical Psychiatry. 2015;76(7):1,478-923.

25. King A, Farst K, Jaeger M, Onukwube J, Robbins J. Maltreatment-related emergency department visits among children 0 to 3 years old in the United States. Child Maltreatment. 2015;20(3):151-161. 
26. Klevens J, Leeb RT. Child maltreatment fatalities in children under 5: Findings from the National Violence Death Reporting System. Child Abuse \& Neglect. 2010;34(4):262-266.

27. Lanier P, Jonson-Reid M, Stahlschmidt MJ, Drake B, Constantino J. Child maltreatment and pediatric health outcomes: A longitudinal study of low-income children. Journal of Pediatric Psychology. 2009;35(5):511-522.

28. Slade EP, Wissow LS. The influence of childhood maltreatment on adolescents' academic performance. Economics of Education Review. 2007;26(5):604-614.

29. Stevens KI, Schneiderman JU, Negriff S, Brinkmann A, Trickett PK. The whole picture: child maltreatment experiences of youths who were physically abused. Child Abuse \& Neglect. 2015;43:30-41.

30. Klein RJ, Schoenborn CA. Age adjustment using the 2000 projected US population. Hyatsville, MD: U.S. Department of Health and Human Services; 2001.

31. SAS [computer program]. Version 9.4. Cary, NC ,2016.

32. Zou G. A modified poisson regression approach to prospective studies with binary data. American Journal of Epidemiology. 2004;159(7):702-706.

33. Campbell KA, Thomas AM, Cook LJ, Keenan HT. Longitudinal experiences of children remaining at home after a first-time investigation for suspected maltreatment. The Journal of Pediatrics. 2012;161(2):340-347.

34. Drake B, Jonson-Reid M, Way I, Chung S. Substantiation and recidivism. Child Maltreatment. 2003;8(4):248-260.

35. Jonson-Reid M, Drake B, Chung S, Way I. Cross-type recidivism among child maltreatment victims and perpetrators. Child Abuse \& Neglect. 2003;27(8):899-917.

36. United States, Child Welfare Information Gateway. Major Federal legislation concerned with child protection, child welfare, and adoption. Washington, DC: Administration for Children and Families, Administration on Children, Youth and Families, Children's Bureau; 2015.

37. United States. Report on P.L. 109-288, the "Child and Family Services Improvement Act of 2006". Washington, DC: U.S. Government Printing Office; 2006.

38. United States. Compilation of Patient Protection and Affordable Care Act : as amended through November 1, 2010 including Patient Protection and Affordable Care Act healthrelated portions of the Health Care and Education Reconciliation Act of 2010. Washington, DC: U.S. Government Printing Office; 2010.

39. Olds DL, Eckenrode J, Henderson CR, et al. Long-term effects of home visitation on maternal life course and child abuse and neglect: Fifteen-year follow-up of a randomized trial. JAMA. 1997;278(8):637-643. 
40. United States. Child and Family Improvement and Innovation Act. Washington, DC: U.S. Government Printing Office; 2011.

41. Adminstration for Children and Families. Child Maltreatment 2011. Washington, DC: U.S. Department of Health and Human Services, Children's Bureau; 2012.

42. Bae H, Solomon PL, Gelles RJ. Multiple child maltreatment recurrence relative to single recurrence and no recurrence. Children and Youth Services Review. 2009;31(6):617-624.

43. McCallum K, Cheng AL. Community factors in differential responses of child protective services. Public Health Nursing. 2015.

44. Jonson-Reid M, Drake B, Kohl PL. Is the overrepresentation of the poor in child welfare caseloads due to bias or need? Children and Youth Services Review. 2009;31(3):422-427.

45. Ortiz MJ, Shusterman GR, Fluke JD. Outcomes for children with allegations of neglect who receive alternative response and traditional investigations: Findings from NCANDS. Protecting Children. 2008;23(1\&2):57-70.

46. Theodore AD, Chang JJ, Runyan DK, Hunter WM, Bangdiwala SI, Agans R. Epidemiologic features of the physical and sexual maltreatment of children in the Carolinas. Pediatrics. 2005;115(3):e331-e337. 
Tables and Figures 
Table 1: Baseline Demographic Characteristics by Year

\begin{tabular}{|c|c|c|c|}
\hline \multicolumn{4}{|c|}{$\begin{array}{l}\text { Demographic Characteristics at Baseline by Year, Children 0-17 years from CO, KA, MA, NH, } \\
\text { National Child Abuse and Neglect Data System (NCANDS): 2007, } 2011\end{array}$} \\
\hline & Total & 2007 & 2011 \\
\hline Total & $158,535(100)$ & $86,582(54.61)$ & $71,953(45.39)$ \\
\hline Characteristic & & $\mathrm{N}(\%)$ & $\mathrm{N}(\%)$ \\
\hline \multicolumn{4}{|l|}{ Age } \\
\hline Under 5 years & $50,374(31.77)$ & $25,085(28.97)$ & $25,289(35.15)$ \\
\hline 5-11 years & $59,154(37.31)$ & $32,378(37.40)$ & $26,776(37.21)$ \\
\hline 12-17 years & $49,007(30.91)$ & $29,119(33.63)$ & $19,888(27.64)$ \\
\hline \multicolumn{4}{|l|}{ Sex } \\
\hline Male & $78,134(49.29)$ & $42,754(49.38)$ & $35,380(49.17)$ \\
\hline Female & $76,966(48.55)$ & $42,126(48.65)$ & $38,840(48.42)$ \\
\hline Missing & $3435(2.16)$ & $1,702(1.97)$ & $1733(2.41)$ \\
\hline \multicolumn{4}{|l|}{ Race/Ethnicity } \\
\hline non-Hispanic White & $65,670(41.42)$ & $37,930(43.81)$ & $27,740(38.55)$ \\
\hline non-Hispanic Black & $12,851(8.11)$ & $7,558(8.73)$ & $5,293(7.36)$ \\
\hline Hispanic-White & $20,158(12.72)$ & $10,730(12.39)$ & $9,428(13.10)$ \\
\hline Hispanic-Black & $1,174(<1)$ & $625(<1)$ & $549(<1)$ \\
\hline Other & $42,470(26.79)$ & $20,990(24.24)$ & $21,480(29.85)$ \\
\hline Missing & $16,212(10.23)$ & $8,749(10.10)$ & $7,463(10.37)$ \\
\hline \multicolumn{4}{|l|}{ Maltreatment Type } \\
\hline Neglect & $84,891(53.55)$ & $44,593(51.50)$ & $40,298(56.01)$ \\
\hline Physical & $32,400(20.44)$ & $17,863(20.63)$ & $14,537(20.20)$ \\
\hline Sexual & $9,387(5.92)$ & $5,248(6.06)$ & $4,139(5.75)$ \\
\hline Other & $25,655(16.18)$ & $14,614(16.88)$ & $11,041(15.34)$ \\
\hline Missing & $6,202(3.91)$ & $4,264(4.92)$ & $1,938(2.69)$ \\
\hline \multicolumn{4}{|l|}{ Report Source } \\
\hline Social Services & $12,583(7.94)$ & $7,361(8.50)$ & $5,222(7.26)$ \\
\hline Health Professional & $18,635(11.75)$ & $9,615(11.11)$ & $9,020(12.54)$ \\
\hline Law Enforcement & $33,046(20.84)$ & $17,411(20.11)$ & 15,635 (21.73) \\
\hline Educational & $27,144(17.12)$ & $15,331(17.71)$ & $11,813(16.42)$ \\
\hline Parent/relative & $15,852(10.00)$ & $8,783(10.14)$ & $7,069(9.82)$ \\
\hline Other & $19,187(12.10)$ & $11,053(12.77)$ & $8,134(11.30)$ \\
\hline Missing & $32,088(20.24)$ & $17,028(19.67)$ & $15,060(20.93)$ \\
\hline
\end{tabular}




\begin{tabular}{|l|l|l|l|}
\hline & & & \\
\hline Re-Report & & & \\
\hline Yes & $38,227(24.11)$ & $18,924(21.86)$ & $19,303(26.83)$ \\
\hline No & $120,308(75.89)$ & $67,658(78.14)$ & $52,650(73.17)$ \\
\hline
\end{tabular}


Table 2 : Baseline Demographic Characteristics by State

\begin{tabular}{|c|c|c|c|c|c|c|c|c|}
\hline \multicolumn{9}{|c|}{$\begin{array}{l}\text { Demographic Characteristics at Baseline by State, Children 0-17 Years from CO, KA, MA, NH, National Child Abuse and Neglect Data } \\
\text { System (NCANDS): 2007, } 2011\end{array}$} \\
\hline & \multicolumn{4}{|c|}{ Intervention States } & \multicolumn{4}{|l|}{ Control States } \\
\hline & \multicolumn{2}{|l|}{ Colorado* } & \multicolumn{2}{|c|}{ Massachusetts* } & \multicolumn{2}{|l|}{ Kansas } & \multicolumn{2}{|c|}{ New Hampshire } \\
\hline & 2007 & 2011 & 2007 & 2011 & 2007 & 2011 & 2007 & 2011 \\
\hline Characteristic & $\mathrm{N}(\%)$ & $\mathrm{N}(\%)$ & $\mathrm{N}(\%)$ & $\mathrm{N}(\%)$ & $\mathrm{N}(\%)$ & $\mathrm{N}(\%)$ & $\mathrm{N}(\%)$ & $\mathrm{N}(\%)$ \\
\hline \multicolumn{9}{|l|}{ Response } \\
\hline Investigation & $25,537(100)$ & $\begin{array}{l}21,496 \\
(92.90)\end{array}$ & $35,516(100)$ & \begin{tabular}{|l|}
16,738 \\
$(59.11)$
\end{tabular} & $19,420(100)$ & $15,167(100)$ & $5,261(100)$ & $5,234(100)$ \\
\hline $\begin{array}{l}\text { Differential } \\
\text { Response }\end{array}$ & 0 & $1,643(7.10)$ & 0 & $\begin{array}{l}11,581 \\
(40.89) \\
\end{array}$ & 0 & 0 & 0 & 0 \\
\hline \multicolumn{9}{|l|}{ Age } \\
\hline Under 5 years & 8,087 (31.67) & $8,723(37.70)$ & $9,169(25.82)$ & $9,974(35.22)$ & $6,416(33.04)$ & $4,864(32.07)$ & $\begin{array}{l}1,259 \\
(23.93)\end{array}$ & $\begin{array}{l}1,695 \\
(32.38)\end{array}$ \\
\hline 5-11 years & 9,941 (38.93) & $8,838(38.20)$ & $\begin{array}{l}12,291 \\
(34.61\end{array}$ & $9,898(34.95)$ & $7,945(40.91)$ & $6,155(40.58)$ & $\begin{array}{l}1,987 \\
(37.77)\end{array}$ & $\begin{array}{l}1,860 \\
(35.54)\end{array}$ \\
\hline $12-17$ years & $7,509(29.40)$ & $5,578(24.11)$ & $\begin{array}{l}14,056 \\
(39.58)\end{array}$ & $8,447(29.83)$ & $5,059(26.05)$ & $4,148(27.35)$ & $\begin{array}{l}2,015 \\
(38.30)\end{array}$ & $\begin{array}{l}1,679 \\
(32.08)\end{array}$ \\
\hline \multicolumn{9}{|l|}{ Sex } \\
\hline Male & \begin{tabular}{|l|}
12,834 \\
$(50.26)$
\end{tabular} & $\begin{array}{l}11,708 \\
(50.60)\end{array}$ & $\begin{array}{l}17,154 \\
(48.30)\end{array}$ & \begin{tabular}{|l|}
13,584 \\
$(47.97)$
\end{tabular} & $9,733(50.12)$ & $7,406(48.83)$ & $\begin{array}{l}2,588 \\
(49.19)\end{array}$ & $\begin{array}{l}2,628 \\
(50.21)\end{array}$ \\
\hline Female & \begin{tabular}{|l|}
12,702 \\
$(49.74)$
\end{tabular} & $\begin{array}{l}11,430 \\
(49.40)\end{array}$ & $\begin{array}{l}16,666 \\
(46.93)\end{array}$ & $\begin{array}{l}13,019 \\
(45.97)\end{array}$ & $9,686(49.88)$ & $7,757(51.14)$ & $\begin{array}{l}2,671 \\
(50.77)\end{array}$ & $\begin{array}{l}2,594 \\
(49.56)\end{array}$ \\
\hline Missing & $1(0)$ & $1(0)$ & $1,696(4.78)$ & $1,716(6.06)$ & $1(0)$ & $4(<1)$ & $2(<1)$ & $12(<1)$ \\
\hline
\end{tabular}




\begin{tabular}{|c|c|c|c|c|c|c|c|c|}
\hline \multicolumn{9}{|l|}{ Race/Ethnicity } \\
\hline non-Hispanic White & $9,641(37.75)$ & $7,368(31.84)$ & $9,811(27.62)$ & $6,294(22.23)$ & $\begin{array}{l}14,225 \\
(73.25)\end{array}$ & $9,993(65.89)$ & $\begin{array}{l}3,969 \\
(75.44)\end{array}$ & $\begin{array}{l}4,031 \\
(77.02)\end{array}$ \\
\hline non-Hispanic Black & $1,976(7.74)$ & $1,340(5.79)$ & $2,940(8.28)$ & $2,048(7.23)$ & $2,478(12.76)$ & $1,771(11.68)$ & $109(2.07)$ & $132(2.52)$ \\
\hline Hispanic-White & $6,771(26.53)$ & $5,332(23.04)$ & $2,240(6.31)$ & $1,840(6.50)$ & $1,310(6.75)$ & $2,017(13.30)$ & $204(3.88)$ & $230(4.39)$ \\
\hline Hispanic-Black & $149(<1)$ & $102(<1)$ & $434(1.22)$ & $398(1.41)$ & $11(<1)$ & $25(<1)$ & $23(<1)$ & $24(<1)$ \\
\hline Other & $5,184(20.30)$ & $7,166(30.97)$ & $\begin{array}{l}14,803 \\
(41.68)\end{array}$ & $\begin{array}{l}13,649 \\
(48.20)\end{array}$ & $69(<1)$ & $112(<1)$ & $680(12.93)$ & $531(10.15)$ \\
\hline Missing & $1,813(7.10)$ & $1,831(7.91)$ & $5,288(14.89)$ & $4,090(14.44)$ & $1,327(6.83)$ & $1,249(8.23)$ & $276(5.25)$ & $286(5.46)$ \\
\hline \multicolumn{9}{|l|}{ Maltreatment Type } \\
\hline Neglect & $\begin{array}{l}14,423 \\
(56.48)\end{array}$ & $\begin{array}{l}14,978 \\
(64.73)\end{array}$ & $\begin{array}{l}22,238 \\
(62.61)\end{array}$ & $\begin{array}{l}18,574 \\
(65.59)\end{array}$ & $4,831(24.88)$ & $3,564(23.50)$ & $\begin{array}{l}2,844 \\
(54.06)\end{array}$ & $\begin{array}{l}3,116 \\
(59.53)\end{array}$ \\
\hline Physical & 4,575 (17.92) & $4,035(17.44)$ & $5,487(15.45)$ & $4,199(14.83)$ & $5,968(30.73)$ & $4,680(30.86)$ & $\begin{array}{l}1,762 \\
(33.49)\end{array}$ & $\begin{array}{l}1,606 \\
(30.68)\end{array}$ \\
\hline Sexual & $2,054(8.04)$ & $1,745(7.54)$ & $643(1.81)$ & $503(1.78)$ & $1,944(10.01)$ & $1,444(9.52)$ & $581(11.04)$ & $437(8.35)$ \\
\hline Other & $704(2.76)$ & $443(1.91)$ & $7,148(20.13)$ & $5,043(17.81)$ & $6,677(34.38)$ & $5,479(36.12)$ & $74(1.41)$ & $75(1.43)$ \\
\hline Missing & $3,781(14.81)$ & $1,938(8.37)$ & 0 & 0 & 0 & 0 & 0 & 0 \\
\hline \multicolumn{9}{|l|}{ Report Source } \\
\hline Social Services & $1,956(7.66)$ & $1,268(5.48)$ & $1,621(4.56)$ & $861(3.04)$ & $3,192(16.44)$ & $2,611(17.22)$ & $437(8.31)$ & $473(9.04)$ \\
\hline Health Professional & $3,947(15.46)$ & $3,937(17.01)$ & 3,717 (10.47) & $3,345(11.81)$ & $1,041(5.36)$ & $944(6.2)$ & $810(15.40)$ & $779(14.88)$ \\
\hline Law Enforcement & $6,437(15.46)$ & $6,324(27.33)$ & $7,741(21.80)$ & $6,401(22.60)$ & $1,898(9.77)$ & $1,894(12.49)$ & $\begin{array}{l}1,011 \\
(19.22)\end{array}$ & $997(19.05)$ \\
\hline Educational & $5,115(20.03)$ & $4,013(17.34)$ & $4,790(13.49)$ & $3,919(13.84)$ & $4,314(22.21)$ & $2,968(19.57)$ & $\begin{array}{l}1,032 \\
(19.62)\end{array}$ & $896(17.12)$ \\
\hline Parent/relative & $3,390(13.27)$ & $3,172(13.71)$ & $1,401(3.94)$ & $884(3.12)$ & $3,144(16.19)$ & $2,165(14.27)$ & $762(14.48)$ & 837 (15.99) \\
\hline Other & $2,620(10.26)$ & $2,070(8.94)$ & $2,986(8.41)$ & $2,007(7.09)$ & $4,667(24.03)$ & $3,334(21.98)$ & $725(13.78)$ & $710(13.57)$ \\
\hline Missing & $2,072(8.11)$ & $2,355(10.18)$ & $\begin{array}{l}13,260 \\
(37.34)\end{array}$ & $\begin{array}{l}10,902 \\
(38.50)\end{array}$ & $1,164(5.99)$ & $1,251(8.25)$ & $484(9.20)$ & $542(10.36)$ \\
\hline \multicolumn{9}{|l|}{ Re-Report } \\
\hline Yes & $5,324(20.85)$ & $5,470(23.64)$ & $8,381(23.60)$ & $8,405(29.68)$ & $4,023(20.72)$ & $3,958(26.10)$ & $\begin{array}{l}1,046 \\
(19.88)\end{array}$ & $\begin{array}{l}1,449 \\
(27.68)\end{array}$ \\
\hline
\end{tabular}


Table 3 : Association between Re-report and Demographics by Intervention

\begin{tabular}{|c|c|c|c|c|c|c|}
\hline \multicolumn{7}{|c|}{$\begin{array}{l}\text { Association between Child Maltreatment Re-Report and demographic characteristics of child maltreatment, by intervention group, } \mathrm{N}= \\
\text { 158,535, children 0-17 years (CO, KA, MA, NH) }\end{array}$} \\
\hline & \multicolumn{3}{|l|}{ Intervention States } & \multicolumn{3}{|l|}{ Control States } \\
\hline & $\begin{array}{l}\text { Model } 1 \\
\text { IRR }(95 \% \mathrm{CI})\end{array}$ & $\begin{array}{l}\text { Model } 2 \\
\text { IRR }(95 \% \mathrm{CI})\end{array}$ & $\begin{array}{l}\text { Model } 3 \\
\text { IRR (95\% CI) }\end{array}$ & $\begin{array}{l}\text { Model } 1 \\
\text { IRR }(95 \% \mathrm{CI})\end{array}$ & $\begin{array}{l}\text { Model } 2 \\
\text { IRR }(95 \% \mathrm{CI})\end{array}$ & $\begin{array}{l}\text { Model } 3 \\
\text { IRR }(95 \% \mathrm{CI})\end{array}$ \\
\hline \multicolumn{7}{|l|}{ Characteristic } \\
\hline \multicolumn{7}{|l|}{ Period } \\
\hline Pre & 1.00 & 1.00 & 1.00 & 1.00 & 1.00 & 1.00 \\
\hline Post & $1.17(1.13,1.22)$ & $1.16(1.13,1.19)$ & $1.13(1.01,1.17)$ & $1.17(1.13,1.22)$ & $1.16(1.11,1.20)$ & $1.17(1.13,1.22)$ \\
\hline \multicolumn{7}{|l|}{ Age } \\
\hline Under 5 years & 1.00 & 1.00 & 1.00 & 1.00 & 1.00 & 1.00 \\
\hline 5-11 years & $0.97(0.95,1.00)$ & $0.97(0.94,1.00)$ & $0.98(0.94,1.02)$ & $0.93(0.89,0.98)$ & $0.93(0.89,0.78)$ & $0.95(0.90,0.99)$ \\
\hline 12-17 years & $0.76(0.74,0.79$ & $0.73(0.71,0.76)$ & $0.74(0.72,0.78)$ & $0.72(0.68,0.75)$ & $0.72(0.68,0.75)$ & $0.73(0.69,0.77)$ \\
\hline \multicolumn{7}{|l|}{ Sex } \\
\hline Male & 1.00 & 1.00 & 1.00 & 1.00 & 1.00 & 1.00 \\
\hline Female & $1.02(0.99,1.04)$ & $1.03(1.00,1.05)$ & $1.04(1.00,1.06)$ & $0.99(0.96,1.03)$ & $1.01(0.98,1.06)$ & $1.02(0.97,1.06)$ \\
\hline \multicolumn{7}{|l|}{ Race/Ethnicity } \\
\hline $\begin{array}{l}\text { non-Hispanic } \\
\text { White }\end{array}$ & 1.00 & 1.00 & 1.00 & 1.00 & 1.00 & 1.00 \\
\hline $\begin{array}{l}\text { non-Hispanic } \\
\text { Black }\end{array}$ & $1.07(1.02,1.12)$ & $1.07(1.02,1.11)$ & $1.07(1.02,1.13)$ & $0.93(0.87,0.99)$ & $0.93(0.87,0.99)$ & $0.93(0.87,1.00)$ \\
\hline Hispanic-White & $0.95(0.92,0.99)$ & $0.93(0.89,0.96)$ & $0.94(0.90,0.98)$ & $0.99(0.92,1.06)$ & $0.97(0.90,1.04)$ & $0.97(0.91,1.05)$ \\
\hline Hispanic-Black & $1.29(1.17,1.43)$ & $1.28(1.15,1.41)$ & $1.34(1.19,1.52)$ & $0.98(0.62,1.54)$ & $0.98(0.62,1.52)$ & $0.99(0.62,1.57)$ \\
\hline Other & $0.53(0.52,0.55)$ & $0.52(0.51,0.54)$ & $0.52(0.50,0.54)$ & $0.93(0.83,1.05)$ & $0.93(0.83,1.05)$ & $0.93(0.82,1.05)$ \\
\hline & & & & & & \\
\hline
\end{tabular}




\begin{tabular}{|c|c|c|c|c|c|c|}
\hline \multicolumn{7}{|l|}{$\begin{array}{l}\text { Maltreatment } \\
\text { Type }\end{array}$} \\
\hline Neglect & 1.00 & 1.00 & 1.00 & 1.00 & 1.00 & 1.00 \\
\hline Physical & $0.91(0.88,0.94)$ & $0.95(0.91,0.98)$ & $0.94(0.90,0.98))$ & $0.91(0.87,0.95)$ & $0.93(0.89,0.98)$ & $0.92(0.88,0.98)$ \\
\hline Sexual & $0.78(0.74,0.84)$ & $0.80(0.75,0.86)$ & $0.79(0.73,0.85)$ & $0.87(0.82,0.91)$ & $0.86(0.80,0.93)$ & $0.87(0.80,0.94)$ \\
\hline Other & $0.96(0.92,0.99)$ & $1.03(0.99,1.07)$ & $1.06(1.00,1.11)$ & $0.81(0.76,0.88)$ & $0.88(0.83,0.92)$ & $0.89(0.84,0.94)$ \\
\hline \multicolumn{7}{|l|}{ Report Source } \\
\hline Social Services & 1.00 & 1.00 & 1.00 & 1.00 & 1.00 & 1.00 \\
\hline $\begin{array}{l}\text { Health } \\
\text { Professional }\end{array}$ & $0.84(0.79,0.89)$ & $0.86(0.80,0.91)$ & $0.86(0.80,0.91)$ & $1.05(0.96,1.14)$ & $1.00(0.91,1.09)$ & $0.99(0.90,1.08)$ \\
\hline $\begin{array}{l}\text { Law } \\
\text { Enforcement }\end{array}$ & $0.87(0.82,0.92)$ & $0.88(0.83,0.93)$ & $0.87(0.82,0.93)$ & $1.03(0.95,1.11)$ & $1.01(0.93,1.09)$ & $1.00(0.93,1.08)$ \\
\hline Educational & $0.84(0.79,0.89)$ & $0.88(0.83,0.94)$ & $0.88(0.83,0.94)$ & $1.03(0.97,1.11)$ & $1.04(0.97,1.12)$ & $1.04(0.97,1.11)$ \\
\hline Parent/relative & $0.99(0.94,1.06)$ & $1.01(0.94,1.08)$ & $1.01(0.94,1.09)$ & $1.12(1.04,1.20)$ & $1.06(0.98,1.14)$ & $1.05(0.98,1.13)$ \\
\hline Other & $1.00(0.94,1.06)$ & $1.03(0.96,1.10)$ & $1.02(0.95,1.09)$ & $1.13(1.06,1.21)$ & $1.07(1.00,1.14)$ & $1.06(0.99,1.14)$ \\
\hline \multicolumn{2}{|c|}{$\begin{array}{l}\text { Model } 2 \text { controls for age and } \\
\text { race/ethnicity }\end{array}$} & & & & & \\
\hline
\end{tabular}


Table 4 : Association between Re-report and Demographics by Policy Period

\begin{tabular}{|c|c|c|c|c|c|c|c|c|}
\hline \multirow{2}{*}{\multicolumn{9}{|c|}{$\begin{array}{l}\text { Association between Child Maltreatment Re-Report and de } \\
\\
\text { Intervention States }\end{array}$}} \\
\hline & & & & & & & & \\
\hline (1) & Pre- Policy & +2 & Post- Policy & & Pre- Policy & & Post- Policy & \\
\hline & $\begin{array}{c}\text { Model } 1 \\
\text { IRR }(95 \% \mathrm{CI})\end{array}$ & $\begin{array}{c}\text { Model } 2 \\
\text { IRR }(95 \% \mathrm{Cl})\end{array}$ & $\begin{array}{c}\text { Model } 1 \\
\text { IRR }(95 \% \mathrm{CI})\end{array}$ & $\begin{array}{c}\text { Model } 2 \\
\operatorname{IRR}(95 \% \mathrm{Cl})\end{array}$ & $\begin{array}{c}\text { Model } 1 \\
\text { IRR }(95 \% \mathrm{Cl})\end{array}$ & $\begin{array}{c}\text { Model } 2 \\
\operatorname{IRR}(95 \% \mathrm{CI})\end{array}$ & $\begin{array}{c}\text { Model } 1 \\
\operatorname{IRR}(95 \% \mathrm{CI})\end{array}$ & $\begin{array}{c}\text { Model } 2 \\
\operatorname{IRR}(95 \% \mathrm{CI})\end{array}$ \\
\hline \multicolumn{9}{|l|}{ Characteristic } \\
\hline & & & & & & & & \\
\hline \multicolumn{9}{|l|}{ Age } \\
\hline Under 5 years & 1.00 & 1.00 & 1.00 & 1.00 & 1.00 & 1.00 & 1.00 & 1.00 \\
\hline $5-11$ years & $\begin{array}{c}1.07(1.03, \\
1.12)\end{array}$ & $\begin{array}{c}1.05(1.00 \\
(1.11)\end{array}$ & $\begin{array}{c}0.94(0.90 \\
0.97)\end{array}$ & $\begin{array}{c}0.96 \text { (0.91, } \\
1.00)\end{array}$ & $\begin{array}{c}0.95(0.89 \\
1.01)\end{array}$ & $\begin{array}{c}0.94(0.88 \\
1.01)\end{array}$ & $\begin{array}{c}0.92(0.86 \\
0.97)\end{array}$ & $\begin{array}{c}0.94(0.88 \\
1.01)\end{array}$ \\
\hline $12-17$ years & $\begin{array}{c}0.99(0.95 \\
1.03)\end{array}$ & $\begin{array}{c}0.94(0.89 \\
0.99)\end{array}$ & $\begin{array}{c}0.57(0.54 \\
0.60)\end{array}$ & $\begin{array}{c}0.58(0.55 \\
0.62)\end{array}$ & $\begin{array}{c}0.79(0.74 \\
0.85)\end{array}$ & $\begin{array}{c}0.78(0.72 \\
0.84)\end{array}$ & $\begin{array}{c}0.65(0.60 \\
0.70)\end{array}$ & $\begin{array}{c}0.67(0.61 \\
0.72)\end{array}$ \\
\hline \multicolumn{9}{|l|}{ Sex } \\
\hline Male & 1.00 & 1.00 & 1.00 & 1.00 & 1.00 & 1.00 & 1.00 & 1.00 \\
\hline Female & $\begin{array}{c}1.03(0.99 \\
1.06)\end{array}$ & $\begin{array}{c}1.03(0.99 \\
1.07)\end{array}$ & $\begin{array}{c}1.01(0.97 \\
1.04) \\
\end{array}$ & $\begin{array}{c}1.04(0.99 \\
1.08)\end{array}$ & $\begin{array}{c}0.97(0.92 \\
1.02) \\
\end{array}$ & $\begin{array}{c}0.98(0.93 \\
1.04)\end{array}$ & $\begin{array}{c}1.02(0.97 \\
1.08) \\
\end{array}$ & $\begin{array}{c}1.05(0.99, \\
1.11) \\
\end{array}$ \\
\hline \multicolumn{9}{|l|}{ Race/Ethnicity } \\
\hline $\begin{array}{r}\text { non-Hispanic } \\
\text { White }\end{array}$ & 1.00 & 1.00 & 1.00 & 1.00 & 1.00 & 1.00 & 1.00 & 1.00 \\
\hline $\begin{array}{r}\text { non-Hispanic } \\
\text { Black }\end{array}$ & $\begin{array}{c}1.00(0.95 \\
1.06)\end{array}$ & $\begin{array}{c}1.02(0.94 \\
1.09)\end{array}$ & $\begin{array}{c}1.13(1.07 \\
1.21)\end{array}$ & $\begin{array}{c}1.13(1.05 \\
1.22)\end{array}$ & $\begin{array}{c}0.91(0.83 \\
1.00)\end{array}$ & $\begin{array}{c}0.93(0.84 \\
1.02)\end{array}$ & $\begin{array}{c}0.95(0.87 \\
1.05)\end{array}$ & $\begin{array}{c}0.94(0.85 \\
1.05)\end{array}$ \\
\hline Hispanic-White & $\begin{array}{c}0.96(0.91 \\
1.00)\end{array}$ & $\begin{array}{c}0.97(0.92 \\
1.03)\end{array}$ & $\begin{array}{c}0.90(0.86 \\
0.95)\end{array}$ & $\begin{array}{c}0.91 \text { (0.96, } \\
0.97)\end{array}$ & $\begin{array}{c}0.99(0.88 \\
1.12)\end{array}$ & $\begin{array}{c}0.98(0.88 \\
1.10)\end{array}$ & $\begin{array}{c}0.94(0.86 \\
1.03)\end{array}$ & $\begin{array}{c}0.923(0.85 \\
1.02)\end{array}$ \\
\hline Hispanic-Black & $\begin{array}{c}1.12(0.97 \\
1.31)\end{array}$ & $\begin{array}{c}1.23(1.02 \\
1.47)\end{array}$ & $\begin{array}{c}1.39(1.22 \\
1.58)\end{array}$ & $\begin{array}{c}1.42(1.21, \\
1.68)\end{array}$ & $\begin{array}{c}0.79(0.35 \\
1.76)\end{array}$ & $\begin{array}{c}0.72(0.30 \\
1.72)\end{array}$ & $\begin{array}{c}1.06(0.61 \\
1.83)\end{array}$ & $\begin{array}{c}1.11(0.64 \\
1.91)\end{array}$ \\
\hline Other & $\begin{array}{c}0.53(0.50 \\
0.55)\end{array}$ & $\begin{array}{c}0.53(0.50 \\
0.56)\end{array}$ & $\begin{array}{c}0.52(0.49 \\
0.53)\end{array}$ & $\begin{array}{c}0.52(0.49 \\
0.54)\end{array}$ & $\begin{array}{c}1.15(1.00, \\
1.33)\end{array}$ & $\begin{array}{c}1.13(0.97 \\
1.32)\end{array}$ & $\begin{array}{c}0.69(0.57, \\
0.84)\end{array}$ & $\begin{array}{c}0.68(0.56 \\
0.84)\end{array}$ \\
\hline
\end{tabular}




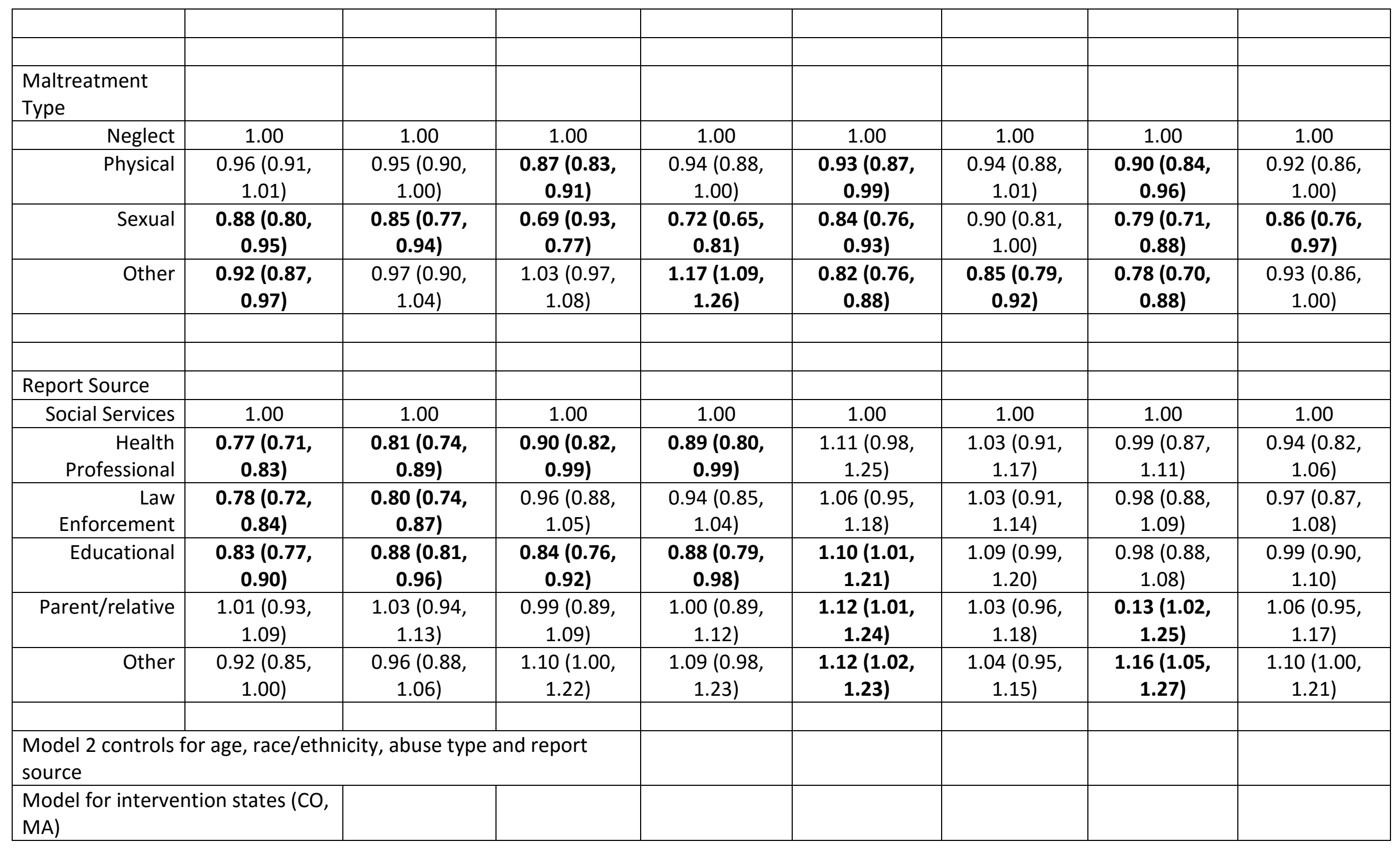


CHAPTER 5. DISCUSSION 


\subsection{Discussion}

Using qualitative and quantitative methods, this dissertation examined the association between child protective service (CPS) response and child maltreatment re-report. In this chapter, we discuss the findings of each independent study and the collective implications of this work. To conclude, we discuss the strengths, weaknesses and public health implications of this dissertation.

\subsection{Study 1 Discussion}

The purpose of this systematic review was to examine the relationship between differential response policy and child maltreatment re-report. After screening 1,009 studies from seven databases, we identified 10 meeting our inclusion criteria. Qualitative synthesis of these studies revealed deficits in the literature inhibiting our understanding of differential response policy. In particular, we concluded that additional research is needed to examine the relationship between policy, perpetrator, and family level characteristics related to maltreatment re-report.

We also identified a need to improve child welfare in four primary areas; research, reporting, practice, and policy. Namely, there is a need to develop and validate a universal screening tool for CPS response assignment. Development of such a tool would reduce much of the individual bias in response assignment and resulting misclassification that cannot be controlled for in statistical analysis.

Our analysis found a deficit in the collection and reporting of perpetrator-level characteristics. This is of importance because, in order to curb maltreatment offenses, a clear understanding of the offenders is necessary. 
This systematic review had limitations. The limited number of studies meeting our inclusion criteria underscored the need for additional research to understand the effects of differential response policy. Studies included in this systematic review also lacked consistency in the reporting of socioeconomic, demographic and behavioral characteristics known to confound the relationship between policy and re-report. Lastly, study subjects in the included studies were followed for short durations, thus minimizing our ability to assess the implications of differential response policy over time.

Strengths of this systematic review included the large number of children included in the analysis, and the identification of public health research needed in the area of child welfare. To our knowledge, this is the first systematic review to examine the relationship between CPS response and child maltreatment re-report.

\subsection{Study 2 Discussion}

This survival analysis sought to compare the risk of child maltreatment re-report among two CPS responses, investigation and differential response. Using data from the National Child Abuse and Neglect Data System (NCANDS), we calculated the 11-year hazard ratios for children aged 0-17 years, living in states with a statewide differential response policy (LA, MN, MO, and WY).

Consistent with prior studies, we found wide variation in the use of differential response by state. We also found a disparate number of records assigned to 'other' abuse, signaling a potential shift in maltreatment surveillance warranting further exploration. This change may also be an indication that maltreatment is evolving beyond the existing classifications.

Our initial results suggested that the risk of re-report was greater in children who received differential response. However, these results also exposed areas of poor data quality within 
NCANDS. Sensitivity analysis correcting for these challenges altered our results to show the opposite finding.

Strengths of this study included the use of a large, nationally representative dataset. Restricting our population to children living in states with a statewide differential response policy also minimized some of the variation observed in county-wide implementation. Our analysis also identified reporter source as a potential mediator between CPS response and re-report.

This study also had limitations. Particularly, we were unable to account for many known confounders because of the high level of missingness in NCANDS. This missingness also precluded our ability to account for co-occurring abuse.

\subsection{Study 3 Discussion}

In this ecologic study, we used a modified Poisson regression to compare the risk and characteristics of child maltreatment re-report before and after state adoption of differential response. Intervention $(\mathrm{CO}, \mathrm{MA})$ and control states $(\mathrm{KA}, \mathrm{NH})$ were matched on proximal location and demographic composition. Analysis used data from NCANDS during the four-year periods before and after the adoption of CAPTA 2010.

Results showed only a slight difference in maltreatment re-report between the pre and post CAPTA periods, suggesting that policy implementation did not directly influence the incidence of maltreatment re-report. We identified three competing policies that may have diluted the effect of CAPTA 2010.

Unlike previous studies, our results found no association between child sex and re-report. However, we found that the risk of sexual maltreatment decreased following CAPTA 2010. 
Results also revealed significant associations between Black race and re-report after policy adoption.

Study limitations included the inability to discern between first time and recurrent reports of maltreatment due to poor data quality within NCANDS. Also, due to missingness in the NCANDS data, we were unable to assess many characteristics known to confound the relationship between CPS response and re-report.

Strengths of the study included our capability to compare the risk of child maltreatment re-report before and after the adoption of a relatively new child welfare policy. We were also able to compare outcomes in two geographic regions of the US, the midwest and northeast.

\subsection{Conclusion}

Differential response policy is an innovative approach to addressing reports of child maltreatment. Although each study in this dissertation yielded unique conclusions, each showed areas of promise and concern. With proper implementation, involving a universal screening tool to reduce assignment bias, differential response may benefit families. Providing resources and support to families in minor crisis may be protective of vulnerable children at risk for acute maltreatment due to parental stress. However, delivery of these services to families in need of greater intervention may place a child in unnecessary harm, and result in serious long-term negative health outcomes.

This dissertation identified the need for a universal CPS screening tool for response assignment, and revealed serious data quality challenges in the national surveillance of child protection. Without future improvements to data collection methods, these barriers will continue to hamper the ability of research in the area of child maltreatment to yield tangible solutions. 
Therefore, we also recommend the development of reporting standards for child maltreatment practice and reporting. 